\title{
Species delimitation at a global scale reveals high species richness with complex biogeography and patterns of symbiont association in Peltigera section Peltigera (lichenized Ascomycota: Lecanoromycetes)
}

\author{
Nicolas Magain, ${ }^{1}$ Camille Truong, ${ }^{1,2}$ Trevor Goward, ${ }^{3}$ Dongling Niu, ${ }^{4}$ Bernard Goffinet, ${ }^{5}$ \\ Emmanuel Sérusiaux, ${ }^{6}$ Orvo Vitikainen, ${ }^{7}$ François Lutzoni ${ }^{1,8}$ \& Jolanta Miadlikowska ${ }^{1,8}$ \\ 1 Department of Biology, Duke University, Durham, North Carolina 27708-0338, U.S.A. \\ 2 Instituto de Biología, Universidad Nacional Autónoma de México (UNAM), C.P. 04510, Mexico City, Mexico \\ 3 UBC Herbarium, Beaty Museum, University of British Columbia, Vancouver, British Columbia V6T 1Z4, Canada \\ 4 Life Science School, Ningxia University, Yinchuan, Ningxia Hui Autonomous Region 750021, China \\ 5 Department of Ecology and Evolutionary Biology, University of Connecticut, Storrs, Connecticut 06269-3043, U.S.A. \\ 6 Evolution and Conservation Biology, University of Liège, Sart Tilman B22, 4000 Liège, Belgium \\ 7 Botanical Museum, Finnish Museum of Natural History, P.O. Box 7, 00014 University of Helsinki, Finland \\ 8 Both authors are last authors for this publication and are listed here in alphabetical order \\ Author for correspondence: Nicolas Magain,Nicolas.magain@duke.edu
}

DOI https://doi.org/10.12705/675.3

\begin{abstract}
This comprehensive phylogenetic revision of sections Peltigera and Retifoveatae of the cyanolichen genus Peltigera is based on DNA sequences from more than 500 specimens from five continents. We amplified five loci (nrITS, $\beta$-tubulin and three intergenic spacers part of colinear orthologous regions [COR]) for the mycobiont, and the $r b c L X$ locus for the cyanobacterial partner Nostoc. Phylogenetic inferences (RAxML, BEAST) and species delimitation methods (bGMYC, bPTP, bPP) suggest the presence of 88 species in section Peltigera, including 50 species new to science, hence uncovering a surprisingly high proportion of previously unnoticed biodiversity. The hypervariable region in ITS1 (ITS1-HR) is a powerful marker to identify species within sections Peltigera and Retifoveatae. Most newly delimited species are restricted to a single biogeographic region, however, up to ten species have a nearly cosmopolitan distribution. The specificity of mycobionts in their association with Nostoc cyanobionts ranges from strict specialists (associate with only one Nostoc phylogroup) to broad generalists (up to eight Nostoc phylogroups uncovered), with widespread species recruiting a broader selection of Nostoc phylogroups than species with limited distributions. In contrast, species from the $P$. didactyla clade characterized by small thalli and asexual vegetative propagules (soredia) associate with fewer Nostoc phylogroups (i.e., are more specialized) despite their broad distributions, and show significantly higher rates of nucleotide substitutions.
\end{abstract}

Keywords collinear orthologous region; COR; cyanobiont; internal transcribed spacer; ITS1-HR; ITS1 hypervariable region; lichen; mycobiont; Nostoc; molecular systematics; Peltigerales; phylogeny; rates of evolution; specificity; symbiosis

Supplementary Material The Electronic Supplement (Tables S1-S6; Figs. S1, S2) and DNA sequence alignments are available from https://doi.org/10.12705/675.3.S1 and https://doi.org/10.12705/675.3.S2, respectively.

\section{INTRODUCTION}

Peltigera Willd. (Lecanoromycetes: Peltigerales) is a genus of lichen-forming fungi (mycobionts) found in associations with cyanobacteria (cyanobionts) from the genus Nostoc Vaucher ex Bornet \& Flahault. While most Peltigera species associate with Nostoc only (bi-membered thalli), a few species associate with a green alga of the genus Coccomyxa Schmidle as their main photobiont, and Nostoc as their secondary photobiont (tri-membered thalli) (Vitikainen, 1994; Miadlikowska \& Lutzoni, 2000). Peltigera sect. Peltigera (the canina group) is one of eight sections of the genus Peltigera (Miadlikowska \& Lutzoni, 2000). It is characterized mostly by the presence of a tomentum on the upper surface of thalli and by the lack of secondary metabolites detectable by thin-layer chromatography
(Holtan-Hartwig, 1993; Vitikainen, 1994; Miadlikowska \& al., 2003). The sister section Retifoveatae Miądl. \& Lutzoni was circumscribed to accommodate a single species (P. retifoveata Vitik.) with a distinct and rich chemical profile (HoltanHartwig, 1993; Miadlikowska \& Lutzoni, 2000). Both sections contain exclusively bi-membered cyanolichens (Miadlikowska \& Lutzoni, 2000; Miadlikowska \& al., 2003).

Section Peltigera includes the emblematic $P$. canina (L.) Willd., type of the genus and one of the first three Peltigera species formally described by Linnaeus (1753) as Lichen caninus. It comprises thirty of the sixty-six species considered by Martínez $\&$ al. (2003) in their worldwide biogeographical study of the genus. Members of section Peltigera are found world-wide, with fifteen species in South America and Asia, thirteen in North America, ten in Europe, and nine in Africa and in Australia-New 
Zealand (Vitikainen, 1994, 1998; Brodo \& al., 2001; Martínez $\&$ al., 2003). Within the last 25 years, ten new species have been described in this section, including five from Papua New Guinea: P. fimbriata Vitik. \& al., P. granulosa Sérus. \& al., P. koponenii Sérus. \& al., P. montis-wilhelmii Sérus. \& al., and P. papuana Sérus. \& al. (Sérusiaux \& al., 2009); two from China: P. wulingensis L.F.Han \& S.Y.Guo (Han \& al., 2013) and P. isidiophora L.F.Han \& S.Y.Guo (Han \& al., 2015); one from Africa: P. lambinonii Goffinet (= P. sorediifera (Nyl.) Vitik.; Goffinet \& Hastings, 1995); and two from North America and Iceland: P. castanea Goward \& al. (Goffinet \& al., 2003) and $P$. islandica T.Goward \& S.S.Manoharan-Basil (ManoharanBasil \& al., 2016). Overall, three species (P. canina, P. didactyla (With.) J.R.Laundon, P. rufescens (Weiss) Humb.) have been reported on all six continents (excluding Antarctica) and five additional species (P. degenii Gyeln., P. lepidophora (Vain.) Bitter, P. membranacea (Ach.) Nyl., P. praetextata (Flörke ex Sommerf.) Zopf, P. ulcerata Müll.Arg.) were reported from at least four continents (Martìnez \& al., 2003). Most of these morphologically delineated species were validated phylogenetically but based only on a few collections and using ribosomal loci exclusively (Miadlikowska \& Lutzoni, 2000; Goffinet \& al., 2003; Miadlikowska \& al., 2003; Sérusiaux \& al., 2009; Han \& al., 2013; Manoharan-Basil \& al., 2016; Jüriado \& al., 2017; but see O’Brien \& al., 2009).

Because many species of section Peltigera have large foliose thalli and are common, especially in the boreal biome, they were often the focus of a wide range of studies, e.g., symbionts culture-based experiments (Miao \& al., 1997), patterns of host specialization (O'Brien \& al., 2005, 2013), genome sequencing (Xavier \& al., 2012), characterization of lectins (Lehr \& al., 1995; Díaz \& al., 2011; Manoharan \& al., 2012), nitrogen fixation estimates and chlorophyll contents (Henriksson \& Pearson, 1981; Darnajoux \& al., 2017), bioaccumulation of metals (Haas \& al., 1998; Darnajoux \& al., 2015), and phytase activity (Higgins \& Crittenden, 2015). Earlier phylogenetic studies on the genus Peltigera focused mostly on species complexes (Goffinet \& al., 2003; O'Brien \& al., 2009), and rarely covered entire sections (Miadlikowska $\&$ al., 2003). In each of the most recent multilocus phylogenetic revisions of specific sections of the genus Peltigera (i.e., P. sect. Polydactylon Miądl. \& Lutzoni, sect. Peltidea (Ach.) Vain., sect. Chloropeltigera Gyeln.), at least one cosmopolitan morphospecies was shown to represent several distinct, and morphologically cryptic, evolutionary lineages (Magain \& al., 2017a, b; Pardo-De la Hoz \& al., in press; Miadlikowska \& al., unpub.).

Section Peltigera includes species with different types of reproductive structures. For example, $P$. canina and $P$. membranacea produce numerous apothecia (ascomata) and, therefore, are assumed to reproduce mostly sexually. Other species develop various types of vegetative propagules that contain the fungal and cyanobacterial partners, such as phyllidia (e.g., P. praetextata), isidia (e.g., P. evansiana Gyeln., P. lepidophora), and soredia (e.g., P. didactyla, P. extenuata (Nyl. ex Vain.) Lojka, P. ulcerata) (Vitikainen, 1994; Goward \& al., 1995; Goffinet \& al., 2003). Despite the presence of asexual propagules, apothecia can also be frequent in some species (e.g.,
P. didactyla or $P$. praetextata). It is assumed that all species can potentially disperse through simple thallus fragmentation. The mode of reproduction in lichens can affect genetic diversity of both main partners and the specificity of their interactions (Otálora \& al., 2010, 2013b; Dal Grande \& al., 2012; Pardo-De la Hoz \& al., in press). Asexual reproduction seems to lead to lower genetic diversity of the two partners, as symbiotic propagules foster vertical transmission of the photobiont. Sexual reproduction of the fungal partner involves an aposymbiotic phase (i.e., horizontal transmission of the photobiont), when the fungus must re-establish a symbiosis with a photosynthetic partner after each ascospore dispersion event. Furthermore, the identity of the symbiotic partners and their patterns of association are likely to drive macroevolutionary trends such as their diversification and evolutionary rates (Magain \& Sérusiaux, 2014; Schneider \& al., 2016; Magain \& al., 2017a).

In Peltigera-Nostoc associations, Peltigera species are often more specialized than their cyanobiont partners (O'Brien \& al., 2013; Magain \& al., 2017a; Chagnon \& al., 2018; Lu \& al., 2018). However, mycobiont specificity is highly variable in section Polydactylon, ranging from highly specialized species, i.e., always associating with the same phylogroup of Nostoc (monophyletic group of Nostoc based on $r b c L X$ phylogeny), to generalist species, i.e., associating with several distinct Nostoc phylogroups (Magain \& al., 2017a). Generalist species generally show broader distribution ranges than specialists, seem to be more recently established, and genetically diverse. Chagnon $\&$ al. (2018) found that interactions between species of $P$. sect. Polydactylon and Nostoc phylogroups were highly modular and anti-nested, indicating strong preferences in interactions. Furthermore, when considering Peltigera communities at a local scale, they found associations to be asymmetric, with generalist Nostoc partners interacting with specialized Peltigera species, but this asymmetry was not detected at a global spatial scale. At an intrabiome scale (boreal biome in Québec, Canada), Lu \& al. (2018) reported that Peltigera species had narrower ranges and showed a high degree of specialization towards more widespread generalist Nostoc phylogroups, and that bioclimatic factors were more limiting in the mycobiont distributions than the availability of cyanobionts. A recent study in Estonia (Jüriado \& al., 2017) found most species of section Peltigera, many of which were undescribed, to have narrow habitat requirements. Pardo-De la Hoz \& al. (in press) showed that the widespread, more temperate, species of section Chloropeltigera associate with more Nostoc phylogroups and show higher level of genetic diversity than the more boreal species of the sister section Peltidea. Based on these previous studies, we expect species from section Peltigera to be mainly generalists because many are widespread temperate species.

A nuclear ribosomal ITS- and LSU-based phylogenetic study of section Peltigera revealed several undescribed lineages that might represent new species (Miadlikowska \& al., 2003). The recent discovery of multiple new species in every section of the genus revised up to date (Miadlikowska $\&$ al., 2014a, unpub.; Magain \& al., 2017a, b; Pardo-De la Hoz \& al., in press), supports the expectation of high species richness in section Peltigera. The goals of this study were to: (1) provide 
a worldwide comprehensive phylogeny for species of section Peltigera based on five molecular markers, including three recently developed and tested collinear orthologous regions (COR) that each include an intergenic spacer; (2) re-evaluate the currently recognized species using species discovery and species validation approaches to assess the level of hidden biodiversity in this section; (3) reveal the patterns of specificity between Peltigera species from this section and their Nostoc phylogroups (based on the $r b c L X$ locus), and compare with the patterns of association detected in other sections of the genus Peltigera; and (4) to determine if the reproductive mode (primarily sexual versus asexual) of the mycobiont impacts specificity pattern as well as rates of nucleotide substitution and species diversification in section Peltigera.

\section{MATERIALS AND METHODS}

Taxon sampling and data acquisition. - More than 500 specimens of Peltigera sect. Peltigera and sect. Retifoveatae (identified as such based on morphology) were selected from several herbaria world-wide (AMNH, B, CDS, CGMS, CONC, CONN, DUKE, H, KW, LG, MAF, MEXU, NY, QFA, UBC, UDBC, UGDA, UMEX, UPS, WIS) or were collected during numerous field trips part of this study (Norway, Canada [Québec], and U.S.A. [North Carolina, Alaska] in 2011; Russia, Colombia, Peru, and Brazil in 2012; U.S.A. [Utah], Canada [Alberta], and Ecuador in 2013; Canada [British Columbia] in 1998-2016). We extracted DNA from 375 specimens (Appendix 1; Electr. Suppl.: Table S1) using a modified protocol from Zolan \& Pukkila (1986) with a $\%$ sodium dodecyl sulphate (SDS) as the extraction buffer. For the mycobiont, we targeted five molecular markers. We amplified ca. $0.6 \mathrm{~kb}$ of the internal transcribed spacer (ITS) of the nuclear ribosomal tandem repeat using the ITS1F (Gardes \& Bruns, 1993) and ITS4 (White \& al., 1990) primers; ca. $0.7 \mathrm{~kb}$ of $\beta$-tubulin using the reverse primer BT2B (Glass \& Donaldson, 1995) and the forward primer T1 (O’Donnell \& Cigelnik, 1997) or alternatively bt_34F (O’Brien \& al., 2009); and three collinear orthologous regions (COR) each including an intergenic spacer (Magain \& al., 2017b): COR1b using primers COR-1bF and COR-1bR-B; COR3 using primers COR-3F-A and COR-3R-B; and COR16 using primers COR-16Fout and COR-16Rmid1. For the cyanobiont, we sequenced ca. $1.0 \mathrm{~kb}$ of the $r b c L X$ region (which includes the last 82 amino acids of the RUBISCO large subunit $[r b c L]$, a putative chaperone gene $[r b c X]$ and two intergenic spacers; Li \& Tabita, 1997) using primers CW and CX, following Rudi \& al. (1998). PCR conditions for ITS and $r b c L X$ follow Magain \& al., 2017a and literature cited therein. $\beta$-tubulin and the three COR markers were amplified using the following conditions: $94^{\circ} \mathrm{C}$ for $30 \mathrm{~s}$, $55^{\circ} \mathrm{C}$ for $30 \mathrm{~s}\left(-0.4^{\%}\right.$ cycle $), 72^{\circ} \mathrm{C}$ for $1 \mathrm{~min}(+2 \mathrm{~s} /$ cycle $)$ for 24 cycles; $94^{\circ} \mathrm{C}$ for $30 \mathrm{~s}, 45^{\circ} \mathrm{C}$ for $30 \mathrm{~s}, 72^{\circ} \mathrm{C}$ for $2 \mathrm{~min}(+3 \mathrm{~s} /$ cycle $)$ for 12 cycles; $72^{\circ} \mathrm{C}$ for $10 \mathrm{~min}$, followed by storage at $4^{\circ} \mathrm{C}$. All PCR amplicons were cleaned with ExoSAP (Affymetrix, Santa Clara, California, U.S.A.) following the manufacturer's protocol. Sequencing was carried out in $10 \mu \mathrm{l}$ reactions using the same primers as for PCR amplification in the following proportions:
$1 \mu \mathrm{l}$ primer $(10 \mu \mathrm{mol} / \mathrm{l}), 1 \mu \mathrm{l}$ purified PCR product, $0.75 \mu \mathrm{l} \mathrm{Big}$ Dye (Big Dye Terminator Cycle sequencing kit, ABIPRISM v.3.1; Perkin-Elmer, Applied Biosystems, Foster City, California, U.S.A.), $3.25 \mu 1$ Big Dye buffer, and $4 \mu$ l double-distilled water. Automated reaction cleanup and visualization was performed at the Duke Genome Sequencing and Analysis Core Facility of the Institute for Genome Sciences and Policies (for details see Gaya \& al., 2012).

All newly acquired sequences were subjected to BLAST searches to confirm the fungal or cyanobacterial origin of each sequence fragment. They were assembled and edited using the software package Sequencher v.4.1 (GeneCodes, 2000) and aligned manually with the program MacClade v.4.08 (Maddison $\&$ Maddison, 2005). The "Nucleotide with AA color" option was used for guiding all alignments for protein-coding genes, including the delimitation of exons and introns. Ambiguously aligned regions sensu Lutzoni \& al. (2000) were delimited manually and excluded from subsequent analyses.

Phylogenetic analyses of the mycobiont datasets. - For Peltigera we generated a total of 1273 sequences: 318 ITS, 199 $\beta$-tubulin, 252 COR1b, 251 COR3 and 253 COR16 (Appendix 1; Electr. Suppl.: Table S1). We also used sequences of ITS and $\beta$-tubulin from other studies (O’Brien \& al., 2009; Sérusiaux \& al., 2009; Han \& al., 2015; Manoharan-Basil \& al., 2016) available in GenBank for a total of 357 ITS and $245 \beta$-tubulin sequences used for this study. Prior to data concatenation, single-locus phylogenies were generated for all five fungal loci using RAxML-HPC2 v.7.2.8 (Stamatakis, 2006; Stamatakis \& al., 2008) as implemented on the CIPRES portal (Miller \& al., 2010). Searches for optimal tree and bootstrap analyses were conducted with the rapid hill-climbing algorithm for 1000 replicates with the GTRGAMMA substitution model (Rodriguez $\&$ al., 1990). To detect topological incongruence among singlelocus datasets, a reciprocal 70\% maximum likelihood (ML) bootstrap support criterion was implemented (Mason-Gamer \& Kellogg, 1996; Reeb \& al., 2004). The single-locus topologies (Electr. Suppl.: Fig. S1A-E) were considered congruent and we proceeded to concatenation.

The concatenated dataset included specimens with at least two of the five targeted loci, except for a few specimens of $P$. fimbriata and $P$. isidiophora for which only ITS was available. Five outgroup species representing section Peltidea (P. aphthosa (L.) Willd., P. malacea (Ach.) Funck) and section Polydactylon (P. hymenina (Ach.) Delise, P. polydactylon (Neck.) Hoffm., P. scabrosa Th.Fr.) were selected for a total of 303 specimens (Appendix 1; Electr. Suppl.: Table S1). Out of 298 ingroup specimens, the following sequences were missing: 4 ITS (1.3\%), $59 \beta$-tubulin (19.8\%), 51 COR1b (17.1\%), 49 COR3 (16.4\%) and 46 COR16 (15.4\%) sequences. A total of 176 specimens (59.1\%) were represented by all five loci, $71(23.8 \%)$ by four loci, $21(7 \%)$ by three loci, $24(8 \%)$ by two loci, and $6(2 \%)$ by a single locus. Section Retifoveatae had the largest amount of missing data (26.7\%), whereas in section Peltigera the proportion of missing data was clade-dependent and varied from $4.8 \%$ to $20.8 \%$. We used PartitionFinder v.1.0.1. (Lanfear $\&$ al., 2012) on a concatenated dataset with no missing data, to determine the best partitioning scheme and the optimal models 
to be used in subsequent multi-locus phylogenetic analyses. The following ten data subsets were pre-delimited: ITS1, ITS2, 5.8S, $\beta$-tubulin 1st, 2nd and 3rd codon positions, and non-coding regions (introns), COR1b, COR3, COR16. We then reinserted all specimens for which we had sequences of at least two loci, using the compare_and_choose function of the PLexus PERL package (Magain, 2018), into a five-locus dataset. The best partitioning scheme for this global dataset included three subsets: ITS1 and ITS2 (with TVMef $+\mathrm{I}+\Gamma$ as the best model); 5.8S and the 1 st and 2 nd codon positions of $\beta$-tubulin (with $\mathrm{JC}$ as the best model); and a third subset with the 3rd codon position, as well as the non-coding regions of $\beta$-tubulin, COR $1 b$, COR3 and COR16 (with $\mathrm{HKY}+\Gamma$ as the best model). We performed maximum likelihood searches for the optimal tree and bootstrap analyses (1000 replicates; GTRGAMMA substitution model) using RAxML v.7.4.2 (Stamatakis 2006; Stamatakis $\&$ al., 2008). We also ran Bayesian analyses for 40 million generations, sampling every 1000th generation with MrBayes v.3.1.2 (Huelsenbeck \& Ronquist, 2001) as implemented on the CIPRES portal. Two independent runs, each composed of four chains, were completed. We assessed the convergence of chains using Tracer v.1.5 (Rambaut \& Drummond, 2007) and Are We There Yet (AWTY; Nylander \& al., 2008) as implemented on the website http://king2.scs.fsu.edu/CEBProjects/awty/awty_start. php (last accessed 8 Feb 2017 [website no longer available]).

Using the resulting concatenated five-locus phylogeny, we divided the dataset into nine subsets corresponding to wellsupported major clades (1-9, Fig. 1). Species delimitations were performed on subclades of the section and separate RAxML analyses were performed on clades 4 to 9 (clades 1-3 contain only a few specimens representing the early evolutionary splits in the section; see Results section) using the same settings as for the complete dataset. An additional analysis was performed on a dataset comprising clades 4-7, with the same settings, to test for differences in evolutionary rates among these clades.

Species delimitation methods. - For clades 4-9, each of the five loci was analyzed separately (except $\beta$-tubulin for clade 4 , because of the large amount of missing data), for a total of 29 analyses. BEAST v.1.7 (Drummond \& Rambaut, 2007) was used to analyze the following partitioned datasets: for ITS: ITS1, ITS2, 5.8S; for $\beta$-tubulin: each codon and non-coding regions; no partitions for COR1b, COR3, COR16. Optimal evolutionary models were selected with MrModeltest v.2 (Nylander, 2004). Bayesian analyses were run for 20 million generations sampling every 200,000th generation. These analyses generated sets of 100 trees each. For each of these tree sets, we completed a bGMYC analysis (Pons \& al., 2006; Reid \& Carstens, 2012) for 50,000 generations with a burn-in of 40,000 generations, a thinning value of 100 and thresholds values of 2 and 20 . We considered a species to be well delimited by bGMYC v.1.0 when the probability of grouping a set of haplotypes together was higher than the probability of any alternative grouping that included at least one haplotype from this putative species (Electr. Suppl.: Table S2). We also used bPTP v.0.51 (Zhang \& al., 2013) on the best ML tree resulting from the concatenated analysis as implemented on http://species.h-its.org/ (last accessed on 7 Feb 2017) using default parameters.
We used bPP v.2.2 (Yang \& Rannala, 2010) to validate species delimitations obtained with bGMYC and bPTP. Specimens were grouped in a distinct lineage for the bPP analyses if at least two of the species discovery methods (any of the five bGMYC analyses on each locus separately and/or the bPTP analysis on the concatenated dataset) suggested they should be considered as distinct species. For each subset, we ran bPP for 100,000 generations, sampling every 2 nd generation, with a burn-in of 2000. Relative nucleotide substitution rates of the loci were estimated using the best topologies resulting from single-loci $\mathrm{ML}$ analyses. We repeated the analyses for a wide variety of $\theta$ and $\tau$ values and examined the changes in the likelihood, as well as the difference between the prior values of $\theta$ (as defined by the prior distribution) and the posterior values of $\theta$ as averaged from the $\theta$ values estimated for each branch (Electr. Suppl.: Table S3).

Testing for differential nucleotide substitution rates. We implemented PAML v.4.8a (Yang, 1997) on the best ML tree reconstructed from a subset of clades 4-7 where we kept one representative per species (as delimited in this study; see Results section) to compare evolutionary rates between the clade comprising sorediate species (clade 4) and the remaining clades in the tree. We ran likelihood ratio tests (LRT) to compare the different scenarios using the best tree with either a strict molecular clock, several scenarios of local clocks along the tree, or no clock (Table 1).

Biogeographical analyses. - For each species delimited as part of this study, we selected specimens for which at least four loci were available. If this was not possible, we selected specimens with the highest number of loci. For computational purposes, and to prevent the dataset to be too asymmetrical, we further pruned the dataset. For species represented by more than five specimens, we kept the specimens according to the following selection scheme: highest number of loci, unique geographic origin, and unique phylogenetic placement. Our final adjusted five-locus matrix consisted of 225 specimens representing 90 species. We ran a Bayesian analysis using BEAST v.2.4.5 (Bouckaert \& al., 2014) for 50 million generations, sampling every 1000th generation, using unlinked substitution models, a lognormal relaxed clock linked among loci, and linked trees. MrModeltest2 (Nylander, 2004) estimated the best substitution models to be: GTR $+\mathrm{I}+\Gamma$ for ITS, HKY $+\mathrm{I}+\Gamma$ for $\beta$-tubulin, and $\mathrm{HKY}+\Gamma$ for COR1b, COR3 and COR16. We collapsed branches within each species (single branch per species) using Mesquite v.3.11 (Maddison \& Maddison, 2015).

We performed biogeographic history analyses on the resulting tree using the R package BioGeoBEARS v.0.2.1 (Matzke, 2013a, b). We delimited nine geographic regions and allowed a maximum of six geographic regions per species or node because of computational limitations. Regions were delimited as follows: Europe, North America, Asia (excluding Indonesia and the Philippines), Africa, Australasia (including Australia, New Zealand, Papua New Guinea, Indonesia and the Philippines), Neotropics (from Mexico to Brazil), Neantarctic (Argentina, Chile), Panboreal (boreal regions of Europe, North America and Asia) and Pacific Northwest (Oregon, Washington, British Columbia). Defined regions follow the observations of distribution patterns of Peltigera species in other sections (e.g., Magain 
Table 1. Likelihood scores for the best ML tree resulting from an analysis on clades 4-7 under different rate conditions.

\begin{tabular}{|c|c|c|c|c|c|c|c|}
\hline Rates & Scenario no. & Clade 4 & Clade 5 & Clade 6 & Clade 7 & No. of rates & $\ln L$ \\
\hline Molecular clock & 1 & $\mathrm{r} 1$ & $\mathrm{r} 1$ & $\mathrm{r} 1$ & $\mathrm{r} 1$ & 1 & -16855.64734 \\
\hline Local clock in clade 4 & 2 & $\mathrm{r} 1$ & $\mathrm{r} 2$ & $\mathrm{r} 2$ & $\mathrm{r} 2$ & 2 & -16737.61097 \\
\hline Local clock in clade $5+6$ & 3 & $\mathrm{r} 1$ & $\mathrm{r} 2$ & $\mathrm{r} 2$ & r1 & 2 & -16760.69642 \\
\hline Local clock in clade 7 & 4 & r1 & r1 & $\mathrm{r} 1$ & $\mathrm{r} 2$ & 2 & -16766.77956 \\
\hline Local clock in clade 6 & 5 & rl & r1 & $\mathrm{r} 2$ & r1 & 2 & -16768.69647 \\
\hline Local clock in clade 5 & 6 & $\mathrm{r} 1$ & $\mathrm{r} 2$ & $\mathrm{r} 1$ & $\mathrm{r} 1$ & 2 & -16774.92650 \\
\hline Local clocks in clade 4 and in clade $5+6$ & 7 & r1 & $\mathrm{r} 2$ & $\mathrm{r} 2$ & r3 & 3 & -16737.60911 \\
\hline No clock & 8 & NA & NA & NA & NA & $\begin{array}{l}\text { equal to no. } \\
\text { of branches }\end{array}$ & -16605.81107 \\
\hline
\end{tabular}

Bold values indicate the best likelihood score overall and the best likelihood score with two rate parameters. NA, not applicable.

\& al., 2017a). We tested six models: DEC, DEC $+\mathrm{J}$ (Ree \& Smith, 2008; Matzke, 2014), and likelihood interpretations of the DIVA (Ronquist, 1997; Ronquist \& Sanmartín, 2011) and BAYAREA models (Landis \& al., 2013), with and without the $\mathrm{J}$ parameter (hereafter referred as DIVALIKE, DIVALIKE $+\mathrm{J}$, BAYAREALIKE and BAYAREALIKE+J). The J parameter represents the relative per-event weight of founder-events (Van Dam \& Matzke, 2016).

Phylogenetic analyses of the cyanobiont dataset. - We amplified and sequenced the $r b c L X$ locus for 305 cyanobionts directly from the same DNA isolated from lichen thalli, which was used to sequence mycobiont loci (Appendix 1; Electr. Suppl.: Table S1). We added 455 sequences from GenBank resulting in a 759-sequence dataset. Identical sequences were collapsed using the script collapse_multi.pl from the PERL package PLexus v.0.1 (Electr. Suppl.: Table S4), resulting in a final dataset of 437 unique sequences. Ambiguous regions of the alignment (i.e., the two spacers) were excluded from the phylogenetic analyses.

We performed phylogenetic analyses on the $r b c L X$ dataset using RAxML-HPC2 v.7.2.8. Optimal tree and bootstrap searches were conducted with the rapid hill-climbing algorithm for 1000 replicates with the GTRGAMMA nucleotide substitution model. The dataset was partitioned according to codon positions, and the best substitution models were determined with MrModeltest2. We ran MrBayes v.3.1.2 as implemented on the CIPRES portal for 50 million generations, sampling every 1000th generation. Two independent runs, each composed of four chains, were performed. We assessed the convergence of chains using Tracer v.1.5 and AWTY as implemented on the website http://king2.scs.fsu.edu/CEBProjects/awty/awty_start. php (last accessed 8 Feb 2017 [website no longer available]). The first $25 \%$ of the samples were removed as burn-in.

Specificity index. - For each Peltigera species for which the cyanobiont's $r b c L X$ was sequenced from at least three specimens, we calculated a Specificity index, adapted from Simpson's index (Simpson, 1949), calculated as

$$
\sum_{i=1}^{N} f_{i}^{2}
$$

where $N$ is the number of Nostoc phylogroups that the species associates with, and $f_{\mathrm{i}}$ is the frequency of association with the phylogroup calculated as the number of $r b c L X$ sequences from this phylogroup divided by the total number of $r b c L X$ sequences available from cyanobionts associated with this Peltigera species. With this index, a true Peltigera specialist, i.e., a species always associating with the same Nostoc phylogroup, has a specificity of 1 , whereas a species associating with one phylogroup in half of the thalli and another one in the other half of the specimens would have a value of 0.5 . A Peltigera species associating with a different phylogroup in each thallus would have a value tending towards 0 with an infinite population size.

Fig. 1. Phylogeny of the genus Peltigera, sections Peltigera and Retifoveatae. Best ML tree resulting from a RaxML analysis on a concatenated dataset of five loci representing 298 specimens and 5 outgroup species from sections Peltidea and Polydactylon (Appendix 1; Electr. Suppl.: Table S1). The overall rooting of the tree follows Magain \& al. (2017a). Black boxes after the reference number and geographic origin of the specimens represent sequenced loci in the following order: ITS, $\beta$-tubulin, COR1b, COR3, COR16. Sections were named according to Miadlikowska $\&$ Lutzoni (2000) and numbered clades were defined in this study. Thick branches received a bootstrap support $\geq 70 \%$ and Bayesian posterior probability support $\geq 0.95$. The consensus of species delimitations (see Results) is indicated by thick vertical lines and brackets. *P. austroamericanalfibrilloides 5 as delimited by the consensus of methods does not appear monophyletic on this tree. Abbreviations: $\mathrm{AB}=\mathrm{Alberta}, \mathrm{ACT}=$ Australian Capital Territory, $\mathrm{AK}=$ Alaska, $\mathrm{AR}=$ Arkansas, $\mathrm{AZ}=$ Arizona, $\mathrm{BC}=$ British Columbia, $\mathrm{CA}=\mathrm{California}, \mathrm{CO}=\mathrm{Colorado}, \mathrm{DA}=$ Dagestan, HE = Hebei, HK = Hokkaido, HS = Honshu, JI = Jilin, KH = Khabarovsk, KR = Krasnoyarsk, KS $=$ Kansas, KU $=$ Kurile Islands, $\mathrm{ME}=$ Maine, $\mathrm{MI}=$ Michigan, $\mathrm{MO}=$ Missouri, $\mathrm{NC}=$ North Carolina, $\mathrm{NM}=$ New Mexico, NSW $=$ New South Wales, NY $=\mathrm{New}$ York, NX $=$ Ningxia, $\mathrm{PA}=$ Pennsylvania, $\mathrm{OK}=$ Oklahoma, $\mathrm{ON}=$ Ontario, $\mathrm{OR}=$ Oregon, $\mathrm{PNG}=$ Papua New Guinea, $\mathrm{QC}=\mathrm{Québec}, \mathrm{SA}=\mathrm{Sakhalin}, \mathrm{SI}=$ Sichuan, TN = Tennessee, UT = Utah, YK = Yukon, YU = Yunnan; X, XI, XII refer to numbers of Chilean Regions as shown in Appendix 1/ Electr. Suppl.: Table S1. 


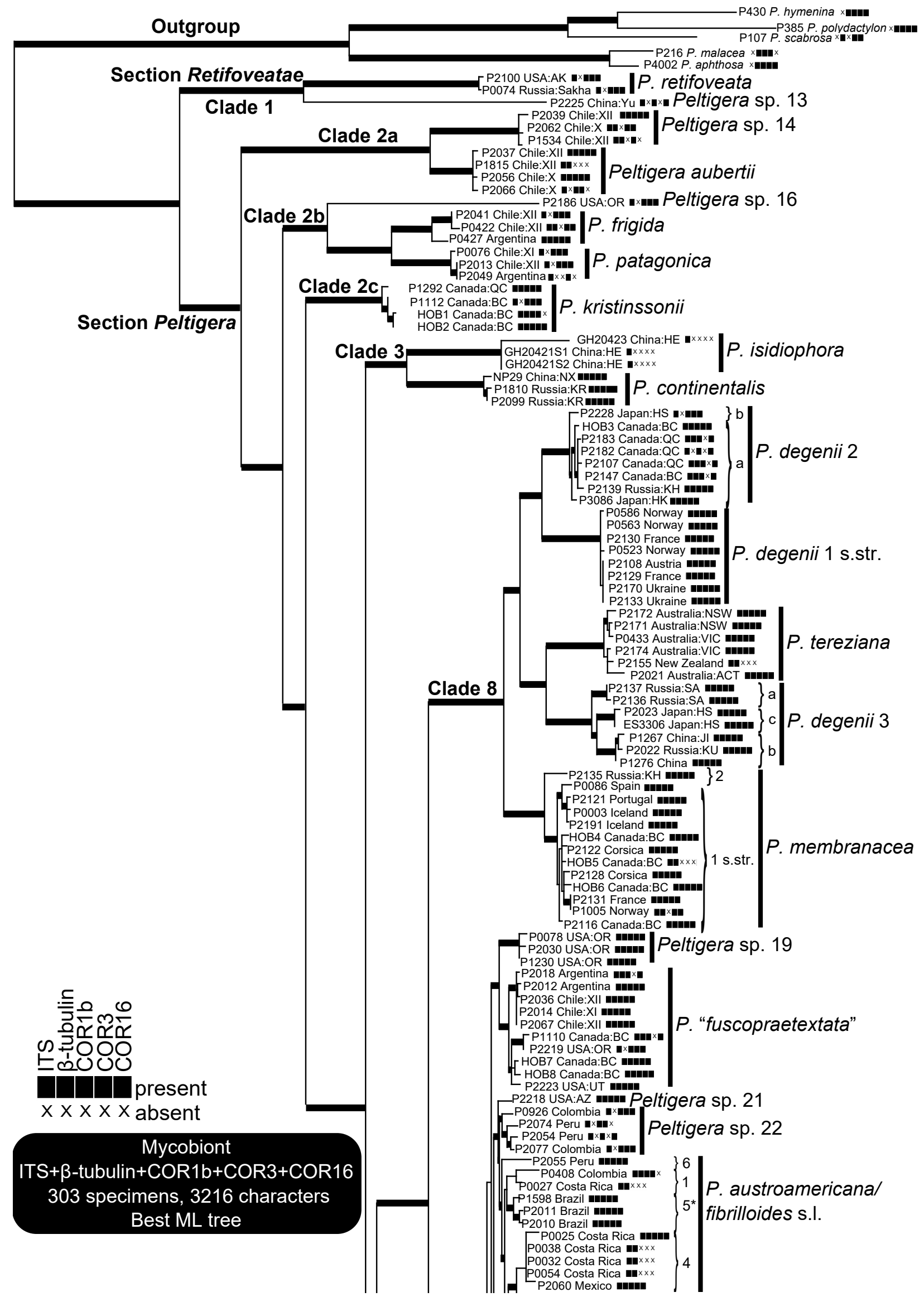




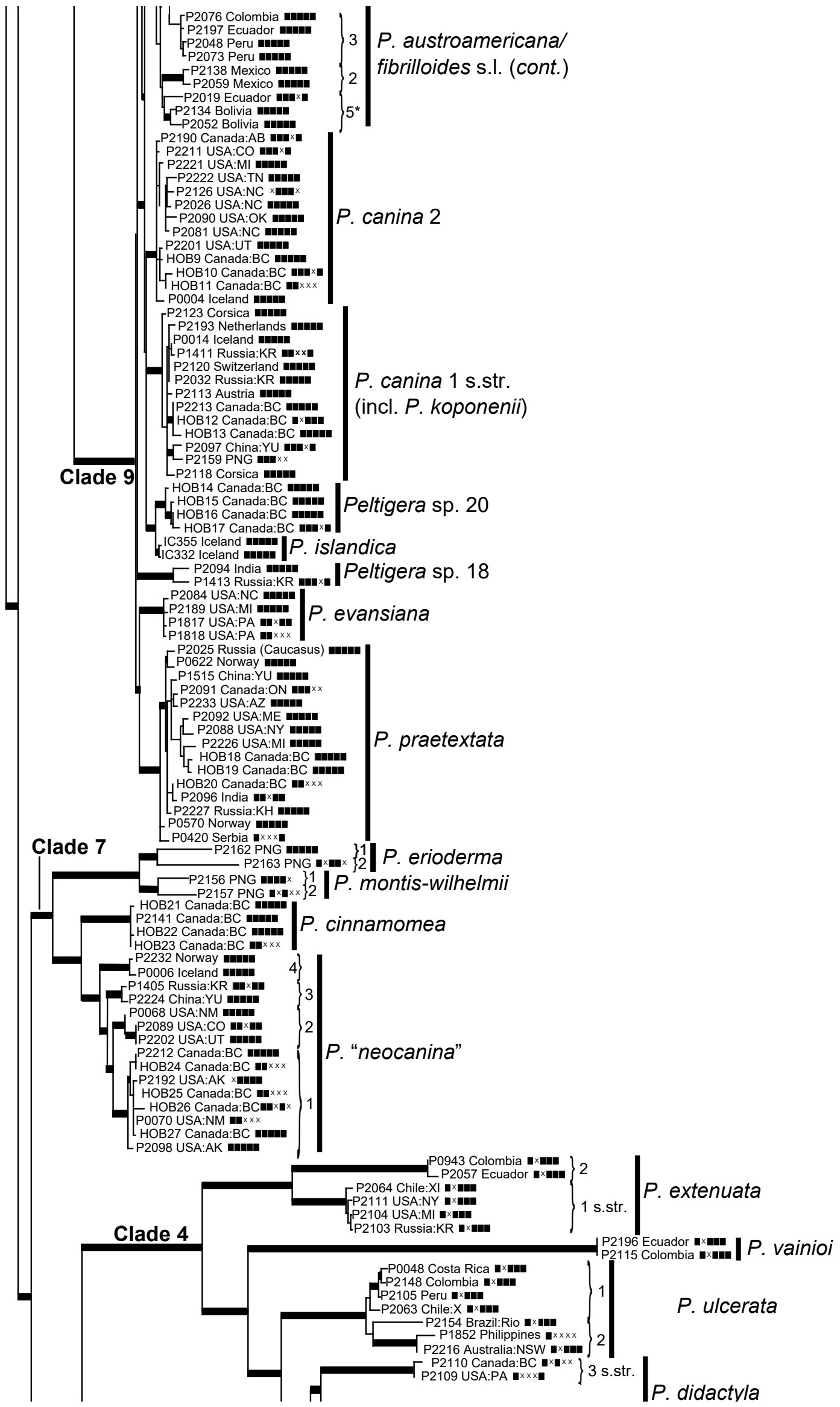




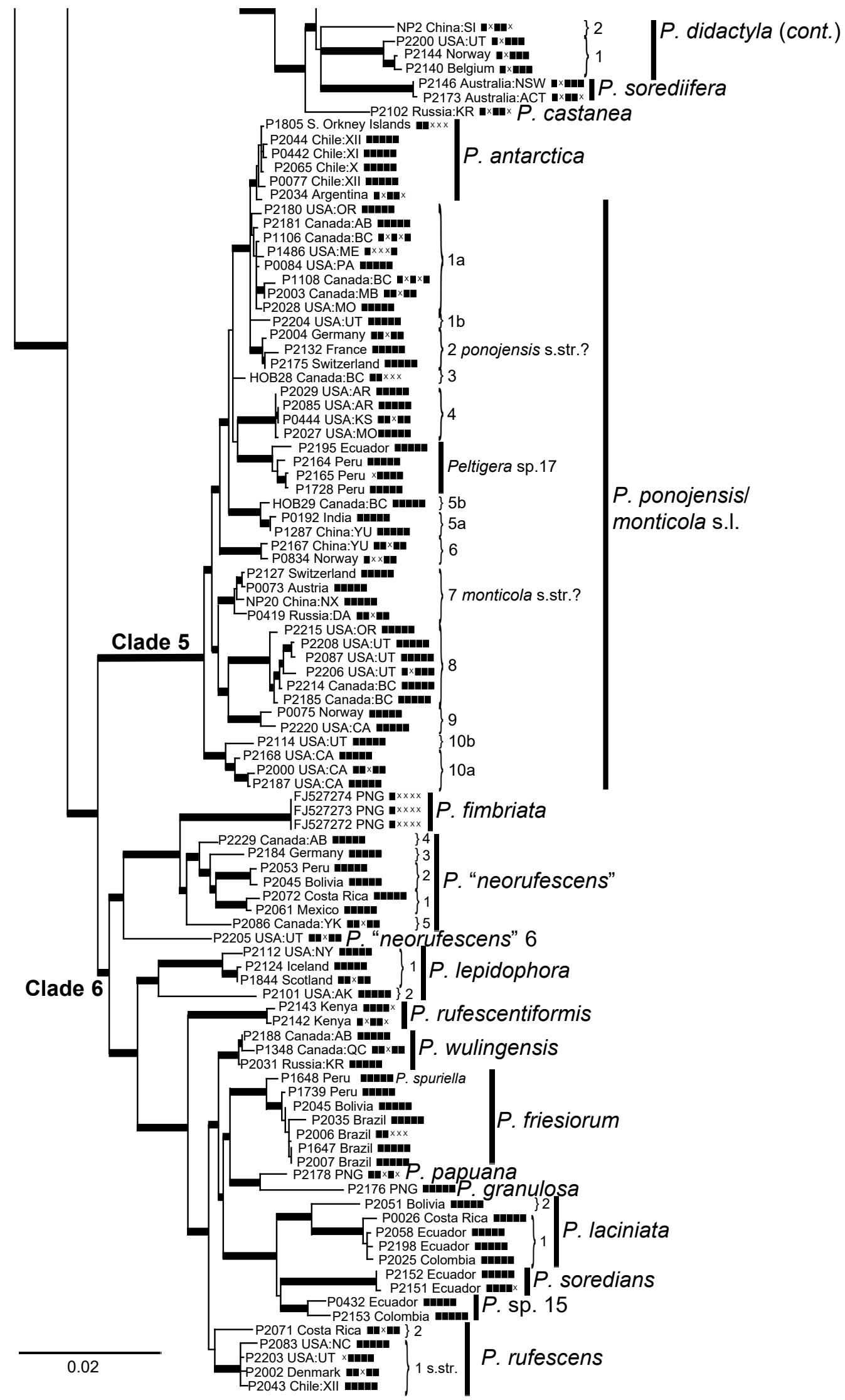




\section{RESULTS}

Phylogenetic relationships and species delimitation in Peltigera sect. Peltigera and sect. Retifoveatae. - The monospecific section Retifoveatae seems to include a second species (Peltigera sp. 13; the numbering of new species follows Magain \& al., 2017a, b, who reported 12 new Peltigera species for section Polydactylon) represented by a single collection from China (clade 1; Fig. 1). The chemistry of this putative new species is similar to the chemistry of $P$. retifoveata. The presence of unique terpenoids was the justification for recognizing a separate section (Retifoveatae) for $P$. retifoveata (Miadlikowska \& Lutzoni, 2000).

Our results suggest the presence of 50 new species for a total of 88 species in section Peltigera. The newly discovered putative species are spread across the section (clades 2 and 3:2 of 8; clade 4: 4 of 10; clade 5: 11 of 15; clade 6: 10 of 20; clade 7: 6 of 9; clade 8: 6 of 9; clade 9: 11 of 17). Ten major clades are well delimited and highly supported in section Peltigera (clades 2a-c, 3-9; Fig. 1); four of them (clades 2a-c, 3) represent lineages from early divergences. The first two divergences (clades 2a and 2b) include (with one exception) specimens from Chile and Argentina representing Peltigera aubertii C.W.Dodge and one newly recognized species $(P$. sp. 14 corresponding to Peltigera sp. nov. in Miadlikowska \& al., 2014a) in clade 2a, and two known species ( $P$. frigida R.Sant., P. patagonica Räsänen) as well as a putative new species from the Pacific Northwest (Oregon) in clade 2b. The next two divergences include the North American P. kristinssonii Vitik. (clade 2c) and an Asian clade of two sister species: $P$. continentalis Vitik. and $P$. isidiophora (clade 3 ). The remaining six clades (clades 4-9), part of a single monophyletic group, are more species rich and contain multiple unnamed lineages intermixed with known species, some of which are non-monophyletic or are nested within broadly delimited species.

Clade 4. - The $P$. didactyla clade includes 24 specimens (Fig. 1) representing six currently recognized, all sorediate, species (Fig. 1): P. castanea, P. didactyla, P. extenuata,
P. sorediifera, P. ulcerata, and P. vainioi Gyeln. Species discovery methods delimited 10 to 14 species in this clade (Fig. 2A; Electr. Suppl.: Table S2). Peltigera castanea, P. sorediifera and $P$. vainioi were considered well-delimited, whereas each of the remaining three species represents potentially multiple species ( $P$. didactyla includes three species, $P$. extenuata includes two, and $P$. ulcerata includes up to four). Twelve lineages were subjected to bPP analyses for validation (Fig. 2A). The final bPP analysis $(\theta=0.02$; Electr. Suppl.: Table S3) supported the recognition of two putative species within $P$. ulcerata (P. ulcerata 1 and 2; Fig. 2A), and validated the remaining eight species.

Clade 5. - The P. ponojensis Gyeln./P. monticola Vitik. clade includes 48 specimens (Fig. 1) representing three currently recognized species: $P$. antarctica C.W.Dodge, $P$. monticola and $P$. ponojensis. This is one of the two clades (together with clade 9) with the highest level of discrepancy among the results provided by the species discovery methods (11 to 17 species recognized) and with multiple specimens failing to group to a species according to our bGMYC criterion (gray boxes in Fig. 2B; Electr. Suppl.: Table S2). Among the 18 lineages selected to be validated by bPP $(\theta=0.0038$; Fig. 2B; Electr. Suppl.: Table S3), 15 were confirmed. Two of them represent the new species $P$. sp. 17 and $P$. antarctica as currently circumscribed, whereas specimens identified as $P$. monticola and $P$. ponojensis were assigned to thirteen mostly intermixed putative species (Fig. 2B).

Clade 6. - The $P$. rufescens clade includes 43 specimens (Fig. 1) representing eleven currently recognized species: Peltigera granulosa, P. fimbriata, P. laciniata (G.Merr.) Gyeln., P. lepidophora, P. papuana, P. rufescens, P. rufescentiformis (Gyeln.) C.W.Dodge, $P$. soredians Vitik., $P$. wulingensis, specimens that probably correspond to P. friesiorum Gyeln. and $P$. spuriella Vain., and a putative species provisionally named $P$. "neorufescens" (Miadlikowska \& Lutzoni, 2000; Miadlikowska \& al., 2003). Species discovery methods suggested the presence of 12 to 19 species. All 19 lineages representing putative species were validated by bPP $(\theta=0.004$; Fig. 2C) with support values $>0.99$ (Fig. 2C; Electr. Suppl.: Table S2).

Fig. 2. Comparison of species delimitations resulting from bGMYC analyses on each locus separately and bPTP analyses on members of the following clades within section Peltigera: 4 (A), 5 (B), 6 (C), 7 (D), 8 (E), and 9 (F). The left panel on each figure represents the best ML tree where thick branches received bootstrap support $\geq 70 \%$. Boxes of the same color indicate congruent species delimitation among methods/loci for each specimen. White boxes indicate missing loci. A gradient of two colors represents conflicting species delimitations with similar probability values (see Electr. Suppl.: Table S2). The columns with locus names represent species delimitation with bGMYC. bPTP results were obtained on the best ML tree resulting from the concatenated 5-locus dataset. The color-coded bars to the left of the lineage names, as well as lineage names in dashed ovals, represent species assignments prior to the bPP analysis, whereas the color-coded bars to the right of the lineage names and the lineage names in black boxes represent the final bPP results (mean value of the $\theta$ parameter of the final analysis is shown above the color-coded bars). The right panel on each figure represents a schematic species tree where triangles indicate lineages merged by bPP, whereas lines represent species validated by bPP, according to the final bPP analysis. Graphs associated with selected nodes represent the posterior probability of keeping the two species separate (from 0 to $1, \mathrm{Y}$ axis) as a function of the prior mean of the $\theta$ value (logarithmic scale, $\mathrm{X}$ axis); the horizontal red line represents a PP value of 0.5 , whereas the vertical green line represents the $\theta$ value chosen for the final analysis (Electr. Suppl.: Table S3). $\theta$ values ranges from 0.001 to 0.032 for clades 5, 7, 8 and 9; from 0.01 to 0.1 for clade 4 ; and from 0.001 to 0.1 for clade 6 . Posterior probability values associated with the final analyses are shown above each graph. Abbreviations: $\mathrm{AB}=\mathrm{Alberta}, \mathrm{ACT}=\mathrm{Australian}$ Capital Territory, $\mathrm{AK}=$ Alaska, $\mathrm{AR}=$ Arkansas, $\mathrm{AZ}=$ Arizona, $\mathrm{BC}=$ British Columbia, $\mathrm{CA}=$ California $, \mathrm{CC}=\mathrm{Caucasus}, \mathrm{CO}=\mathrm{Colorado}$, $\mathrm{DA}=$ Dagestan, HE $=$ Hebei, HK $=$ Hokkaido, HS $=$ Honshu, JI $=$ Jilin, KH $=$ Khabarovsk, KR $=$ Krasnoyarsk, KS $=$ Kansas, KU $=$ Kurile Islands, $\mathrm{ME}=$ Maine, $\mathrm{MI}=$ Michigan, $\mathrm{MO}=$ Missouri, $\mathrm{NC}=$ North Carolina, $\mathrm{NM}=$ New Mexico, NSW $=$ New South Wales, $\mathrm{NY}=\mathrm{New}$ York, $\mathrm{NX}=$ Ningxia, $\mathrm{PA}=$ Pennsylvania, $\mathrm{OK}=$ Oklahoma, $\mathrm{ON}=$ Ontario, $\mathrm{OR}=$ Oregon, $\mathrm{PNG}=$ Papua New Guinea, $\mathrm{QC}=\mathrm{Québec}, \mathrm{SA}=\mathrm{Sakhalin}$, $\mathrm{SI}=$ Sichuan, $\mathrm{TN}=$ Tennessee, $\mathrm{UT}=\mathrm{Utah}, \mathrm{YK}=$ Yukon, $\mathrm{YU}=$ Yunnan; X, XI, XII refer to numbers of Chilean Regions as shown in Electr. Suppl.: Table S1. Specimens in the ponojensis/monticola clade were abbreviated as pon./mont. and austroamericanalfibrilloides as austr./fibr. 
A)

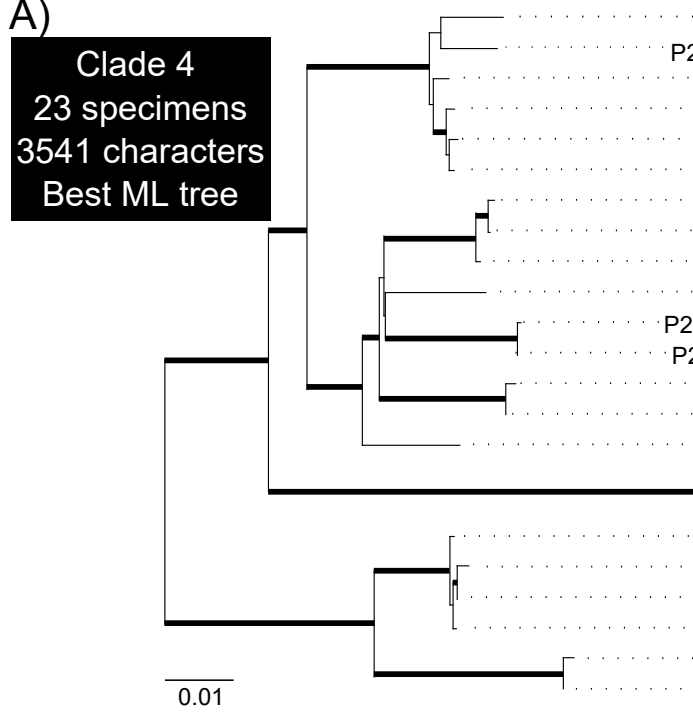

B)

\section{Clade 5 \\ 48 specimens \\ 3973 characters \\ Best ML tree}

P2154Brazil

2216Australia:NSW

P2063Chile:X

P2148 Colombia

P2105Peru

P0048CostaRica

P2140Belgium

P2144Norway

P2200USA:UT

NP2 China:SI

P2173 Australia:NSW

2146 Australia:ACT

P2110 Canada:BC

P2109 USA:PA

P2102 Russia:KR

P2196 Ecuador

2115 Colombia

P2111 USA:NY

P2064 Chile:XI

P2104 USA:MI

P2103 Russia:KR

P2057 Ecuador

P0943 Colombia

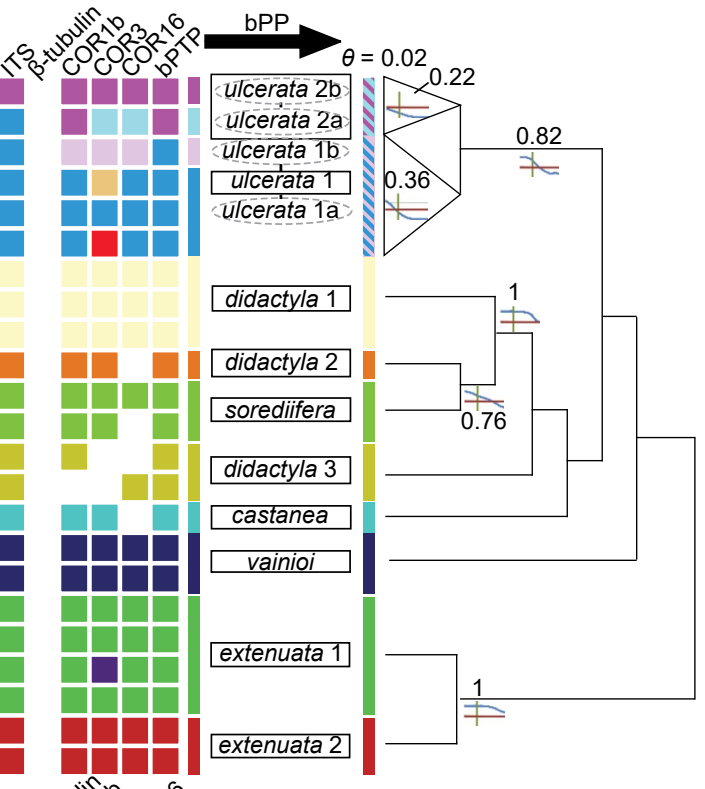

P22028 USA:MO

P2181 Canada:AB

P1106 Canada:BC

P2003 Canada:MB

P1108 Canada:BC

P0084 USA:PA

P1486 USA:ME

P2180 USA:OR

P2004 Germany

P2175 Switzerland

P2132 France

P0077 Chile:XII

. P2065 Chile:X

P2044 Chile:XII

P0442 Chile:XI

P2034 Argentina

P1805 S. Orkney Islands

- HOB28 Canada:BC

- P0444 USA:KS

P2029 USA:AR

P2085 USA:AR

P2027 USA:MO

P2165 Peru

P1728 Peru

P2164 Peru

P2195 Ecuador

P0192 India

P1287 China

HOB29 Canada:BC

P2167 China:YU

P0834 Norway

P2220 USA:CA

P0075 Norway

P2215 USA:OR

P2185 Canada:BC

P2087 USA:UT

P2208 USA:UT

P2206 USA:UT

P2214 Canada:BC

P0419 Russia:DA

P2127 Switzerland

P0073 Austria

NP20 China:NX

P2114 USA:UT

P2187 USA:CA

P2000 USA:CA

P2168 USA:CA

bPP

$\theta=0.0038$
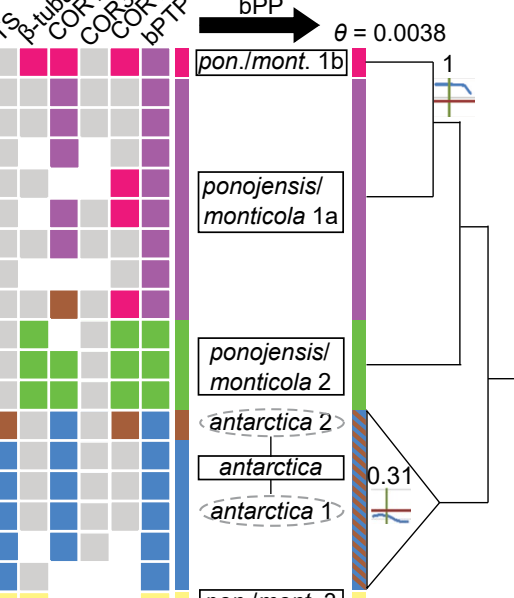

pon.Imont. 3

pón. Imont. 4 aे

pon.Imont. 4

бon. Imont. 4b

sp. $\overline{1} \overline{\mathrm{a}}$ -

sp. 17

sp. 17b-

ponojensis/

monticola $5 a$

pon.Imont. 5b

ponojensisl

monticola 6

ponojensis/

monticola 7

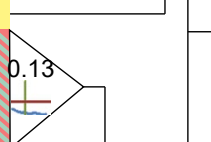

ponojensis/

monticola 8

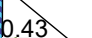

0.43
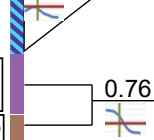

-

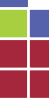

$+$

-

ponojensis/

monticola 9

pon./mont. 10b

ponojensis/

monticola 10a

0.98

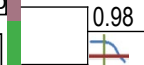


Clade 7. - The P. cinnamomea Goward clade includes 23 specimens (Fig. 1) representing three currently recognized species: $P$. cinnamomea, $P$. erioderma Vain., and $P$. montiswilhelmii, as well as one putative species provisionally named Peltigera "neocanina" (informally introduced by Miadlikowska \& Lutzoni, 2000 and Miadlikowska \& al., 2003 and referred to by O'Brien \& al., 2009). Discovery analyses on 21 specimens suggested the presence of 8 to 10 species (Fig. 2D; Electr. Suppl.: Table S2). Of the ten lineages representing putative species, bPP validated $(\theta=0.0032)$ all but one ( $P$. "neocanina" 1a and $1 \mathrm{~b}$ were merged) (Fig. 2D). Peltigera "neocanina" seems to include four species, whereas $P$. erioderma and $P$. montiswilhelmi, each seems to include two distinct species.

Clade 8. - The P. degenii/P. membranacea clade includes 42 specimens (Fig. 1) representing three currently recognized species: P. degenii, P. membranacea and P. tereziana Gyeln. Species discovery methods suggested the presence of 8 to 11 species (Fig. 2E; Electr. Suppl.: Table S2). All nine tested lineages representing putative species were validated by bPP $(\theta=$ 0.0025 ) with PP values $>0.99$ (Fig. 2E). Peltigera membranacea and $P$. degenii seem to include two and six species, respectively.

Clade 9. - The $P$. canina clade includes 91 specimens (Fig. 1) representing seven currently recognized species (P. austroamericana Zahlbr., P. canina, P. evansiana Gyeln., P. fibrilloides (Gyeln.) Vitik., P. islandica, P. koponenii, P. praetextata), one putative species provisionally named $P$. "fuscopraetextata" (informally introduced by Miadlikowska \& al. [2003] and referred to by O'Brien \& al., 2009) and five unnamed lineages (Peltigera spp. 18-22). Species discovery methods showed a high disagreement in the number of suggested putative species

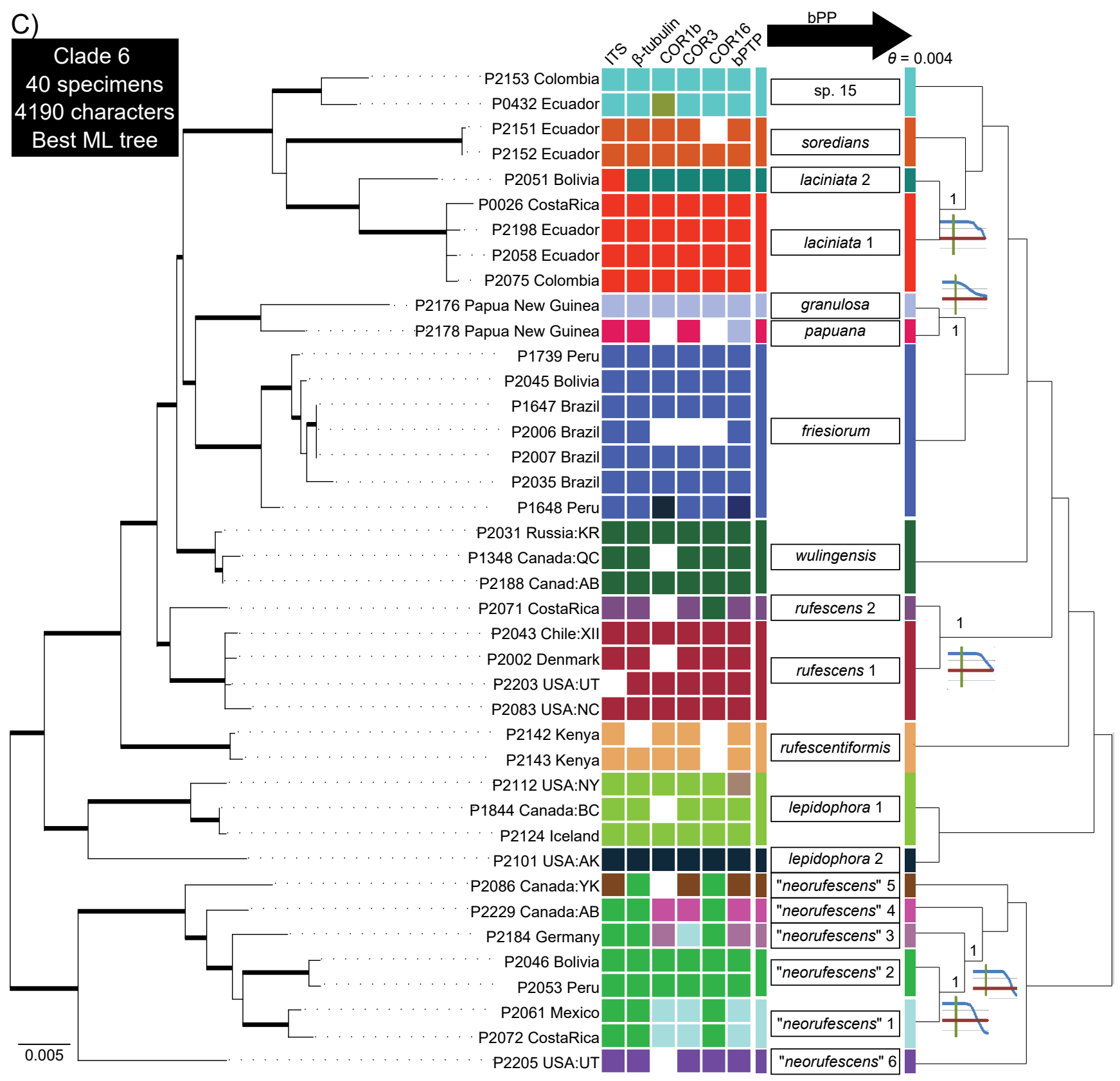


D)

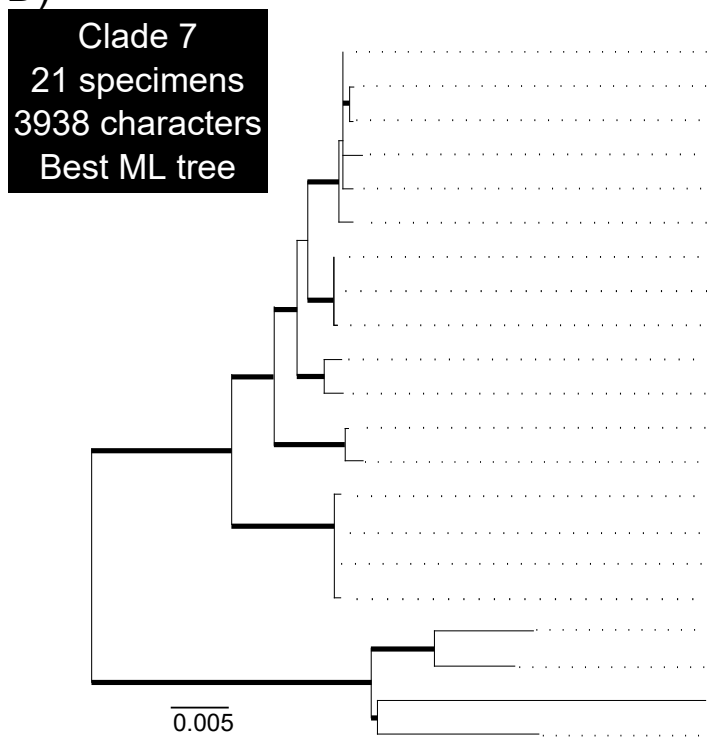

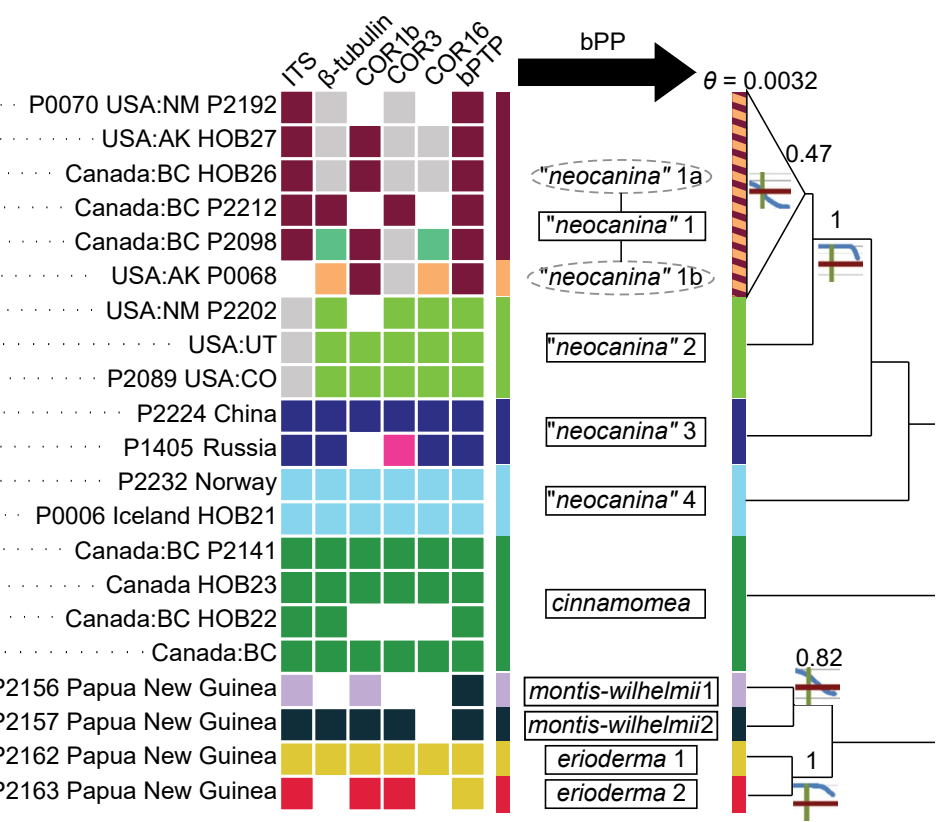

E)

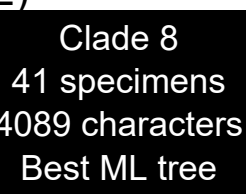

0.003

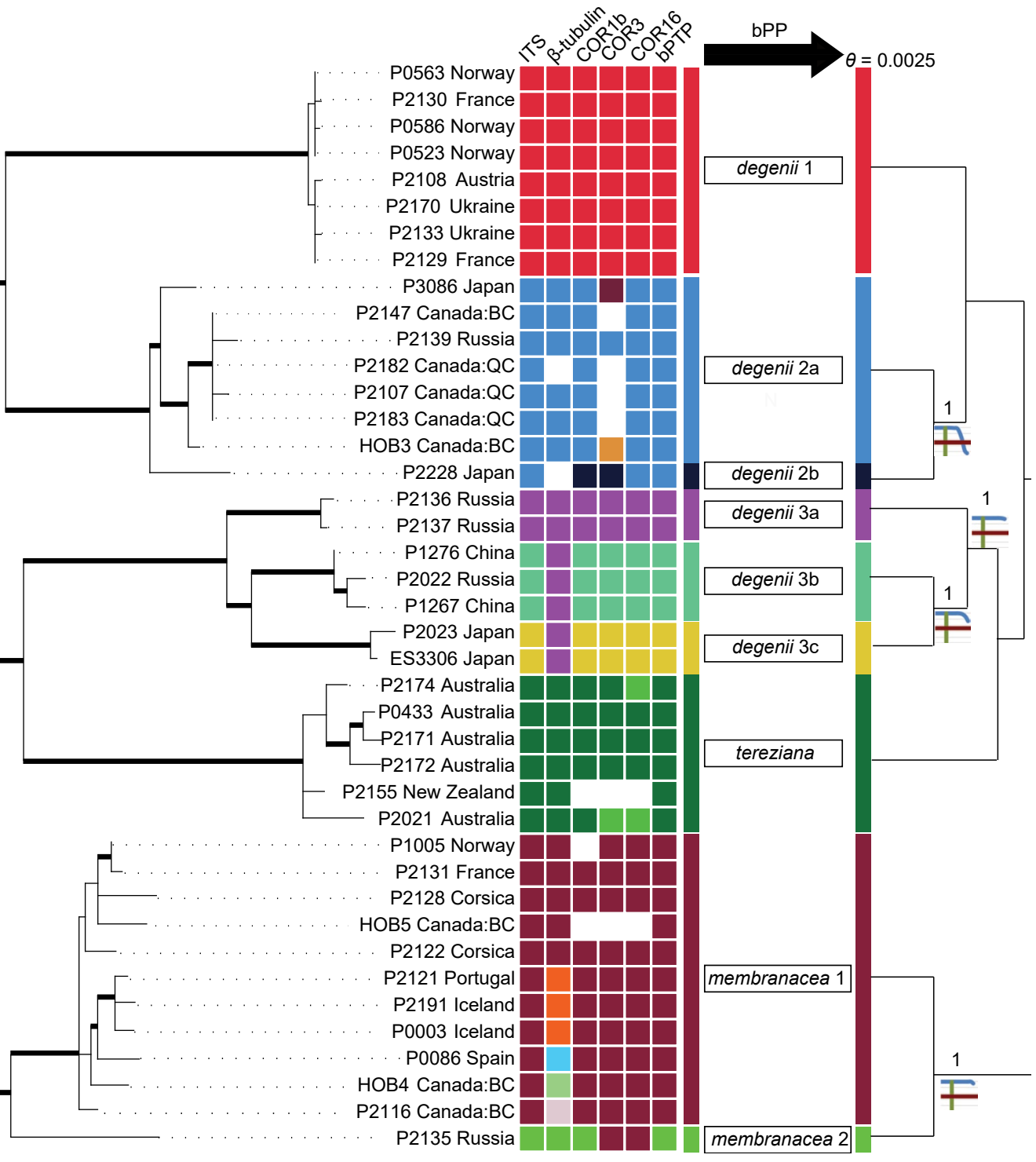


F) Clade 9
91 specimens
3908 characters
Best ML tree

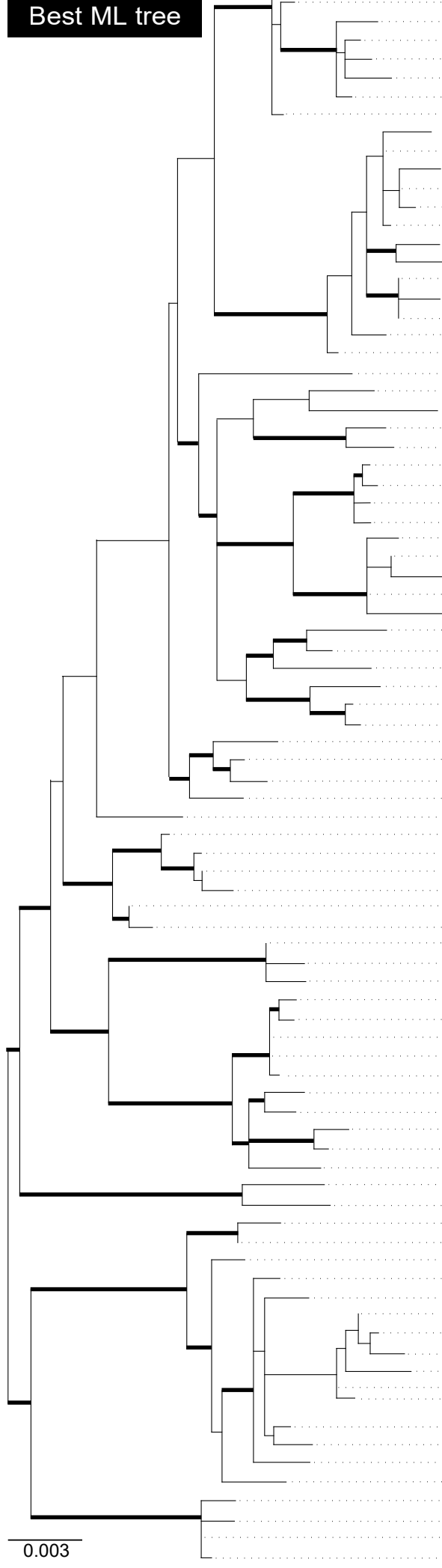

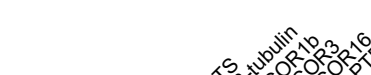

P2201 USA:UT HOB11 Canada:BC HOB10 Canada:BC HOB9 Canada:BC P2190 Canada:AB P0004 Iceland P2221 USA:MI P2090 USA:OK P2026 USA:NC P2126 USA:NC P2222 USA:TN

P2081 USA:NC P2211 USA:CO P2193 Netherlands P2120 Switzerland P2113 Austria P0014 Iceland P1411 Russia:KR P2032 Russia:KR

P2159 PNG

P2097 China:YU

P2213 Canada:BC

HOB13 Canada:BC

OB12 Canada:BC

P2118 Corsica P2055 Peru P0027 CostaRica P0408 Colombia P0408 Colombia P2059 Mexico P2048 Peru P2073 Peru

P2197 Ecuador P2076 Colombia P0032 CostaRica P0038 CostaRica P0025 CostaRica P0054 CostaRica P2052 Bolivia P2134 Bolivia P2019 Ecuador

P1598 Brazil

P2010 Brazil P2011 Brazil P2077 Colombia P2054 Peru P0926 Colombia P2218 USA:AZ HOB14 Canada:BC HOB15 Canada:BC HOB16 Canada:BC HOB17 Canada:BC IC332 Iceland IC355 Iceland P1230 USA:OR P0078 USA:OR P2030 USA:OR P2012 Argentina

P2036 Chile:XII P2067 Chile:XII P2014 Chile:XI

P2018 Argentina

HOB8 Canada:BC

HOB7 Canada:BC

P1110 Canada:BC

P2219 USA:OR

P2223 USA:UT

P2094 India

P1413 Russia:KR

P0420 Serbia

P0570 Norway

P2025 Russia:CC

P2227 Russia:KH

P1515 China:YU

HOB20 Canada:BC

HOB19 Canada:BC

HOB18 Canada:BC

P2226 USA:M

P2092 USA:ME

P2091 Canada:ON

P2233 USA:AZ

P2096 India

P0622 Norway

P2189 USA:MI

P2084 USA:NC

P1818 USA:PA

P1817 USA:PA

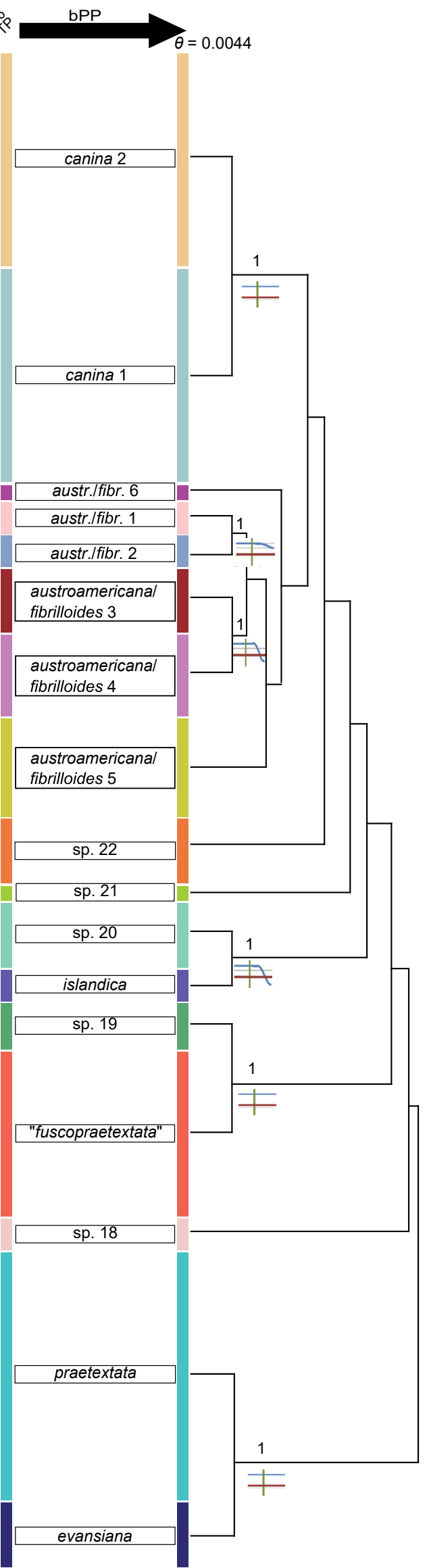


(10 to 24) and some specimens remained outside of recognized species according to bGMYC (gray boxes in Fig. 2F; Electr. Suppl.: Table S2). Seventeen putative species were subjected to species validation using bPP $(\theta=0.0044)$. All were validated with PP $>0.99$. Specimens identified as Peltigera austroamericana and $P$. fibrilloides were intermixed within six distinct monophyletic groups (P. austr./fibr. 1-6). Monophyletic Peltigera canina seems to represent two species, including Peltigera koponenii nested in P. canina 1. Delimitations of the remaining species, i.e., $P$. praetextata, $P$. evansiana, and $P$. sp. 22 did not change (Fig. 2F).

Contribution of intergenic spacers from COR to species delimitation. - Although species discovery methods provided largely congruent results for most parts of the tree, there were some differences. For example, the addition of the three new COR loci that led to the recognition of a much higher number of species (but see Magain \& al., 2017b). Genetic variation in these intergenic spacers could either unveil unknown species diversity not detected by commonly used markers like ITS and $\beta$-tubulin, or alternatively could reflect intraspecific structure. Cases supporting the recognition of several lineages deriving exclusively from COR regions include five and six species recognized within $P$. "neorufescens" and $P$. austroamericanal fibrilloides, respectively, versus 1-2 using other markers (Fig. 2C, F). Peltigera canina 1 and 2, which were treated as a single species based on ITS, were resolved as two distinct species based on all other loci, including $\beta$-tubulin.

Sensitivity analyses for $\boldsymbol{\theta}$ values. - Our species delimitation depends largely on the $\theta$ value selected for the bPP validation analyses. It is very difficult to estimate this value because mutation rates and population sizes are unknown for lichenforming fungi (Magain \& al., 2017a). Therefore, we provided information about the observed changes in species delimitation as a function of the $\theta$ prior values, to assess the sensitivity of the delimitations and consider alternative hypotheses (Figs. 2A-F; Electr. Suppl.: Table S3). Cases where slightly higher values of $\theta$ resulted in the merging of otherwise distinct lineages include $P$. ponojensis/monticola $5 \mathrm{a}$ and $5 \mathrm{~b}$ (in clade 5), P. montis-wilhelmii 1 and 2 (in clade 7), P. ulcerata 1 and 2, and $P$. didactyla $2 / P$. sorediifera (in clade 4). Noticeably higher $\theta$ values caused additional merging in $P$. islandica and Peltigera sp. 20 in clade 9 (Manoharan-Basil \& al., 2016); P. laciniata 1 and 2, P. granulosa and P. papuana, P. "neorufescens" 1-3, $P$. rufescens 1 and 2 in clade 6 , or $P$. degenii $2 \mathrm{a}$ and $2 \mathrm{~b}$ in clade 8 . Very high values of $\theta$ would lead to much broader species delimitations.

Nucleotide substitution rate heterogeneity among clades 4-7 in section Peltigera. - In the five-locus phylogeny (Fig. 1), clade 4 seems to be evolving faster compared to the other clades. We tested various scenarios of rates distribution by enforcing different molecular rate models across a phylogeny resulting from a dataset restricted to clades 4-7. A scenario without molecular clock along the tree (scenario 8; Table 1) was significantly better than the other models. A strict molecular clock (all rates equal, scenario 1) was rejected, suggesting a pattern of rate heterogeneity among clades. A model with a different rate of nucleotide substitution in clade 4 (scenario 2) was the best of the scenarios where a local rate was applied to one specific clade (i.e., compared to scenarios 3-6). A scenario with three rates (one for clade 4, one for clade 5-6 and one for clade 7 (scenario 7), was not significantly better than scenario 2 , but was significantly better than the other scenarios with two rates (scenarios 3-6). Our results suggest that the rate of nucleotide substitution in clade 4 (scenario 2 ) is nearly twice (1.92) as high as in the rest of the tree.

Nostoc phylogeny. - Overall, the $r b c L X$ phylogeny with two major Nostoc clades and three subclades within Nostoc clade 2 (Fig. 3) matches topologies from previous studies (Otálora \& al., 2010; Magain \& al., 2017a). Nostoc clade 1 and subclades 1 and 2 within clade 2 received high support. All cyanobionts associated with members of sections Peltigera and Retifoveatae belong to Nostoc clade 2 subclade 3, and many of them are part of a very large polytomy inside this subclade. In addition to the phylogroups delimited by O'Brien \& al. (2013; phylogroups I-VI) and Magain \& al. (2017a; phylogroups VII-XX), we recognized 28 phylogroups (phylogroups XXIXLVIII) to accommodate well-defined clades containing newly added $r b c L X$ sequences from Nostoc cyanobionts that were not represented in the previous studies. Phylogroups XXV, XXVI, XXVII, XXX, XXXI, XXXII, XXXIII, XXXVII, and XXXIX received low support, however, Nostoc strains within many of these clades seem to be associated with Peltigera species that share similar ecological conditions. The remaining phylogroups are mostly well-supported by ML bootstrap and/or Bayesian posterior probabilities (Fig. 3).

Specificity of Peltigera species. - The Specificity index (S-index) for species of section Peltigera ranges from 0.2 to 1 (Electr. Suppl.: Table S5; Figs. 4 and 5). Species for which we obtained $r b c L X$ sequences from only three to four thalli show, on average, higher specificity values than species for which we sequenced $r b c L X$ from more than four thalli (Fig. 4A). None of these species received an S-index value below 0.4 , demonstrating the bias of small sample size toward high levels of specialization. Therefore, we compared the $\mathrm{S}$-index values for species with at least five $r b c L X$ sequences. The average specificity is lower in section Peltigera (95\% confidence interval: $0.49 \pm 0.08$; Fig. 4B) than in section Polydactylon (95\% confidence interval: $0.57 \pm 0.13$; Fig. 4 C). Six of 25 species $(24 \%)$ in section Peltigera have $\mathrm{S}$-indexes $\geq 0.6$ (Fig. 4B) compared to 7 of 17 species (41\%) in section Polydactylon (Fig. 4C); whereas 9 of $25(36 \%)$ species in section Peltigera have S-indexes $<0.4$ versus 5 of 17 (29\%) in section Polydactylon.

Levels of specificity in section Peltigera seem to represent a continuum rather than distinct categories (Fig. 4B). Most species do not show a high degree of specialization, but early diverged species have in general high degrees of specificity (e.g., $P$. retifoveata and its phylogroup XXXIIIa, and P. kristinssonii with phylogroup VI [Fig. 5], which is concordant with the study by Magain \& al. (2017a) for section Polydactylon. However, most early diverged species in section Peltigera were generally poorly sampled or are relatively rare, which may partly explain this trend. Moreover, $P$. frigida and P. aubertii, part of early speciation events (clades $2 \mathrm{a}$ and $\mathrm{b}$ ), are exceptions with intermediate levels of specialization (Fig. 5). 


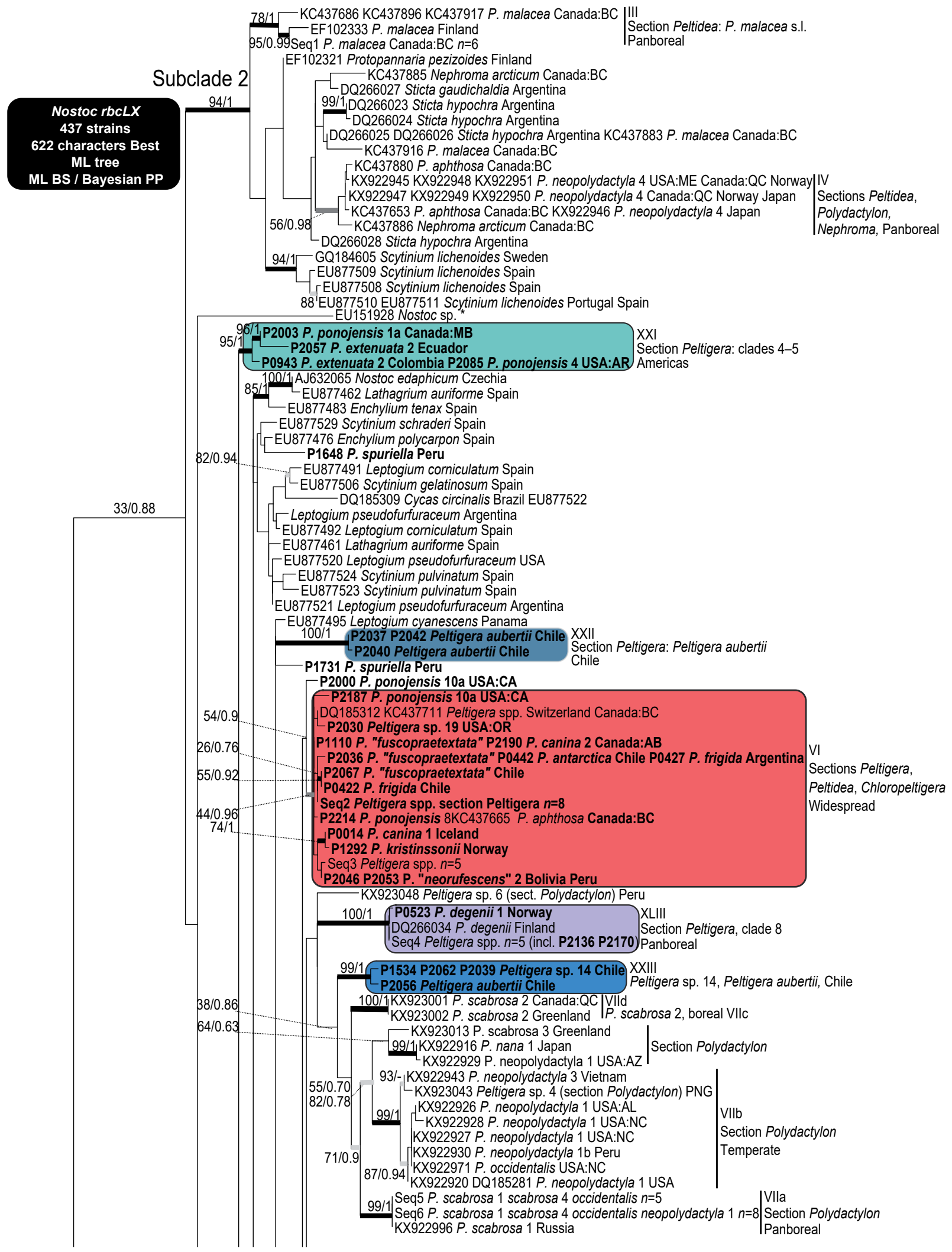

Fig. 3. Best ML tree for Nostoc resulting from a phylogenetic analysis on the $r b c L X$ locus (622 characters) for 437 strains. The delimitation of Nostoc clades and subclades are concordant with Otálora \& al. (2010). The delimitation of phylogroups follows O’Brien \& al. (2013; phylogroups III-VI), Magain \& al. (2017a; phylogroups VII-XX), and this study (phylogroups XXI-XLIII). Strains shown in bold represent sequences from sections Peltigera and Retifoveatae generated for this study. Colored boxes delimit Nostoc phylogroups, which contain newly generated sequences from cyanobionts associated with mycobionts of sections Peltigera and Retifoveatae. The remaining phylogroups are delimited by 


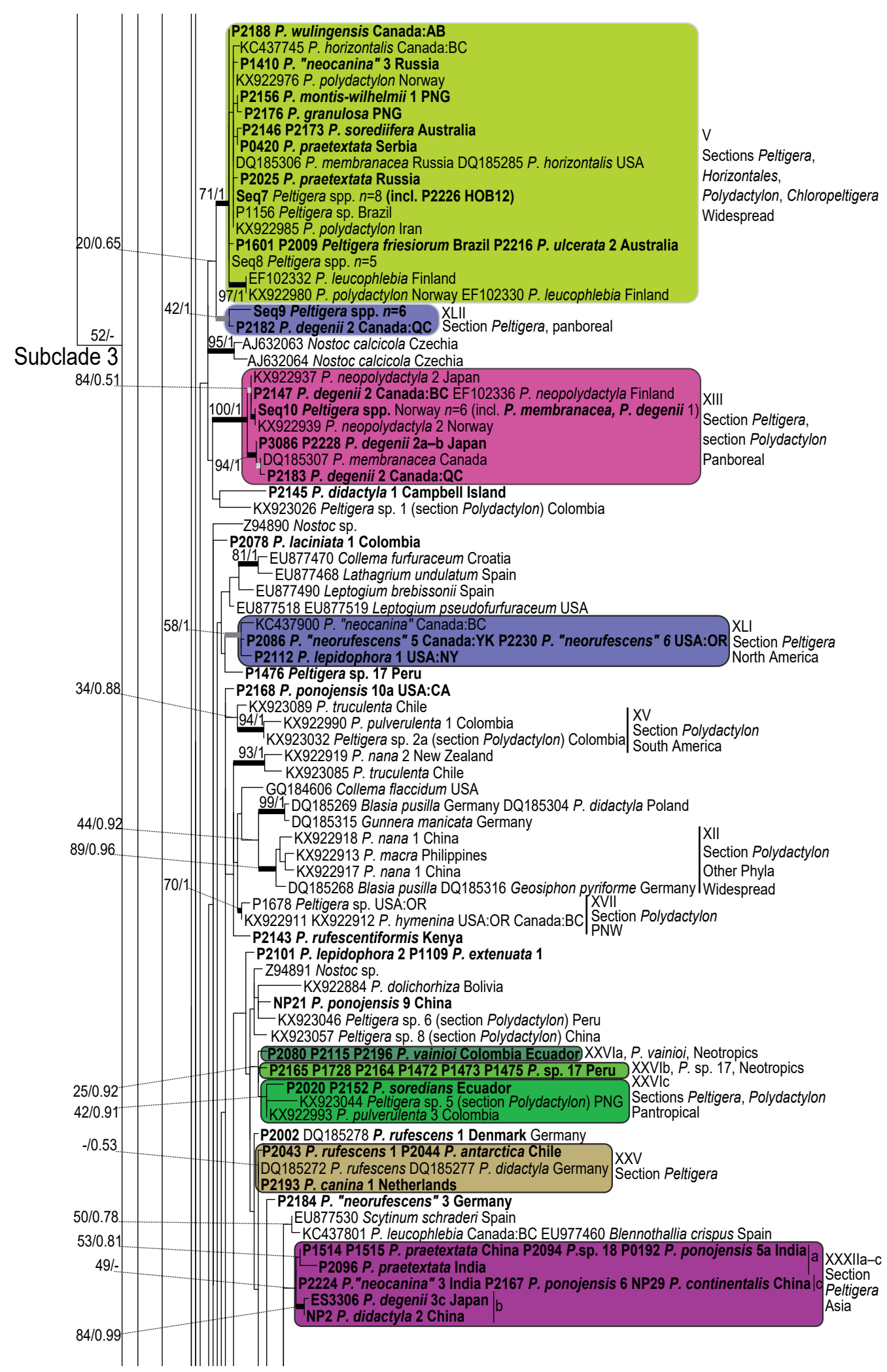

black vertical bars. Values above or below branches represent the ML bootstrap support (before slash) and Bayesian posterior probabilities (after slash) when at least one branch is considered supported (ML BS $\geq 70 \%$ and or Bayesian PP $\geq 0.95$ ). Thick branches received ML BS $\geq$ $70 \%$ and Bayesian $\mathrm{PP} \geq 0.95$, dark gray branches received ML BS $<70 \%$ and Bayesian PP $\geq 0.95$, whereas light gray branches received ML BS $\geq 70 \%$ and Bayesian PP $<0.95$. Number of identical sequences $(n)$ represented by a single strain in the phylogeny is provided after the terminal name and the complete list of sequences is included in Electr. Suppl.: Table S4. Symbionts of the ponojensis/monticola clade were abbreviated as ponojensis and austroamericanalfibrilloides as austroamericana. 


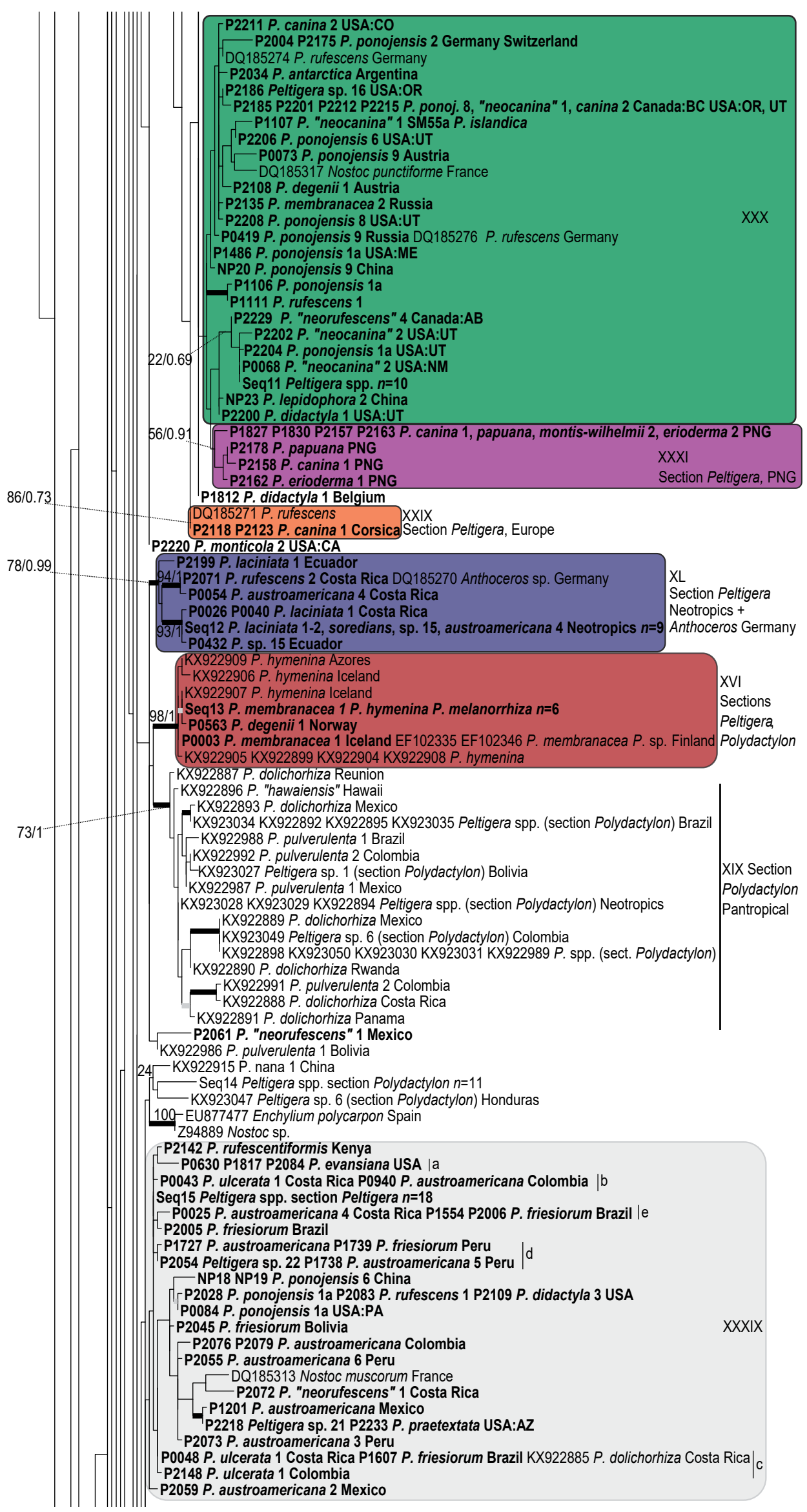




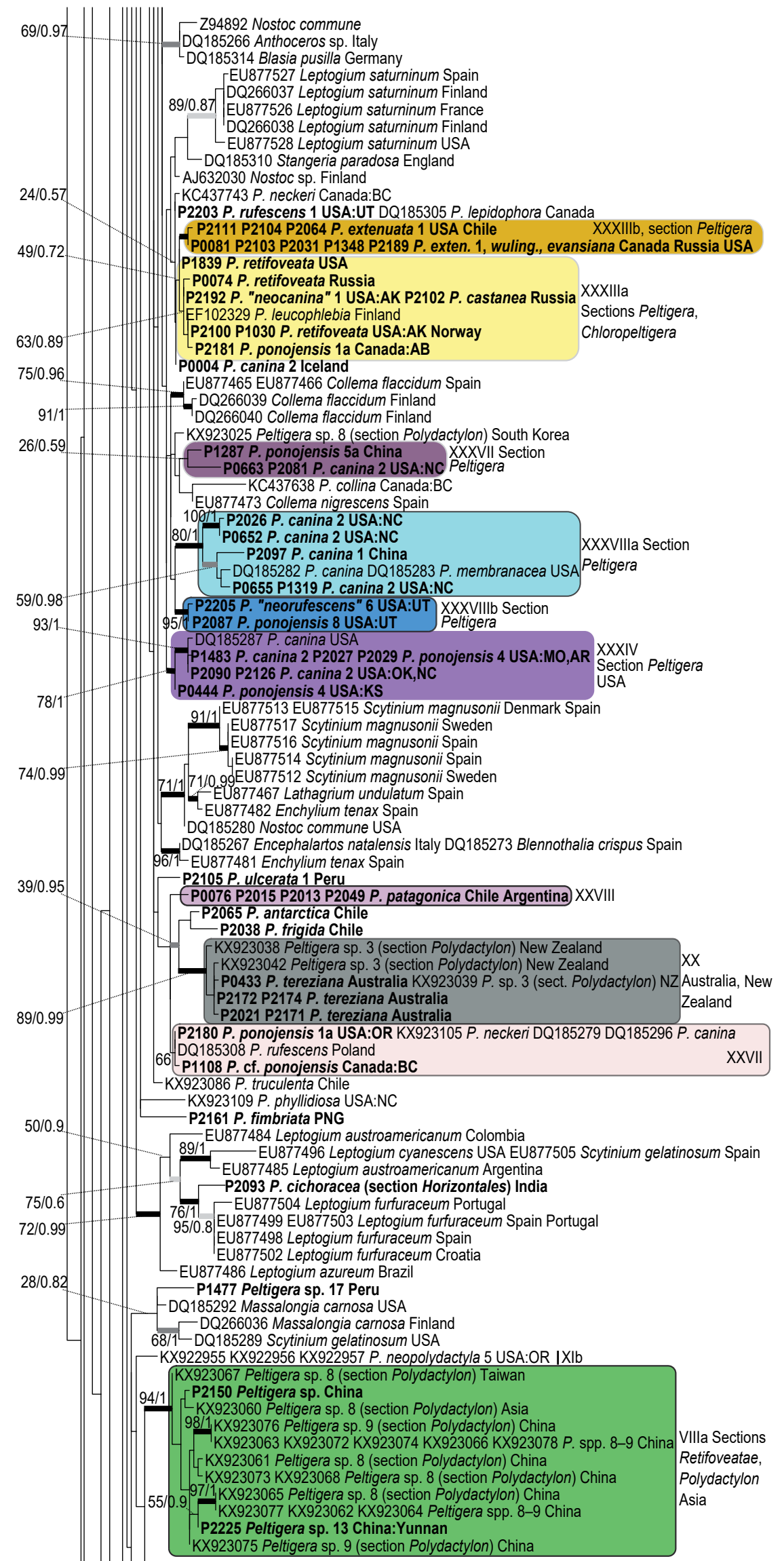




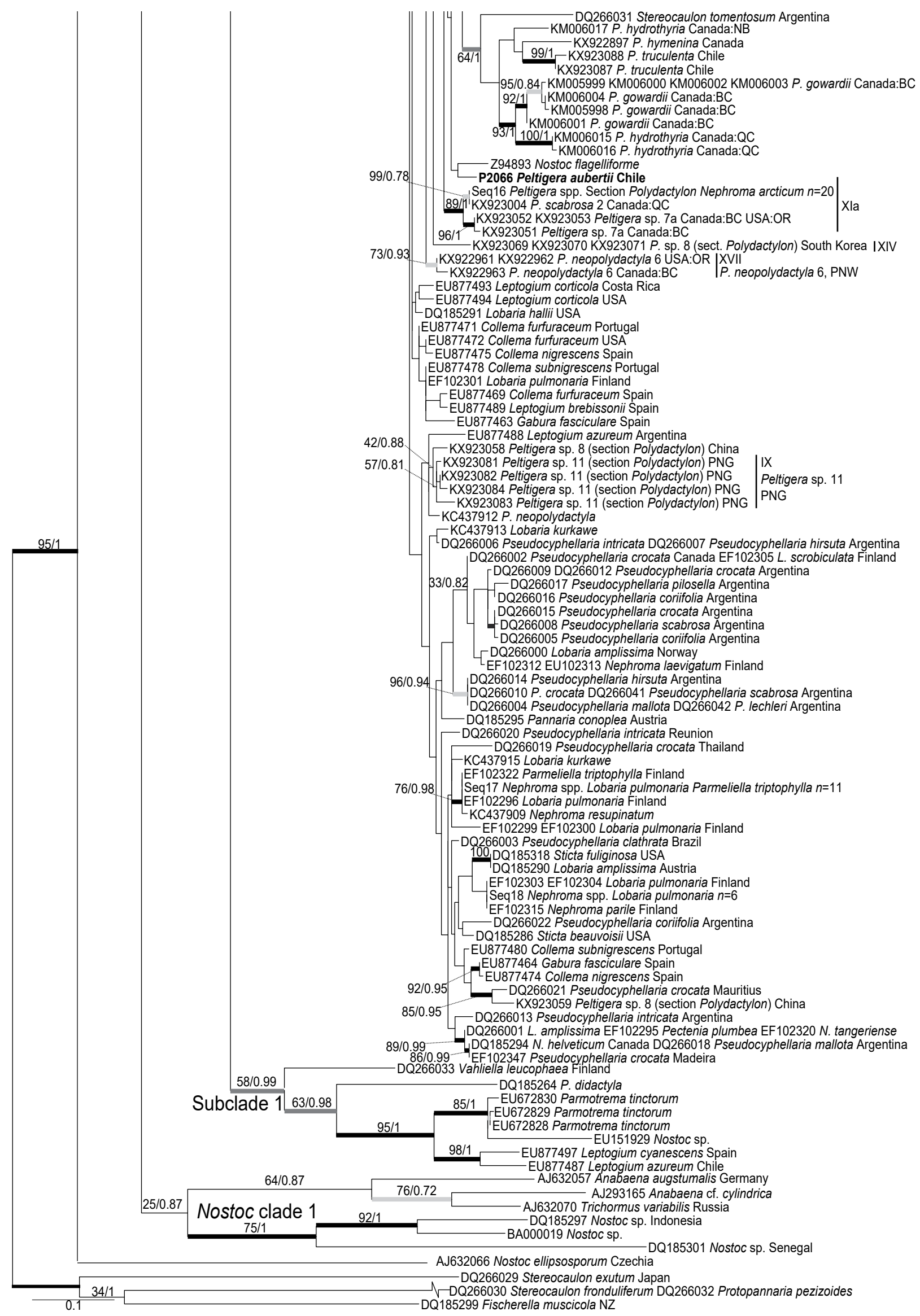


Contrary to the recent neotropical species of section Polydactylon, which are mostly generalists (Magain \& al., 2017a), neotropical species from section Peltigera displayed moderate to high levels of specificity toward their cyanobionts, except for $P$. friesiorum with a Specificity index of 0.36 (Fig. 5). In section Peltigera, we detected two examples of one-to-one reciprocal specificity: $P$. vainio $i$ with its phylogroup XXVIa and $P$. patagonica with phylogroup XXVIII. Another example of strong specificity involves the widespread $P$. extenuata 1 , which was found with phylogroup XXXIIIb along a broad geographic range from Chile to Russia (Krasnoyarsk Region).

A) $1.00-$

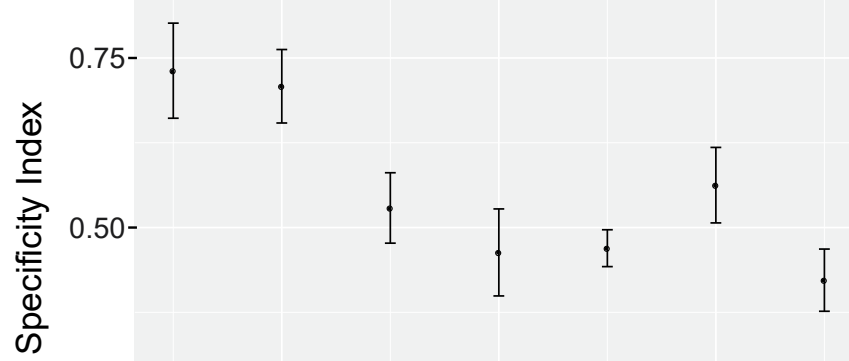

$0.25-$

$0.00-$

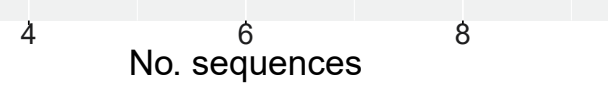

B) 1.00
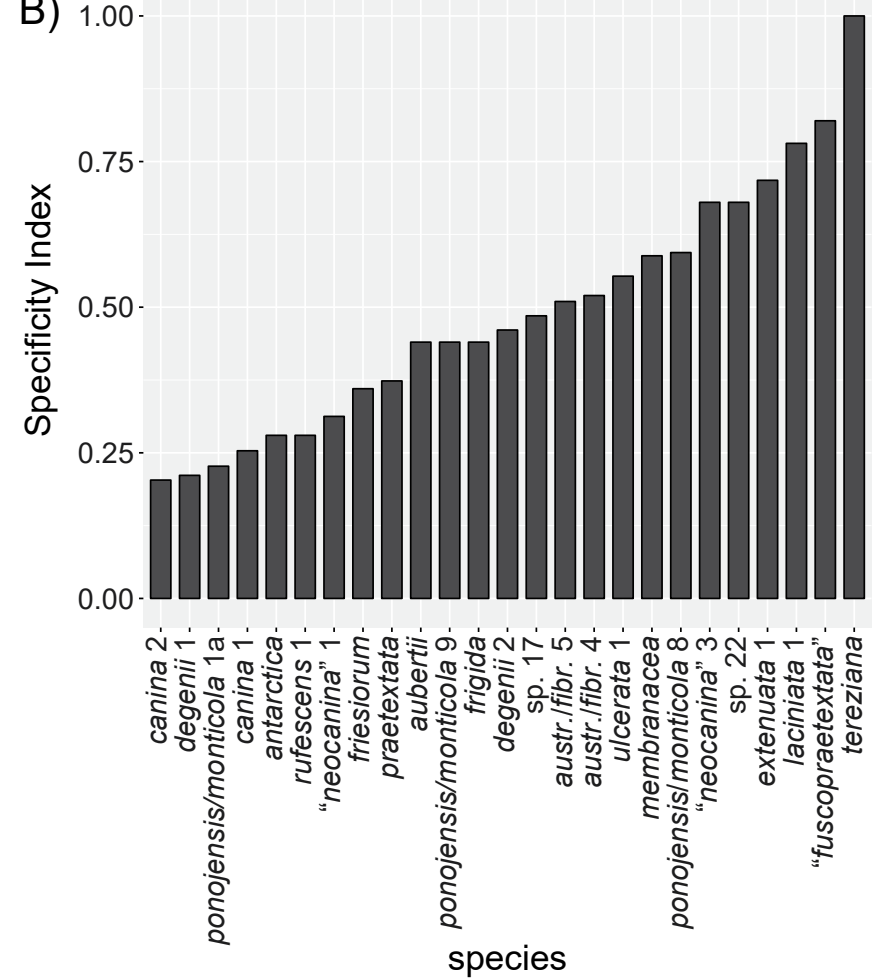

Distribution and specificity of Nostoc phylogroups. Many Nostoc phylogroups associating with members of section Peltigera are widespread geographically and were found in association with multiple Peltigera species from this section. For example, phylogroup V occurred in 53 thalli of 20 species from section Peltigera (clades 4-9; Fig. 5). This Nostoc phylogroup was found in association with five species from section Polydactylon, and members of three other sections (P. sect. Horizontales Miądl. \& Lutzoni, sect. Peltidea, sect. Chloropeltigera; Magain \& al., 2017a). Nostoc phylogroup V has an almost cosmopolitan distribution and was collected on all continents except Africa and Antarctica, from where little or no data is available (Fig. 3). Nostoc phylogroup VI was found in 28 thalli representing 12 species from four clades of section Peltigera (Fig. 5). This phylogroup is also commonly associated with species from section Chloropeltigera (Fig. 3) (O'Brien \& al., 2013; Magain \& al., 2017a; Pardo-De la Hoz \& al., in press) and was collected in the two Americas and in Europe. Phylogroup XXX was reported from 35 thalli representing 19 species, whereas phylogroup XXXIX was found in 36 thalli

Fig. 4. A, Average raw Specificity index of Peltigera species calculated as the sum of the square frequencies of interactions with Nostoc as a function of the number of $r b c L X$ sequences of the cyanobiont; B, Raw Specificity index for each species of section Peltigera for which we obtained $r b c L X$ sequences from more than five cyanobionts; C, Raw Specificity index for each species of section Polydactylon for which $r b c L X$ sequences were available from more than five cyanobionts (Magain \& al., 2017a). Specimens in the austroamericanalfibrilloides as austr./fibr..
C)
1.00
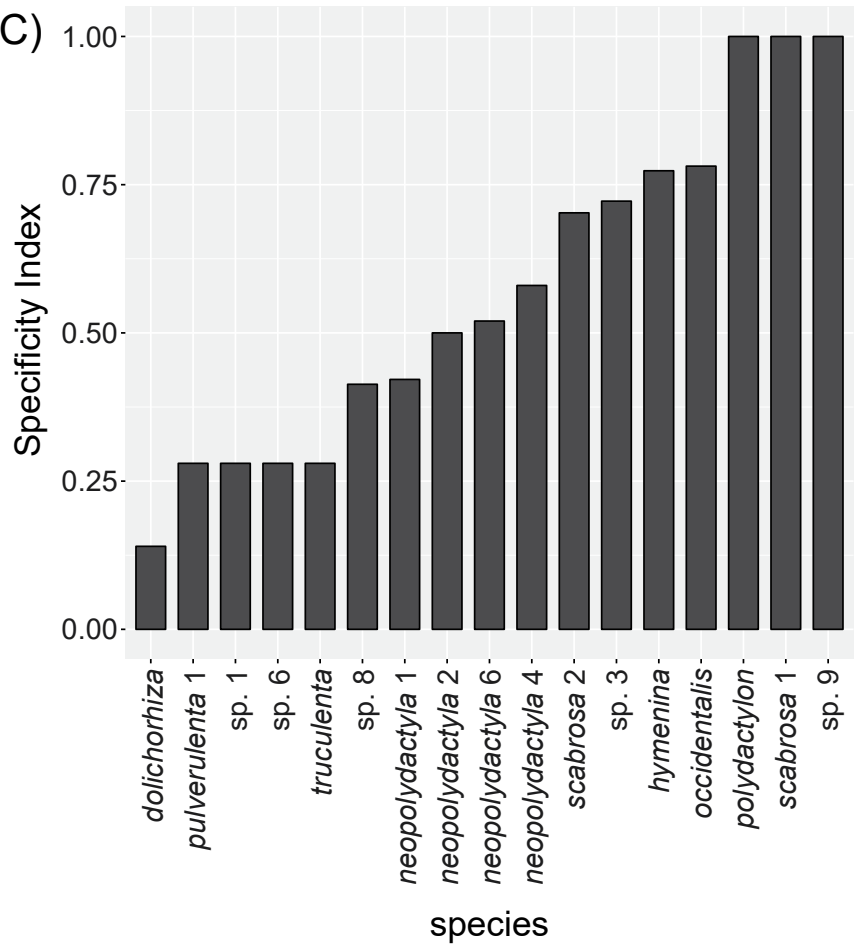
Table 2. Likelihood values and estimations of parameters for the six models tested for biogeographical analyses with BioGeoBEARS.

\begin{tabular}{lccccc}
\hline Model & $\mathrm{LnL}$ & No. parameters & $\mathrm{d}$ & $\mathrm{e}$ & $\mathrm{j}$ \\
\hline DEC & -331.5867 & 2 & 0.0610 & 0.0425 & 0 \\
DEC+J & $\mathbf{- 3 0 5 . 2 0 4 8}$ & 3 & 0.0437 & $1.00 \mathrm{E}-12$ & 0.0433 \\
DIVALIKE & -327.2447 & 2 & 0.0688 & $1.00 \mathrm{E}-12$ & 0 \\
DIVALIKE+J & -309.0618 & 3 & 0.0504 & $1.38 \mathrm{E}-08$ & 0.0341 \\
BAYAREALIKE & -352.1448 & 2 & 0.0594 & 0.6401 & 0 \\
BAYAREALIKE+J & -315.6641 & 3 & 0.0355 & $1.00 \mathrm{E}-07$ & 0.0676 \\
\hline
\end{tabular}

The best likelihood value is shown in bold. $d$, dispersal; e, local extinction; $j$, founder effect.

representing 14 species (Fig. 5). These two phylogroups have almost cosmopolitan distributions. However, their monophyletic delimitation was poorly supported in the Nostoc phylogeny (Fig. 3).

Similar to other sections such as Peltidea and Polydactylon (O’Brien \& al., 2013; Magain \& al., 2017a), Nostoc phylogroups with very high specificity were also found in section Peltigera. They involve three phylogroups from the Neantarctic region: phylogroup XXII associated exclusively with Peltigera aubertii, phylogroup XXVIII found with $P$. patagonica, and phylogroup XXIII associated with Peltigera sp. 14 and a single specimen of Peltigera aubertii. Cases of high Nostoc phylogroup specificity were also found in the Neotropics: phylogroup XXVIa was found only from thalli of $P$. vainioi, and phylogroup XXVIb from $P$. sp. 17. Some other phylogroups were restricted to a single region, for example phylogroup XXXI did not occur outside of Papua New Guinea (Fig. 3).

Nostoc phylogroup specificity was also detected at broader phylogenetic scales. For example, some Nostoc phylogroups are currently known to associate with only one section of the genus Peltigera. Nineteen Nostoc phylogroups were found exclusively in association with Peltigera species from sections Peltigera and Retifoveatae. Fourteen phylogroups associating with species from section Polydactylon were never found in thalli of Peltigera species from section Peltigera (Fig. 3;
Magain \& al., 2017a). This broader phylogenetic scale of specificity does not pertain only to rare phylogroups. Very common phylogroups in section Polydactylon (e.g., VIIa, VIIb, XIa, and IV) have not yet been recovered from thalli of species from section Peltigera. Similarly, phylogroups VI, XXX and XXXIX, commonly found in section Peltigera, seemingly do not form symbiotic associations with Peltigera species from section Polydactylon. The only phylogroups shared by sections Peltigera, Retifoveatae and Polydactylon are phylogroups V, VIIIa, XIII, XVI and XX (Fig. 3).

Biogeographical history of Peltigera section Peltigera. - The DEC $+\mathrm{J}$ model has three parameters: dispersal (d), local extinction (e) and founder-effect (j) (Table 2). In our BioGeoBears analysis, the local extinction (e) parameter was close to 0 , whereas we obtained similar values $(\sim 0.043)$ for parameters $\mathrm{d}$ and $\mathrm{j}$. All three models with parameter $\mathrm{j}$ (Table 2 ), as well as DIVALIKE estimated very low values for the local extinction parameter (e), whereas values of $d$ and e were of the same order for the DEC and BAYAREALIKE models. Under the DEC $+\mathrm{J}$ model, the ancestor of section Peltigera originated in the Neantarctic region, but several subsequent nodes were reconstructed as of Asian origin, including the common ancestor of clades 8 and 9 . The ancestors of clades 5-7 most likely inhabited North America, and the ancestor of clade 4 the Neotropics.

Fig. 5. Biogeographical patterns and specificity of Peltigera species within sections Peltigera and Retifoveatae toward their cyanobiont. The main tree represents a simplified BEAST chronogram (five-locus tree based on 3216 characters for 225 specimens) where each of the 90 putative Peltigera species from sections Peltigera and Retifoveatae, as defined by species delimitation methods (Fig. 2), is represented by one terminal branch. Pie charts associated with selected nodes summarize results of the biogeographical ancestral analysis as implemented in BioGeoBEARS, using the DEC $+\mathrm{J}$ model (Table 2). Pie charts color scheme corresponds to areas delimited in the map on the top left corner and black color represents the sum of all remaining probabilities. Background colors extending from the terminal branches and corresponding abbreviations represent geographic regions where thalli were sampled (as shown on the map on the top left corner). Additional colors are used when the species is present in two regions. Those correspond to their two-letter codes. When a species was collected in three or more regions, the name of the species is shown in bold and the background color is white. The capital letters in front of the species epithet refer to the capital letters on the geographical map: $\mathrm{A}=\mathrm{Asia}, \mathrm{B}=$ Panboreal, $\mathrm{C}=$ Neantarctics, $\mathrm{E}=$ Europe, $\mathrm{F}=$ Africa, $\mathrm{N}=$ North America, $\mathrm{P}=$ Pacific Northwest, $\mathrm{T}=$ Neotropics, $\mathrm{Z}=$ Australasia. The pie charts on the right of the species epithets represent the Nostoc phylogroups with which each species is associated. The size of each pie chart is proportional to the number of $r b c L X$ sequences available for this species and the sizes of the portions within each pie chart correspond to the number of $r b c L X$ sequences representing each phylogroup. Species for which we have no Nostoc information do not have a pie chart. The colors within pie charts correspond to Nostoc phylogroups as defined in Fig. 3 and represented in the legend provided here. White portions of the pie charts represent Nostoc haplotypes that are outside of defined phylogroups. When four or more rbcLX sequences were available, the raw Specificity index is shown next to the corresponding pie chart. Specimens in the austroamericanal fibrilloides as austroamericana. 


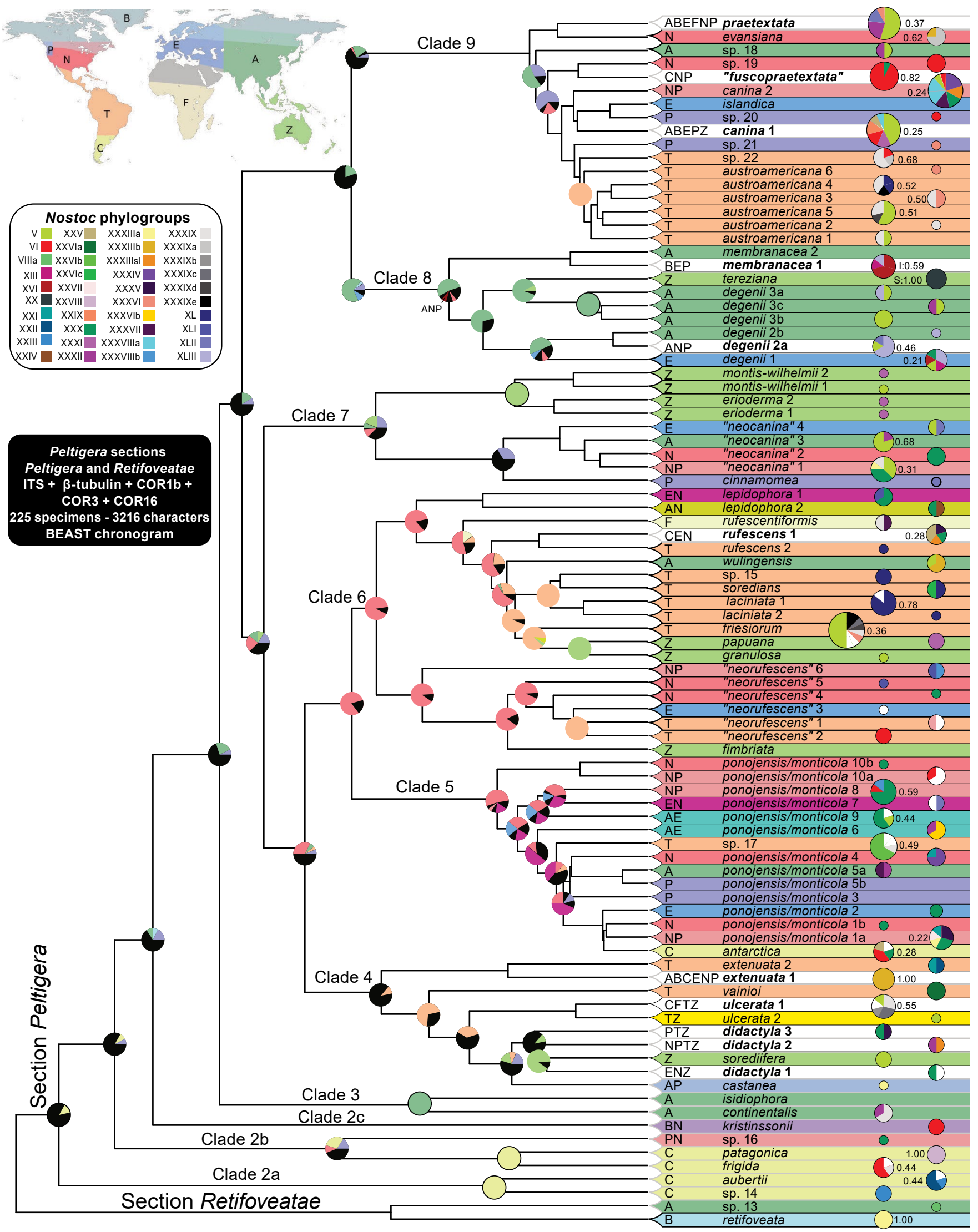


ITS1 hypervariable region (ITS1-HR) sequence comparison. - A high level of variation among ITS sequences especially within the ITS1 spacer, required the exclusion of 50\% of the total 1036 sites of the alignment used for phylogenetic analyses. One of the excluded ambiguously aligned regions within the ITS1 spacer is the hypervariable region ITS1-HR sensu Miadlikowska $\&$ al. (2003), which varies greatly in length and can contain microsatellites with single nucleotide strings or short repeats. We re-delimited the ITS1-HR locus (sites 111-237 of the ITS1 alignment from Miadlikowska \& al., 2003) to include additional variable sites (a total fragment corresponding to positions $182-335$ of the ITS1 alignment). The inclusion of conserved flanking sites helped to extend the use of the ITS-HR as a powerful taxonomic marker, at the species level, to the entire section Peltigera. We added an ITS sequence from P. spuriella and 175 sequences from GenBank to our dataset (Electr. Suppl.: Table S6). No ITS1 sequence was available for P. fimbriata. A total of 201 different sequences of the ITS1-HR region were present among the 537 individuals from section Peltigera for which ITS sequences without missing/ambiguous data were available. Eighty-three of these sequences were found in more than one individual whereas the remaining 118 were unique (Electr. Suppl.: Fig. S2). The sequences varied in length from sixteen sites (conserved flanking region only) in $P$. islandica and its sister species $P$. sp. 20, to 137 nucleotides in P. membranacea 1 (Electr. Suppl.: Fig. S2). With some rare exceptions where identical sequences were shared among different putative species (e.g., $P$. islandica with $P$. sp. 20; P. antarctica with $P$. ponojensis/monticola 1 and $2 ; P$. granulosa with $P$. papuana and $P$. friesiorum), overall, sequences of the ITS1-HR were more similar within than among species.

\section{DISCUSSION}

Species delimitation in Peltigera sect. Peltigera and sect. Retifoveatae. - Overall the phylogeny for section Peltigera (Fig. 1) is in agreement with the topology recovered by Miadlikowska $\&$ al. (2003), which was based on ribosomal loci together with the recoded ambiguous regions (including ITS1-HR) and a considerably smaller set of species mostly from Europe and North America. Our phylogeny (Fig. 1) is more robust, as many previously unresolved or poorly supported relationships among and within major clades received high support. A single discrepancy between these two studies involved the placement of the P. cinnamomea clade (clade 7), which is sister to clade 4-6 (Fig. 1) versus clade 8-9 in Miadlikowska \& al. (2003).

The proportion of uncovered biodiversity in section Peltigera is remarkably high (57\%) (Fig. 2), but perhaps not unexpected considering earlier studies that had highlighted a phylogenetic structure indicative of several species complexes (e.g., Goffinet \& al., 2003; Miadlikowska \& al., 2003). Furthermore, the dramatic increase in species richness in this section parallels the trend emerging from inferences based on DNA data in other lineages of Peltigerales (Moncada \& al., 2014a, b; Lücking \& al., 2017; Magain \& al., 2017a, b; Simon $\&$ al., 2018), as well as in other groups of lichen-forming fungi.
Similar to our findings, many widespread morphospecies were split into numerous more restricted phylogenetic species in the genera Rhizoplaca Zopf (Lecanoraceae, Leavitt \& al., 2011), Melanohalea O.Blanco \& al. (Parmeliaceae, Leavitt \& al., 2013) and Protoparmelia M.Choisy (Parmeliaceae, Singh \& al., 2015). Extreme examples include the presence of hundreds of undiscovered species in overlooked groups, especially in tropical regions, such as in the genus Cora Fr. (although based on a single marker [ITS]) or the family Graphidaceae (Lücking \& al., 2014a, b). The high discrepancies between the phylogeny-based species delimitation methods on one hand, and traditional morphospecies on the other hand, leads to questioning the adequacy of using morphology as the leading criterion for describing lichen-forming fungal species (Lumbsch \& Leavitt, 2011).

A recent study by Sukumaran \& Knowles (2017) demonstrated that species delimitation methods relying on multispecies coalescence can interpret lineages reflecting intraspecific genetic structure as different species and, therefore, can inflate species biodiversity. Cases involving known morphology-based species that were validated phylogenetically as monophyletic, but that are split into multiple species by species delimitation methods, can represent structured intraspecific populations. Consequently, the resulting nested sister species are often phenotypically cryptic. Combining several methods can improve species delimitation (Carstens \& al., 2013) but results can only be as good as the amount and quality of the data available, and the performance of the methods used.

Three main geographic patterns underlined the resulting species delimitations in section Peltigera (Fig. 5): (1) monophyletic morphospecies divided into several sympatric species (e.g., $P$. austroamericana/P. fibrilloides [six lineages] and $P$. laciniata [two lineages in the Neotropics], $P$. montis-wilhelmii and P. erioderma [two lineages for each, in Papua New Guinea], and P. lepidophora [two lineages in the Northern Hemisphere]); (2) monophyletic morphospecies divided into several species showing distinct geographic patterns (e.g., P. "neocanina" [four lineages, of which two occur in North America, one in Asia and one in Europe], $P$. "neorufescens" 1-5 [five lineages, two of which are in North America, one in Europe and two in the Neotropics]); (3) monophyletic morphospecies divided into several species showing restricted geographic pattern (e.g., P. degenii [three main groups, one in Europe, the second one mostly in North America, but also present in Asia, and the third group is found in Asia; the latter lineage was additionally divided into three lineages, well corroborated with geographic patterns, i.e., Sakhalin vs. Honshu vs. Kurile Islands and Jilin], P. ponojensis/ monticola complex [fourteen species with partially overlapping distributions, together with the Neantarctic $P$. antarctica and the Neotropical $P$. sp. 17 being part of this clade (Fig. 5). Peltigera canina is another well-known species divided into two species - one mostly restricted to North America and the other with almost a cosmopolitan distribution, while both putative species co-occur in Iceland and North America.

In our study, some putative species, such as $P$. canina 1 and 2 were represented by a large number of individuals ( 20 or more specimens), whereas others, such as within morphospecies P. lepidophora, $P$. "neorufescens" and $P$. "neocanina", 
include a single or often no more than two specimens (Fig. 2; Electr. Suppl.: Fig. S2). Singleton species are very common in species delimitation studies, and it has been suggested that in most cases they result from undersampling (Coddington $\&$ al., 2009). However, simulation studies showed that the GMYC model still performs well in the presence of large amounts of singleton species (Fujiawa \& Barraclough, 2013). Whether Peltigera singletons represent distinct species or artifacts of the implemented methods awaits further testing based on additional samples bridging the current localities (often distant) and using complementary methods that rely on other models with different assumptions.

Our analyses confirmed that some taxa introduced informally in previous studies (Miadlikowska \& Lutzoni, 2000; Miadlikowska \& al., 2003; Jüriado \& al., 2017) represent undescribed species, or assemblages of undescribed species, delimited consistently by multiple methods (e.g., Peltigera "fuscopraetextata", $P$. "neocanina" and $P$. "neorufescens"). Other provisionally named taxa should be merged (as indicated by Miadlikowska \& al., 2003), such as $P$. "pallidorufescens", which is synonymous with $P$. "fuscopraetextata", and $P$. "fuscoponojensis" which is nested within the $P$. "neorufescens" clade. The specimen of $P$. "scotteri" 1 included in Miadlikowska \& al. (2003) belongs to $P$. ponojensis/monticola 10 , whereas $P$. "scotteri" 2 represents $P$. degenii 2a. The collection of $P$. "latopraetextata" 1 falls within $P$. cinnamomea, $P$. "latopraetextata" 3 belongs to $P$. praetextata, $P$. "boreorufescens" 1 represents $P$. canina 2, and $P$. "boreorufescens" 2 belongs to $P$. "neocanina" 1 . These provisional names will be corrected in all relevant GenBank records.

A recent study (Jüriado \& al., 2017) reported a high level of undescribed species in section Peltigera collected in Estonia. Several lineages recognized by the authors based on ITS sequences correspond to species delimited in this study using multiple loci and methods. For example, Estonian lineages of $P$. didactyla I, II, and III represent $P$. didactyla 1 ( $P$. sp. 2 in Goffinet \& al., 2003), P. didactyla 3 ( $P$. didactyla s.str. in Goffinet \& al., 2003), and P. didactyla 2 (P. sp. 3 in Goffinet $\&$ al., 2003), respectively. Peltigera lepidophora from Jüriado $\&$ al. (2017) corresponds to our P. lepidophora 1, a species already known from Europe and North America and their $P$. aff. neocanina corresponds to our $P$. "neocanina" 4, collected in Norway and Iceland. Apart from the hyperdiverse $P$. "neorufescens" complex, all lineages detected in section Peltigera by Jüriado \& al. (2017) were also sampled in our study. Furthermore, several species that were thought to occur exclusively or predominantly in North America seem to have much broader ranges as suggested by the recent records for $P$. canina 2 (corresponding to $P$. canina I), $P$. "neorufescens" 5 (corresponding to $P$. neorufescens), and $P$. "neocanina" 1 (corresponding to $P$. neocanina) from Estonia (Jüriado \& al., 2017).

We reassessed the utility of the ITS1 hypervariable region (ITS1-HR) as a reliable tool to distinguish species in section Peltigera and Retifoveatae proposed by Miadlikowska \& al. (2003). As in 2003, we found that sequences of the ITS1-HR were more similar within the majority of the monophyletic lineages delimited as species than among them, and therefore, this hypervariable region continues to be a powerful marker to identify most species. However, we also have rare cases where morphologically distinct sister species have sometimes identical ITS1-HR sequences (e.g., P. friesiorum/P. papuana/P. granulosa; Electr. Suppl.: Fig. S2). Occurrences of similar types of ITS1-HR sequences across multiple recognized species, were overall rare and mostly restricted to large species complexes such as $P$. ponojensis/monticola, where phylogenetic relationships among putative species are not well established and poorly supported (Fig. 1; Electr. Suppl.: Fig. S2). In this clade, the morphotypes corresponding to $P$. ponojensis and P. monticola were rarely segregated into separate species and mostly mixed together across multiple delimited species. One of the few exceptions are the morphologically unique $P$. sp. 17 (the only species in this clade with sorediated isidia) that resembles P. boulydelesdainii Gyeln. (except for the absence of secondary metabolites), however its ITS-HR region is similar or identical to sequences recorded in other members of the $P$. ponojensis/ monticola clade (Electr. Suppl.: Fig. S2). The description of P. plittii Gyeln. (type specimen collected in Colorado, U.S.A.) matches morphotypes of $P$. ponojensis/monticola 8 , however, the disentanglement of this entire species complex requires a separate comprehensive revision.

Our results also suggest that $P$. fibrilloides and $P$. austroamericana (morphologically distinct; i.e., the tomentous versus glabrous upper thallus of $P$. fibrilloides versus $P$. austroamericana morphotypes, among other differences) may represent the same species because individuals growing intermixed in nature were mixed phylogenetically, and share the same ITS1-HR sequence (Fig. 1; Electr. Suppl.: Fig. S2). Another case of two named species with identical ITS1-HR sequences, includes P. koponenii, from Papua New Guinea, which is nested within P. canina 1 (representing $P$. canina s.str.), which together are separated from $P$. canina 2, a new putative species known from North America, Iceland and Estonia (Figs. 1 and 2; Electr. Suppl.: Fig. S2). Although our analyses recognized two putative species, the high similarity in the ITS1-HR region suggests that $P$. sp. 20, known only from British Colombia, should be merged with $P$. islandica as already indicated by Manoharan-Basil \& al. (2016). A broader distribution of $P$. islandica is also in agreement with the recent report of P. islandica in Estonia (Jüriado \& al., 2017). We used the name $P$. antarctica (described by Dodge, 1968, from Antarctica) for a clade in P. ponojensis/monticola complex encompassing a set of specimens morphologically and geographically consistent with $P$. patagonica, however, phylogenetically unrelated and associated with different cyanobionts (phylogroup XXVIII in $P$. patagonica, but VI, XXX, and XXV in $P$. antarctica). Peltigera austroamericanalfibrilloides 5 encompasses typically glabrous species and could correspond to $P$. austroamericana s.str. The name P. ecuadoriana Gyeln. is available for one of the recognized lineages of this clade. Finally, P. spuriella potentially represented by two specimens (P1648, P1731) seems to be closely related to $P$. friesiorum, based on the phylogeny and similarity of their ITS-HR region. Despite their distinct thallus morphology, both species were often considered conspecific by most species delimitation methods. 
Heterogeneity of nucleotide substitution rates: sorediate, fast growing, species have higher rates of evolution. - We estimated that the nucleotide substitution rates are nearly two times faster in clade 4 ( $P$. didactyla clade) compared to clades 5-7 in section Peltigera (Fig. 1). All species in clade 4 produce asexual propagules (soredia) and therefore, can disperse both the fungal and cyanobacterial partners simultaneously (i.e., vertical transmission of the cyanobiont). Two other sorediate species, $P$. sp. 17 and $P$. granulosa, which are placed outside of clade 4 , i.e., among non-sorediate taxa in clades 5 and 6 , respectively, do not seem to evolve at a faster rate. Overall, our results seem to contradict the expectation of higher evolutionary rates in sexually reproducing species compared to asexually reproducing species (see Melián \& al., 2012, for a discussion; Rydholm \& al., 2006). However, most of the species in clade 4 also reproduce sexually as suggested by the common presence of apothecia on their thalli. Compared to the majority of species from other clades (Vitikainen, 1994), species in clade 4 (e.g., P. didactyla and P. ulcerata) are typical early successional lichens with very small and fast growing thalli, often with apothecia ( $P$. didactyla), and consequently probably have a drastically shorter generation time, leading to higher evolutionary rates, as it was suggested for animals (Martin \& Palumbi, 1993). The fact that they also show very broad geographic distributions (Fig. 5) may also contribute to larger population sizes. Another result supporting higher evolutionary rates and/ or population sizes for clade 4 is that the estimated value of $\theta$ for bPP analyses, which was higher than for all other clades (0.02 vs. $0.0025-0.0044)$ in section Peltigera. Other factors have been proposed for explaining variation in substitution rates in lichen-forming fungi, such as changes in ecological conditions. It was suggested that evolutionary rates were higher in parmelioid lichens growing in tropical and oceanic habitats compared to those in more arid habitats (Lumbsch \& al., 2008). Otálora \& al. (2013a) reported that clades including species from tropical and humid habitats have higher evolutionary rates in the Collemataceae. We have not detected this trend in section Peltigera.

Biogeographical patterns in Peltigera sect. Peltigera. Four of the five early diverging species, i.e., Peltigera sp. 14 and P. aubertii, P. frigida and P. patagonica (Fig. 5) are restricted to southern Chile and Argentina. The most recent common ancestor of section Peltigera could have inhabited the Neantarctic region of South America. A similar result was found in the genus Flavoparmelia Hale (Parmeliaceae), which comprises several subcosmopolitan species and whose origin was reconstructed in South America (Del-Prado \& al., 2013). Most ancestors at the deepest nodes of the phylogeny seem to have originated in Asia and North America (Fig. 5). One possible scenario leading to the current distribution of species would have been a dispersion north from the Neantarctic to the Pacific Northwest, followed by a dispersion across North America and to Asia. An alternative scenario could involve a more broadly distributed ancestor than the extant species and, consequently, the current Neantarctic species would be the result of paleoendemism. The ancestor of clade 4 (sorediated, fast growing, species) was inferred to occur in the Neotropics, clades 5 and
6 (and potentially clades 4-6) in North America, and clade 8-9 in Asia. Most species in clade 9 may have diversified in the Pacific Northwest region, before the P. austroamericanal sp. 22 group dispersed to the Neotropics (Fig. 5).

The biogeographical analyses highlight at least five dispersion events to the Neotropics, all most likely from a Beringian origin (i.e., the ancestors of clade 4 , the $P$. laciniata/sp. 15 group, the $P$. "neorufescens" 1 and 2 clade, $P$. sp. 17 and the $P$. austroamericana/sp. 22 group; Fig. 5). A similar pattern was detected in section Polydactylon for Peltigera sp. 6, which is sister to the panboreal P. occidentalis ( $\AA$.E.Dahl) Kristinsson (Magain \& al., 2017a). With the exception of clade 4, all these southern dispersion events were relatively recent in the history of the section. The reverse scenario seems to be plausible within clade 4 where the ancestral taxa were likely to be Neotropical, and very widespread species such as $P$. extenuata and $P$. didactyla, or their ancestors dispersed from this area to reach their current subcosmopolitan ranges. Only two inferred dispersion events (with the exception of subcosmopolitan species), for $P$. antarctica and $P$. "fuscopraetextata" were to the Neantarctics and occurred rather from North America than from the Neotropics. This pattern differs from the observation in section Polydactylon, where the only Neantarctic species, $P$. truculenta, originated from a Neotropical group (Magain \& al., 2017a).

Dispersion to Australasia could have occurred from Asia (for P. tereziana) but also from the Americas, i.e., the Neotropics for the ancestor of the clade comprising P. papuana and P. granulosa, and from North America for the ancestor of $P$. fimbriata (Fig. 5). Except for the sorediate species from clade 4 ( $P$. ulcerata, $P$. didactyla), the remaining subcosmopolitan species, such as $P$. canina 1 or $P$. praetextata, are absent from the Neotropics. In two cases ( $P$. extenuata 1 and 2, P. rufescens 1 and 2), the neotropical members of the morphospecies appear as a sister species to a clade containing widespread and morphologically similar individuals from other regions, including Neantarctic (bipolar distribution). This pattern may suggest that climatic differences were a barrier impacting species distribution more than geographic distance. The importance of climate in shaping the ranges of both mycobionts and photobionts, has been shown in Peltigera (Magain \& al., 2017a; Lu \& al., 2018), other genera of lichenized fungi, such as Cetraria Ach. (Fernández-Mendoza \& al., 2011) and Protoparmelia (Singh \& al., 2016), as well as in bryophytes (Lewis \& al., 2014).

Contrary to clade 4, which encompasses widespread sorediate, fast growing, species, most broadly distributed species are sister to species with very limited ranges. Examples include $P$. rufescens 1, part of a group of eleven species, each restricted to a single region, $P$. canina 1 , closely related to $P$. islandica and Peltigera sp. 20, restricted to Iceland and to the Pacific Northwest, respectively, and $P$. praetextata, sister to $P$. evansiana, known only from North America.

A recent study questioned the use of DEC and DEC $+\mathrm{J}$ models because they inflate the contribution of cladogenetic events to the likelihood (Ree \& Sanmartín, 2018). Our study did not aim to detect the relative impacts of cladogenesis and 
anagenesis, but rather to reconstruct the global biogeographic patterns in section Peltigera. Overall, four of the six models tested (DEC, DEC $+\mathrm{J}$, DIVALIKE, DIVALIKE $+\mathrm{J}$ ) globally agree on the reconstruction of the geographical distribution of the ancestors of the main clades discussed in the results section (Neotropical for clade 4, North American for clades 5 and 6, Asian for clades 8, 9 and the common ancestor of clades 4-9). Results with one model, BAYAREALIKE, suggest that the ancestors at the deep nodes had worldwide distributions, and that current species distributions are the result of drastic reductions of their ranges. Results with BAYAREALIKE $+\mathrm{J}$ are somewhat intermediary, suggesting a Holarctic distribution for most of these deep nodes.

Evolution and ecology of symbiotic specificity. - In general, it seems that the specificity of Peltigera species towards their cyanobionts is driven in part by the mode of reproduction, at least in clade 4 , where many sorediate species associate with fewer cyanobionts than members of other clades (Fig. 5). Exceptions include $P$. didactyla s.l., which seems to behave like a generalist, but this species, unlike $P$. ulcerata s.l. and $P$. extenuata s.l., frequently produce apothecia (Vitikainen, 1994; Miadlikowska \& Lutzoni, 2000; Goffinet \& al., 2003) and hence the horizontal transmission of the photobiont in P. didactyla may account for the lower specificity observed. Outside of clade 4 , the occurrence of asexual propagules, allowing the vertical transmission of the photobiont, also leads to higher specificity compared to species lacking vegetative propagules. Sorediate (P. sp. 17), isidiate (P. evansiana) or phyllidiate ( $P$. "fuscopraetextata") species consistently have higher levels of specificity. Similarly, among two species in the genus Pectenia P.M.Jørg. $\&$ al. (former Degelia Arv. \& D.J.Galloway), a vegetatively reproducing species was reported to be more specialized than its sexually reproducing close relative (Otálora \& al., 2013b). Otálora \& al. (2010) also found high levels of specificity in several species reproducing through asexual propagules in the family Collemataceae compared to closely related but sexually reproducing species. However, other studies (Wornik \& Grube, 2010; Leavitt \& al., 2015) on lichens involving green algae, instead of Nostoc, did not report a direct link between the reproduction mode and specificity.

Among the species for which we sequenced cyanobionts from more than five thalli, we found one strict mycobiont specialist $-P$. tereziana, that was associated with only one Nostoc phylogroup (Fig. 4B). Cases of strict specialists with lower Nostoc sampling include Peltigera vainioi, $P$. retifoveata, P. patagonica, P. papuana and Peltigera sp. 14. The fact that these species were found with a relatively rare Nostoc phylogroups (XXXVIa, XXXVIIIa, XXXI, and XXIII, respectively) may suggest that the observed specificity is real, whereas high specificity in P. degenii $3 \mathrm{~b}$ and Peltigera sp. 19, which were only collected three times each, and always with very widespread phylogroups (V and VI, respectively) may be an artifact of a low sampling. Species sampled many times with a common phylogroup (such as $P$. "fuscopraetextata" with phylogroup VI) probably represent real cases of specialization on a widespread and generalist Nostoc phylogroup (Fig. 5; Electr. Suppl.: Table S1).
Many of the specialist species in section Peltigera have narrow geographic ranges and often have specific ecological niches, such as Peltigera sp. 14, which was collected in Chile from relatively wet to semi-aquatic habitats. Peltigera patagonica and $P$. aubertii were only found in the Neantarctic region, and $P$. vainioi is a rare species in the Neotropics. The distribution of $P$. retifoveata is restricted to the boreal zone, whereas P. tereziana occurs in Australia and New Zealand, and P. papuana in Papua New Guinea. A similar trend was reported for species from section Polydactylon (Magain \& al., 2017a) and outside of the genus Peltigera, in Pectenia (Otálora $\&$ al., 2013), and in the family Collemataceae (Otálora \& al., 2010), where specialist species have smaller ranges and are more restricted ecologically. At the other end of the spectrum, cosmopolitan or subcosmopolitan species, such as $P$. canina 1 (= P. canina $\mathrm{s}$.str.), $P$. rufescens $1, P$. ponojensis/monticola 9 or $P$. praetextata are generalists. At a global spatial scale (see Chagnon \& al., 2018), this inverse correspondence between the level of specificity and geographic range of the mycobiont suggests that the ability to associate with a wider spectrum of photobionts increases the potential of a species to occupy greater geographical areas, whereas specialists restricted to one cyanobacterial partner might be limited by the availability of their cyanobiont, especially if the Nostoc phylogroup has a narrow distribution and is not a generalist. Another strategy leading to a larger range is to be specialized on a widespread and generalist phylogroup, such as $P$. "fuscopraetextata" with phylogroup VI or P. membranacea 1 with phylogroup XVI. A similar pattern was detected in section Polydactylon (Magain $\&$ al., 2017a) for $P$. polydactylon being a specialist with the common and generalist phylogroup $\mathrm{V}$ and $P$. hymenina often found with widespread and generalist phylogroup XVI.

True generalist interactions should involve frequent associations between the most abundant partners, as well as several rare interactions with rare partners (Vázquez \& al., 2007). Such a pattern was observed in several cases in section Peltigera. For example, in South America, P. friesiorum was found multiple times associated with the widespread phylogroups $\mathrm{V}$ (eight times) and XXXIX (five times) in addition to four unique interactions. This is also the case for $P$. canina $1, P$. praetextata, $P$. "neocanina" 1 , and $P$. austroamericana 5 , which associate frequently with phylogroup $\mathrm{V}$ but were also reported several times with other, less common phylogroups. Photobionts can show a similar pattern, for example Nostoc phylogroup V is frequently found (seven to eight times) with common species such as $P$. canina $1, P$. friesiorum and $P$. praetextata, but in addition was sometimes reported with rare species such as P. granulosa, P. montis-wilhelmii 1 or P. wulingensis (Fig. 3; Electr. Suppl.: Table S1). Our results confirm specificity patterns observed in section Peltigera at a local scale (O'Brien $\&$ al., 2013). In general, Peltigera species that are generalists at an intercontinental scale might appear to be more specialized at a local scale, such as $P$. canina 1 and 2 , which are mostly specialized on Nostoc from phylogroup VI in British Columbia (O'Brien \& al., 2013) but are generalists at a global scale. Chagnon \& al. (2018) also showed a higher asymmetry at local scales (several specialist mycobionts associating with 
one or two generalist Nostoc phylogroups), compared to more symmetric associations at a global scale.

Within section Peltigera, clade 4 differs from other clades in several aspects. It includes morphologically distinct species with generally small, fast growing, thalli and with asexual propagules (soralia). This clade has the highest number of widespread species, with five of ten species occurring in three or more biogeographic regions while other clades contain no (clade 5 , clade 7 ) or only a few species (one in clade 6 , two in clade 8 and three in clade 9) with such broad distributions. Clade 4 has the highest average Specificity index ( 0.64 vs. $0.41-0.57$ for other clades), the greatest number of species (three) associated with a single Nostoc phylogroup, as well as significantly higher rates of nucleotide substitutions (Table 1).

In summary, most species in section Peltigera show a relatively low level of specificity compared to section Polydactylon (Magain \& al., 2017a). This could be due to differences in ecological requirements, as members of the canina group seem to be more ubiquitous compared to species from section Polydactylon, which are found mostly in boreal areas and at high elevations. This difference could also be due to the recent origin of many of the species in section Peltigera, which is the most speciose section of the genus Peltigera. Most specialists in section Peltigera either originated early during the evolution of the section (clades 2a-c; Figs. 1 and 5) or reproduce through vegetative propagules (clade 4; Figs. 1 and 5). Unlike section Polydactylon, section Peltigera includes several very widespread, almost cosmopolitan species. Large distributions should favor the maintenance of a generalist selection of photobionts, allowing these species to grow in a higher number of ecological and geographical environments. Future challenges include the formal description of putative species revealed by this study, following further validations using multidisciplinary approaches based on population genetics, phylogenomics, network analyses and physio-ecological studies. A global phylogenetic study of the genus Peltigera is now needed to enhance our understanding of its biodiversity, biogeography and patterns of symbiotic interactions.

\section{AUTHOR CONTRIBUTIONS}

NM designed this study, generated data, ran analyses and wrote the paper. CT designed this study, generated data, ran analyses and contributed to the writing of this article. DN generated data and edited the manuscript. TG, BG, ES and OV contributed to the taxonomy and systematics of this study, and edited the manuscript. JM and FL designed the entire project, including this study, they oversaw the implementation of every phase and aspects of this study, mentored two postdoctoral researchers (CT and NM), and co-wrote the manuscript with NM. — ORCID: NM, https://orcid.org/0000-0001-54099518; BG, https://orcid.org/0000-0002-2754-3895; ES, https://orcid. org/0000-0002-0456-0131

\section{ACKNOWLEDGEMENTS}

We thank the curators of all herbaria and collaborators who provided material for this study. We are grateful to all colleagues who helped us organize and successfully execute the field trips for this project. We thank members of the Lutzoni Lab (Carlos Pardo-De la Hoz and KoHsuan Chen) for useful discussions. We thank Ian Medeiros for performing TLC on selected specimens. We thank associate editor Mats Wedin and two anonymous reviewers for valuable comments on the manuscript. This study was supported by the National Science Foundation (NSF) REVSYS award on the genus Peltigera DEB-1025930 and NSF SG DEB-1556995 on phylogenetic and network analyses using Peltigera as a model system to FL and JM as well as NSF grant DEB-1354631 to BG.

\section{- LITERATURE CITED}

Bouckaert, R., Heled, J., Kühnert, D., Vaughan, T., Wu, C.H., Xie, D., Suchard, M.A., Rambaut, A. \& Drummond, A.J. 2014. BEAST 2: A software platform for Bayesian evolutionary analysis. PLOS Computat. Biol. 10: e1003537. https://doi.org/10.1371/ journal.pcbi.1003537

Brodo, I., Sharnoff, S.D. \& Sharnoff, S. 2001. Lichens of North America. New Haven: Yale University Press.

Carstens, B.C., Pelletier, T.A., Reid, N.M. \& Satler, J.D. 2013. How to fail at species delimitation. Molec. Ecol. 22: 4369-4383. https:// doi.org $/ 10.1111 / \mathrm{mec} .12413$

Chagnon, P.-L., Magain, N., Miadlikowska, J. \& Lutzoni, F. 2018. Strong specificity and network modularity at a very fine phylogenetic scale in the lichen genus Peltigera. Oecologia 187: 167-182. https://doi.org/10.1016/j.ympev.2014.04.003

Coddington, J.A., Agnarsson, I., Miller, J.A., Kuntner, M. \& Hormiga, G. 2009. Undersampling bias: The null hypothesis for singleton species in tropical arthropod surveys. J. Anim. Ecol. 78: 573-584. https://doi.org/10.1111/j.1365-2656.2009.01525.x

Dal Grande, F., Widmer, I., Wagner, H. \& Scheidegger, C. 2012. Vertical and horizontal photobiont transmission within populations of a lichen symbiosis. Molec. Ecol. 21: 3159-3172. https:// doi.org/10.1111/j.1365-294X.2012.05482.x

Darnajoux, R., Lutzoni, F., Miadlikowska, J. \& Bellenger, J.-P. 2015. Determination of elemental baseline using peltigeralean lichens from Northeastern Canada (Québec): Initial data collection for long term monitoring of the impact of global climate change on boreal and subarctic areas in Canada. Sci. Total Environm. 533: 1-7. https://doi.org/10.1016/j.scitotenv.2015.06.030

Darnajoux, R., Zhang, X., McRose, D.L., Miadlikowska, J., Lutzoni, F., Kraepiel, A.M.L. \& Bellenger, J.-P. 2017. Biological nitrogen fixation by alternative nitrogenases in boreal cyanolichens: Importance of molybdenum availability and implications for current biological nitrogen fixation estimates. New Phytol. 213: 680-689. https://doi.org/10.1111/nph.14166

Del-Prado, R., Blanco, O., Lumbsch, H.T., Divakar, P.K., Elix, J., Molina, M.C. \& Crespo, A. 2013. Molecular phylogeny and historical biogeography of the lichen-forming fungal genus Flavoparmelia (Ascomycota: Parmeliaceae). Taxon 62: 928-939. https://doi.org/10.12705/625.22

Díaz, E.M., Vicente-Manzanares, M., Sacristan, M., Vicente, C. \& Legaz, M.E. 2011. Fungal lectin of Peltigera canina induces chemotropism of compatible Nostoc cells by constriction-relaxation pulses of cyanobiont cytoskeleton. Pl. Signal. Behav. 6: 1525-1536. https://doi.org/10.4161/psb.6.10.16687

Dodge, C.W. 1968. Lichenological notes on the flora of the Antarctic Continent and the subantarctic islands. VII and VIII. Nova Hedwigia: 15: 285-332. 
Drummond, A.J. \& Rambaut, A. 2007. BEAST: Bayesian evolutionary analysis by sampling trees. B. M. C. Evol. Biol. 7: 214. https://doi. org/10.1186/1471-2148-7-214

Fernández-Mendoza, F., Domaschke, S., García, M.A., Jordan, P., Martín, M.P. \& Printzen, C. 2011. Population structure of mycobionts and photobionts of the widespread lichen Cetraria aculeata. Molec. Ecol. 20: 1208-1232. https://doi. $\operatorname{org} / 10.1111 / \mathrm{j} .1365-294 X .2010 .04993 . x$

Fujisawa, T. \& Barraclough, T.G. 2013. Delimiting species using single-locus data and the Generalized Mixed Yule Coalescent approach: A revised method and evaluation on simulated data sets. Syst. Biol. 62: 707-724. https://doi.org/10.1093/sysbio/syt033

Gardes, M. \& Bruns, T.D. 1993. ITS primers with enhanced specificity for basidiomycetes-application to the identification of mycorrhizae and rusts. Molec. Ecol. 2: 113-118.

Gaya, E., Högnabba, F., Holguin, Á., Molnar, K., Fernández-Brime, S., Stenroos, S., Arup, U., Søchting, U., Van den Boom, P., Lücking, R. Sipman, H.J.M. \& Lutzoni, F. 2012. Implementing a cumulative supermatrix approach for a comprehensive phylogenetic study of the Teloschistales (Pezizomycotina, Ascomycota). Molec. Phylogen. Evol. 63: 374-387.

GeneCodes 2000. Sequencher, version 4.1, DNA sequence analysis software. Ann Arbor: Gene Codes Corporation. https:/www.genecodes.com/sequencher

Glass, N.L. \& Donaldson, G.C. 1995. Development of primer sets designed for use with the PCR to amplify conserved genes from filamentous ascomycetes. Appl. Environm. Microbiol. 61: 1323-1330.

Goffinet, B. \& Hastings, R.I. 1995. Two new sorediate taxa of Peltigera. Lichenologist 27: 43-58. https://doi.org/10.1006/lich.1995.0004

Goffinet, B., Miadlikowska, J. \& Goward, T. 2003. Phylogenetic inferences based on nrDNA sequences support five morphospecies within the Peltigera didactyla complex (lichenized Ascomycota). Bryologist 106: 349-364. https://doi.org/10.1639/01

Goward, T., Goffinet, B. \& Vitikainen, O. 1995. Synopsis of the genus Peltigera (lichenized Ascomycetes) in British Columbia, with a key to the North American species. Canad. J. Bot. 73: 91-111. https:// doi.org/10.1139/b95-012

Haas, J.R., Bailey, E.H. \& Purvis, O.W. 1998. Bioaccumulation of metals by lichens: uptake of aqueous uranium by Peltigera membranacea as a function of time and pH. Amer. Mineral. 83: 1494-1502.

Han, L.-F., Zhang, Y.-Y. \& Guo, S.-Y. 2013. Peltigera wulingensis, a new lichen (Ascomycota) from north China. Lichenologist 45: 329-336. https://doi.org/10.1017/S0024282912000837

Han, L.-F., Zheng, T.-X. \& Guo, S.-Y. 2015. A new species in the lichen genus Peltigera from northern China based on morphology and DNA sequence data. Bryologist 118: 46-53. https://doi. org/10.1639/0007-2745-118.1.046

Henriksson, E. \& Pearson, L. 1981. Nitrogen fixation rate and chlorophyll content of the lichen Peltigera canina exposed to sulfur dioxide. Amer. J. Bot. 68: 680-684. https://doi.org/10.1002/j.1537-2197.1981. tb12400.x

Higgins, N.F. \& Crittenden, P.D. 2015. Phytase activity in lichens. New Phytol. 208: 544-554. https://doi.org/10.1111/nph.13454

Holtan-Hartwig, J. 1993. The lichen genus Peltigera, exclusive of the P. canina group, in Norway. Sommerfeltia 15: 1-77. https://doi. org/10.1017/S0024282994000150

Huelsenbeck, J.P. \& Ronquist, F. 2001. MRBAYES: Bayesian inference of phylogenetic trees. Bioinformatics 17: 754-755.

Jüriado, I., Kaasalainen, U. \& Rikkinen, J. 2017. Specialist taxa restricted to threatened habitats contribute significantly to the regional diversity of Peltigera (Lecanoromycetes, Ascomycota) in Estonia. Fungal Ecol. 30: 76-87. https://doi.org/10.1016/j. funeco.2017.08.004

Landis, M.J., Matzke, N.J., Moore, B.R. \& Huelsenbeck, J.P. 2013. Bayesian analysis of biogeography when the number of areas is large. Syst. Biol. 62: 789-804. https://doi.org/10.1093/sysbio/syt040

Lanfear, R., Calcott, B., Ho, S.Y. \& Guindon, S. 2012. PartitionFinder:
Combined selection of partitioning schemes and substitution models for phylogenetic analyses. Molec. Biol. Evol. 29: 1695-1701. https://oi.org/10.1093/molbev/mss020

Leavitt, S.D., Fankhauser, J.D., Leavitt, D.H., Porter, L.D., Johnson, L.A. \& Clair, L.L. 2011. Complex patterns of speciation in cosmopolitan "rock posy" lichens-Discovering and delimiting cryptic fungal species in the lichen-forming Rhizoplaca melanophthalma species-complex (Lecanoraceae, Ascomycota). Molec. Phylogen. Evol. 59: 587-602. https://doi.org/10.1016/j.ympev.2011.03.020

Leavitt, S.D., Esslinger, T.L., Spribille, T., Divakar, P.K. \& Lumbsch, H.T. 2013. Multilocus phylogeny of the lichen-forming fungal genus Melanohalea (Parmeliaceae, Ascomycota): Insights on diversity, distributions, and a comparison of species tree and concatenated topologies. Molec. Phylogen. Evol. 66: 138-152. https://doi.org/10.1016/j.ympev.2012.09.013

Leavitt, S.D., Kraichak, E., Nelsen, M.P., Altermann, S., Divakar, P.K., Alors, D., Esslinger, T.L., Crespo, A. \& Lumbsch, T. 2015 Fungal specificity and selectivity for algae play a major role in determining lichen partnerships across diverse ecogeographic regions in the lichen-forming family Parmeliaceae (Ascomycota). Molec. Ecol. 24: 3779-3797. https://doi.org/10.1111/mec.13271

Lehr, H., Fleminger, G. \& Galun, M. 1995. Lectin from the lichen Peltigera membranacea (Ach.) Nyl.: Characterization and function. Symbiosis 18: 1-13.

Lewis, L.R., Rozzi, R. \& Goffinet, B. 2014. Direct long-distance dispersal shapes a New World amphitropical disjunction in the dispersal-limited dung moss Tetraplodon (Bryopsida: Splachnaceae). J. Biogeogr. 41: 2385-2395. https://doi.org/10.1111/jbi.12385

Li, L.-A. \& Tabita, F.R. 1997. Maximum activity of recombinant ribulose 1, 5-bisphosphate carboxylase/oxygenase of Anabaena sp. strain CA requires the product of the $r b c X$ gene. J. Bacteriol. 179: 3793-3796.

Linnaeus, C. 1753. Species plantarum, vol. 2. Holmiae [Stockholm]: impensis Laurentii Salvii. https://doi.org/10.5962/bhl.title.669

Lu, J., Magain, N., Miadlikowska, J., Coyle, J., Truong, C. \& Lutzoni, F. 2018. Bioclimatic factors at an intrabiome scale are more limiting than cyanobiont availability for the lichen-forming genus Peltigera. Amer. J. Bot. 105: 1198-1211.

Lücking, R., Dal-Forno, M., Sikaroodi, M., Gillevet, P.M., Bungartz, F., Moncada, B., Yánez-Ayabaca, A., Chaves, J.L., Coca, L.F. \& Lawrey, J.D. 2014a. A single macrolichen constitutes hundreds of unrecognized species. Proc. Natl. Acad. Sci. U.S.A. 111: 11091-11096. https://doi.org/10.1073/pnas.1403517111

Lücking, R., Johnston, M.K., Aptroot, A., Kraichak, E., Lendemer, J.C., Boonpragob, K., Caceres, M.E., Ertz, D., Ferraro, L.I., Jia, Z.F. \& Kalb, K. 2014b. One hundred and seventy-five new species of Graphidaceae: Closing the gap or a drop in the bucket? Phytotaxa 189: 7-38.

Lücking, R., Moncada, B., McCune, B., Farkas, E., Goffinet, B., Parker, D., Chaves, J.L., Lőkös, L., Nelson, P.R., Spribille, T. \& Stenroos, S. 2017. Pseudocyphellaria crocata (Ascomycota: Lobariaceae) in the Americas is revealed to be thirteen species, and none of them is P. crocata. Bryologist 120: 441-500. https:// doi.org/10.1639/0007-2745-120.4.14

Lumbsch, H.T. \& Leavitt, S.D. 2011. Goodbye morphology? A paradigm shift in the delimitation of species in lichenized fungi. Fungal Diversity 50: 59-72.

Lumbsch, H.T., Hipp, A.L., Divakar, P.K., Blanco, O.\& Crespo, A. 2008. Accelerated evolutionary rates in tropical and oceanic parmelioid lichens (Ascomycota). B. M. C. Evol. Biol. 8: 257. https:// doi.org/10.1186/1471-2148-8-257

Lutzoni, F., Wagner, P., Reeb, V. \& Zoller, S. 2000. Integrating ambiguously aligned regions of DNA sequences in phylogenetic analyses without violating positional homology. Syst. Biol. 49: 628-651.

Maddison, D.R. \& Maddison, W.P. 2005. MacClade 4: Analysis of phylogeny and character evolution, version 4.08 a. https://macclade. org/macclade.html 
Maddison, W.P. \& Maddison, D.R. 2015. Mesquite: A modular system for evolutionary analysis, version 3.11. https://www. mesquiteproject.org/

Magain, N. 2018. PLexus, a PERL package to handle DNA matrices. Available from the author. https:/github.com/NicolasMagain/ PLexus

Magain, N. \& Sérusiaux, E. 2014. Do photobiont switch and cephalodia emancipation act as evolutionary drivers in the lichen symbiosis? A case study in the Pannariaceae (Peltigerales). PLOS ONE 9: e89876. https://doi.org/10.1371/journal.pone.0089876

Magain, N., Miadlikowska, J., Goffinet, B., Sérusiaux, E. \& Lutzoni, F. 2017a Macroevolution of specificity in cyanolichens of the genus Peltigera section Polydactylon (Lecanoromycetes, Ascomycota). Syst. Biol. 66: 74-99. https://doi.org/10.1093/sysbio/syw065

Magain, N., Miadlikowska, J., Mueller, O., Gajdeczka, M., Truong, C., Salamov, A.A., Dubchak, I., Grigoriev, I.V., Goffinet, B., Sérusiaux, E. \& Lutzoni, F. 2017b Conserved genomic collinearity as a source of broadly applicable, fast evolving, markers to resolve species complexes: A case study using the lichen-forming genus Peltigera section Polydactylon. Molec. Phylogen. Evol. 117: 10-29. https://doi.org/10.1016/j.ympev.2017.08.013

Manoharan, S.S., Miao, V.P. \& Andrésson, Ó.S. 2012. LEC-2, a highly variable lectin in the lichen Peltigera membranacea. Symbiosis 58: 91-98. https://doi.org/10.1007/s13199-012-0206-y

Manoharan-Basil, S.S., Miadlikowska, J., Goward, T., Andresson, O.S. \& Vivian, P.W. 2016. Peltigera islandica, a new cyanolichen species in section Peltigera. Lichenologist 48: 451-467. https://doi. org $/ 10.1017 / \mathrm{S} 0024282916000414$

Martin, A.P. \& Palumbi, S.R. 1993. Body size, metabolic rate, generation time, and the molecular clock. Proc. Natl. Acad. Sci. U.S.A. 90: 4087-4091. https://doi.org/10.1073/pnas.90.9.4087

Martínez, I., Burgaz, A.R., Vitikainen, O. \& Escudero, A. 2003. Distribution patterns in the genus Peltigera Willd. Lichenologist 35: 301-323. https://doi.org/10.1016/S0024-2829(03)00041-0

Mason-Gamer, R.J. \& Kellogg, E.A. 1996. Testing for phylogenetic conflict among molecular data sets in the tribe Triticeae (Gramineae). Syst. Biol. 45: 524-545. https://doi.org/10.1093/ sysbio/45.4.524

Matzke, N.J. 2013a. BioGeoBEARS: Biogeography with Bayesian (and likelihood) evolutionary analysis in R scripts. R package, version 0.21. https://phylo.wikidot.com/biogeobears

Matzke, N.J. 2013b. Probabilistic historical biogeography: New models for founder-event speciation, imperfect detection, and fossils allow improved accuracy and model-testing. Frontiers Biogeogr. 5: 242-248. https://escholarship.org/uc/item/44j7n141

Matzke, N.J. 2014. Model selection in historical biogeography reveals that founder-event speciation is a crucial process in island clades. Syst. Biol. 63: 951-970. https://doi.org/10.1093/sysbio/syu056

Melián, C.J., Alonso, D., Allesina, S., Condit, R.S. \& Etienne, R.S. 2012. Does sex speed up evolutionary rate and increase biodiversity? PLOS Computat. Biol. 6: e1002414. https://doi.org/10.1371/ journal.pcbi.1002414

Miadlikowska, J. \& Lutzoni, F. 2000. Phylogenetic revision of the genus Peltigera (lichen-forming Ascomycota) based on morphological, chemical, and large subunit nuclear ribosomal DNA data. Int. J. Pl. Sci. 161: 925-958. https://doi.org/10.1086/317568

Miadlikowska, J., Lutzoni, F., Goward, T., Zoller, S. \& Posada, D. 2003. New approach to an old problem: Incorporating signal from gap-rich regions of ITS and rDNA large subunit into phylogenetic analyses to resolve the Peltigera canina species complex. Mycologia 95: 1181-1203. https://doi.org/10.2307/3761919

Miadlikowska, J., Richardson, D., Magain, N., Ball, B., Anderson, F., Cameron, R., Lendemer, J., Truong, C. \& Lutzoni, F. 2014a. Phylogenetic placement, species delimitation, and cyanobiont identity of endangered aquatic Peltigera species (lichen-forming Ascomycota, Lecanoromycetes). Amer. J. Bot. 101: 1141-1156. https://doi.org/10.3732/ajb.1400267
Miadlikowska, J., Kauff, F., Högnabba, F., Oliver, J.C., Molnár, K., Fraker, E., Gaya, E., Hafellner, J., Hofstetter, V., Gueidan, C., Otálora, M.A.G., Hodkinson, B., Kukwa, M., Lücking, R., Björk, C., Sipman, H.J.M., Burgaz, A.R., Thell, A., Passo, A., Myllys, L., Goward, T., Fernández-Brime, S., Hestmark, G., Lendemer, J., Lumbsch, H.T., Schmull, M., Schoch, C.L., Sérusiaux, E., Maddison, D.R., Arnold, A.E., Stenroos, S. \& Lutzoni, F. 2014b. Multigene phylogenetic synthesis for the class Lecanoromycetes (Ascomycota): 1307 fungi representing 1139 infrageneric taxa, 312 genera and 66 families. Molec. Phylogen. Evol. 79: 132-168. https://doi.org/10.1016/j.ympev.2014.04.003

Miao, V., Rabenau, A. \& Lee, A. 1997. Cultural and molecular characterization of photobionts of Peltigera membranacea. Lichenologist 29: 571-586.

Miller, M.A., Pfeiffer, W. \& Schwartz, T. 2010. Creating the CIPRES Science Gateway for inference of large phylogenetic trees. Pp. 45-52 in: Proceedings of the Gateway Computing Environments Workshop (GCE), New Orleans, Louisiana, 14 Nov 2010. Piscataway: IEEE.

Moncada, B., Lücking, R. \& Suárez, A. 2014a. Molecular phylogeny of the genus Sticta (lichenized Ascomycota: Lobariaceae) in Colombia. Fungal Diversity 64: 205-231. https://doi.org/10.1007/ s13225-013-0230-0

Moncada, B., Reidy, B. \& Lücking, R. 2014b. A phylogenetic revision of Hawaiian Pseudocyphellaria sensu lato (lichenized Ascomycota: Lobariaceae) reveals eight new species and a high degree of inferred endemism. Bryologist 117: 119-160. https://doi. org/10.1639/0007-2745-117.2.119

Nylander, J.A.A. 2004. MrModeltest, version 2. Program distributed by the author. Evolutionary Biology Centre, Uppsala University. http://www.abc.se/ nylander/mrmodeltest $2 /$ mrmodeltest $2 . h t m l$

Nylander, J.A.A., Wilgenbusch, J.C., Warren, D.L. \& Swofford, D.L. 2008. AWTY (are we there yet?): A system for graphical exploration of MCMC convergence in Bayesian phylogenetics. Bioinformatics 24: 581-583. https://doi.org/10.1093/bioinformatics/btm388

O'Brien, H.E., Miadlikowska, J. \& Lutzoni, F. 2005. Assessing host specialization in symbiotic cyanobacteria associated with four closely related species of the lichen fungus Peltigera. Eur. J. Phycol. 40: 363-378. https://doi.org/10.1080/09670260500342647

O'Brien, H.E., Miadlikowska, J. \& Lutzoni, F. 2009. Assessing reproductive isolation in highly diverse communities of the lichenforming fungal genus Peltigera. Evolution 63: 2076-2086. https:// doi.org/10.1111/j.1558-5646.2009.00685.x

O'Brien, H.E., Miadlikowska, J. \& Lutzoni, F. 2013. Assessing population structure and host specialization in lichenized cyanobacteria. New Phytol. 198: 557-566. https://doi.org/10.1111/nph.12165

O'Donnell, K. \& Cigelnik, E. 1997. Two divergent intragenomic rDNA ITS2 types within a monophyletic lineage of the fungus Fusarium are nonorthologous. Molec. Phylogen. Evol. 7: 103-116. https://doi. org/10.1006/mpev.1996.0376

Otálora, M.A., Martínez, I., O’Brien, H., Molina, M.C., Aragón, G. \& Lutzoni, F. 2010. Multiple origins of high reciprocal symbiotic specificity at an intercontinental spatial scale among gelatinous lichens (Collemataceae, Lecanoromycetes). Molec. Phylogen. Evol. 56: 1089-1095. https://doi.org/10.1016/j.ympev.2010.05.013

Otálora, M.A., Aragón, G., Martínez, I. \& Wedin, M. 2013a. Cardinal characters on a slippery slope-A re-evaluation of phylogeny, character evolution, and evolutionary rates in the jelly lichens (Collemataceae s. str). Molec. Phylogen. Evol. 68: 185-198. https:// doi.org/10.1016/j.ympev.2013.04.004

Otálora, M.A., Salvador, C., Martínez, I. \& Aragón, G. 2013b. Does the reproductive strategy affect the transmission and genetic diversity of bionts in cyanolichens? A case study using two closely related species. Microbial Ecol. 65: 517-530. https://doi.org/10.1007/ s00248-012-0136-5

Pardo-De la Hoz, C., Magain, N., Lutzoni, F., Goward, T., Restrepo, S. \& Miadlikowska, J. In press. Contrasting symbiotic patterns in 
two closely related lineages of trimembered lichens of the genus Peltigera. Frontiers Microbiol.

Pons, J., Barraclough, T.G., Gomez-Zurita, J., Cardoso, A., Duran, D.P., Hazell, S., Kamoun, S., Sumlin, W.D. \& Vogler, A.P. 2006. Sequence-based species delimitation for the DNA taxonomy of undescribed insects. Syst. Biol. 55: 595-609.

Rambaut, A. \& Drummond, A. 2007. Tracer, version 1.5. http://beast. bio.ed.ac.uk

Ree, R.H. \& Sanmartín, I. 2018. Conceptual and statistical problems with the $\mathrm{DEC}+\mathrm{J}$ model of founder-event speciation and its comparison with DEC via model selection. J. Biogeogr. 45: 741-749. https://doi.org/10.1111/jbi.13173

Ree, R.H. \& Smith, S.A. 2008. Maximum likelihood inference of geographic range evolution by dispersal, local extinction, and cladogenesis. Syst. Biol. 57: 4-14. https://doi.org/10.1080/10635150701883881

Reeb, V., Lutzoni, F. \& Roux, C. 2004. Contribution of $R P B 2$ to multilocus phylogenetic studies of the euascomycetes (Pezizomycotina, Fungi) with special emphasis on the lichen-forming Acarosporaceae and evolution of polyspory. Molec. Phylogen. Evol. 32: 1036-1060. https://doi.org/10.1016/j.ympev.2004.04.012

Reid, N.M. \& Carstens, B.C. 2012. Phylogenetic estimation error can decrease the accuracy of species delimitation: A Bayesian implementation of the general mixed Yule-coalescent model. B. M. C. Evol. Biol. 12: 196.

Rodriguez, F., Oliver, J.L., Marin, A. \& Medina, J.R. 1990. The general stochastic model of nucleotide substitution. J. Theor. Biol. 142: 485-501.

Ronquist, F. 1997. Dispersal-vicariance analysis: A new approach to the quantification of historical biogeography. Syst. Biol. 46: 195-203. https://doi.org/10.1093/sysbio/46.1.195

Ronquist, F. \& Sanmartín, I. 2011. Phylogenetic methods in biogeography. Annual Rev. Ecol. Evol. Syst. 42: 441-464. https://doi. org/10.1146/annurev-ecolsys-102209-144710

Rudi, K., Skulberg, O.M. \& Jakobsen, K.S. 1998. Evolution of cyanobacteria by exchange of genetic material among phyletically related strains. J. Bacteriol. 180: 3453-3461.

Rydholm, C., Szakacs, G. \& Lutzoni, F. 2006. Low genetic variation and no detectable population structure in Aspergillus fumigatus compared to closely related Neosartorya species. Eukar. Cell 5: 650-657. https://doi.org/10.1128/EC.5.4.650-657.2006

Schneider, K., Resl, P. \& Spribille, T. 2016. Escape from the cryptic species trap: Lichen evolution on both sides of a cyanobacterial acquisition event. Molec. Ecol. 25: 3453-3468. https://doi.org/10.1111/ mec. 13636

Sérusiaux, E., Goffinet, B., Miadlikowska, J. \& Vitikainen, O. 2009. Taxonomy, phylogeny and biogeography of the lichen genus Peltigera in Papua New Guinea. Fungal Diversity 38: 185-224.

Simon, A., Goffinet, B., Magain, N. \& Sérusiaux, E. 2018. High diversity, high insular endemism and recent origin in the lichen genus Sticta (lichenized Ascomycota, Peltigerales) in Madagascar and the Mascarenes. Molec. Phylogen. Evol. 122: 15-28. https:// doi.org/10.1016/j.ympev.2018.01.012

Simpson, E.H. 1949. Measurement of diversity. Nature 163: 688. doi:10.1038/163688a0

Singh, G., Dal Grande, F., Divakar, P.K., Otte, J., Leavitt, S.D., Szczepanska, K., Krespo, A., Rico, V.J., Aptroot, A., Cáceres,
M.E., Lumbsch, H.T. \& Schmitt, I. 2015. Coalescent-based species delimitation approach uncovers high cryptic diversity in the cosmopolitan lichen-forming fungal genus Protoparmelia (Lecanorales, Ascomycota). PLOS ONE 10: e0124625. https://doi. org/10.1371/journal.pone.0124625

Singh, G., Dal Grande, F., Divakar, P.K., Otte, J., Crespo, A. \& Schmitt, I. 2016. Fungal-algal association patterns in lichen symbiosis linked to macroclimate. New Phytol. 214: 317-329. https:// doi.org/10.1111/nph.14366

Stamatakis, A. 2006. RAxML-VI-HPC: Maximum likelihoodbased phylogenetic analyses with thousands of taxa and mixed models. Bioinformatics 22: 2688-2690. https://doi.org/10.1093/ bioinformatics/btl446

Stamatakis, A., Hoover, P. \& Rougemont, J. 2008. A rapid bootstrap algorithm for the RAxML web servers. Syst. Biol. 57: 758-771. https://doi.org/10.1080/10635150802429642

Sukumaran, J. \& Knowles, L.L. 2017. Multispecies coalescent delimits structure, not species. Proc. Natl. Acad. Sci. U.S.A. 114: 1607-1612. https://oi.org/10.1073/pnas.1607921114

Van Dam, M.H. \& Matzke, N.J. 2016. Evaluating the influence of connectivity and distance on biogeographical patterns in the southwestern deserts of North America. J. Biogeogr. 43: 1514-1532. https://doi.org/10.1111/jbi.12727

Vázquez, D.P., Melián, C.J., Williams, N.M., Blüthgen, N., Krasnov, B.R. \& Poulin, R. 2007. Species abundance and asymmetric interaction strength in ecological networks. Oikos 116: 1120-1127. https://doi.org/10.1111/j.0030-1299.2007.15828.x

Vitikainen, O. 1994. Taxonomic revision of Peltigera (lichenized Ascomycotina) in Europe. Acta Bot. Fenn. 152: 1-96.

Vitikainen, O. 1998. Taxonomic notes on neotropical species of Peltigera. Pp. 135-139 in: Marcelli, M.P. \& Seaward, M.R.D. (eds), Lichenology in Latin America: History, current knowledge and applications. São Paulo: CETESB.

White, T.J., Bruns, T., Lee, S. \& Taylor, J.L. 1990. Amplification and direct sequencing of fungal ribosomal RNA genes for phylogenetics. Pp. 315-322 in: Innis, M.A., Gelfand, D.H., Sninsky, J.J. \& White, T.J. (eds.), PCR protocols: A guide to methods and applications. San Diego: Academic Press.

Wornik, S. \& Grube, M. 2010. Joint dispersal does not imply maintenance of partnerships in lichen symbioses. Microbial Ecol. 59: 150-157. https://doi.org/10.1007/s00248-009-9584-y

Xavier, B.B., Miao, V.P., Jónsson, Z.O. \& Andrésson, Ó.S. 2012. Mitochondrial genomes from the lichenized fungi Peltigera membranacea and Peltigera malacea: Features and phylogeny. Fungal Biol. 116: 802-814. https://doi.org/10.1016/j.funbio.2012.04.013

Yang, Z. 1997. PAML: A program package for phylogenetic analysis by maximum likelihood. Computer Applic. Biosci. 13: 555-556.

Yang, Z. \& Rannala, B. 2010. Bayesian species delimitation using multilocus sequence data. Proc. Natl. Acad. Sci. U.S.A. 107: 92649269. https://doi.org/10.1073/pnas.0913022107

Zhang, J., Kapli, P., Pavlidis, P. \& Stamatakis, A. 2013. A general species delimitation method with applications to phylogenetic placements. Bioinformatics 29: 2869-2876. https://doi.org/10.1093/ bioinformatics/btt499

Zolan, M. \& Pukkila, P. 1986. Inheritance of DNA methylation in Coprinus cinereus. Molec. Cell. Biol. 6: 195-200. 
Appendix 1. Taxon sampling for Peltigera sect. Peltigera and sect. Retifoveatae and five outgroup species, with associated voucher information, including mycobiont and cyanobiont sequences. Newly generated sequences are indicated in bold. An extended version is available in the Electronic Supplement as Table S1 and includes clade numbers, DNA id and (when applicable) the cyanobiont $r b c L X$ phylogroup.

Peltigera aphthosa (L.) Willd., U.S.A.: AK, Miadlikowska s.n. (OSC), -, MH771012, MH770256, MH770507, MH770009, -; P. antarctica C.W.Dodge, Chile: Region XII, Goffinet 6837 (CONN), MH758271, MH770824, MH770051, MH770300, MH769795, KX923110; P. antarctica C.W.Dodge, Chile: Region XI, Rubio 4073 (H), MH758272, MH770825, MH770052, MH770301, MH769796, MH770563; P. antarctica C.W.Dodge, South Orkney Islands, Lindsay $935(\mathrm{H})$, MH758275, MH770826, -, -, -, -; P. antarctica C.W.Dodge, Argentina, Stenroos 1954 (H), MH758270, -, MH770053, MH770302,-, MH770564; $\boldsymbol{P}$. antarctica C.W.Dodge, Chile: Region XII, Goffinet 10521-2 (CONN), MH758273, MH770827, MH770054, MH770303, MH769797, MH770565; P. antarctica C.W.Dodge, Chile: Region X, Wheeler \& Nelson 5893 (CONC), MH758274, MH770828, MH770055, MH770304, MH769798, MH770566; P. aubertii C.W.Dodge, Chile: Region XII, Stenroos 2459 (H), MH758229, MH770812, -, -, -, -; P. aubertii C.W.Dodge, Chile: Region XII, Goffinet 10559 (CONN), MH758230, MH770813, MH770013, MH770259, MH769760, MH770512; P. aubertii C.W.Dodge, Chile: Region XII, Shaw 18004 (DUKE), MH758231, -,-,-,-, MH770513; $\boldsymbol{P}$. aubertii C.W.Dodge, Chile: Region XII, Goffinet 10558 (CONN), MH758232,-,-,-,-, MH770514; P. aubertii C.W.Dodge, Chile: Region X, Wheeler \& Nelson 3191 (CONC), MH758233, MH770814, MH770014, MH770260, MH769761, MH770515; P. aubertii C.W.Dodge, Chile: Region X, Wheeler \& Nelson 5870 (CONC), MH758234, -, MH770015, MH770261, -, MH770516; P. austroamericana Zahlbr./fibrilloides (Gyeln.) Vitik. 1, Costa Rica, Miadlikowska \& Lutzoni 23.03.03-10 (DUKE 0357975), MH758454, MH770954, -, -, -, MH770742; P. austroamericana Zahlbr./fibrilloides (Gyeln.) Vitik. 1, Colombia, Dumont \& al. $4066(\mathrm{H})$, MH758440, MH770955, MH770185, MH770444, MH770743; P. austroamericana Zahlbr./fibrilloides (Gyeln.) Vitik. 2, Mexico, Herrera-Campos 13380 (MEXU), MH758442, MH770956, MH770186, MH770445, MH769940, MH770744; P. austroamericana Zahlbr./fibrilloides (Gyeln.) Vitik. 2, Mexico, Herrera-Campos 13381 (MEXU), MH758462, MH770957, MH770187, MH770446, MH769941, MH770745; P. austroamericana Zahlbr./fibrilloides (Gyeln.) Vitik. 3, Peru, Lutzoni 05.23.212-7 (DUKE 0357974), MH758465, MH770958, MH770188, MH770447, MH769942, MH770746; P. austroamericana Zahlbr./fibrilloides (Gyeln.) Vitik. 3, Peru, Rivas Plata \& Ramos s.n. (DUKE 0357973), MH758466, MH770959, MH770189, MH770448, MH769943, MH770747; P. austroamericana Zahlbr./ fibrilloides (Gyeln.) Vitik. 3, Colombia, Lücking 33628 (UDBC), MH758451, MH770960, MH770190, MH770449, MH769944, MH770748; P. austroamericana Zahlbr./fibrilloides (Gyeln.) Vitik. 3, Ecuador, Truong 3975 (DUKE 040152), MH758460, MH770961, MH770191, MH770450, MH769945, MH770749; P. austroamericana Zahlbr./fibrilloides (Gyeln.) Vitik. 4, Costa Rica, Miadlikowska \& Lutzoni 23.03.03-8 (DUKE 0401856), MH758453, MH770962, MH770192, MH770451, MH769946, MH770750; P. austroamericana Zahlbr./fibrilloides (Gyeln.) Vitik. 4, Costa Rica, Miadlikowska \& Lutzoni 23.03.03-15 (DUKE 0401855), MH758455, MH770963,-,-,-, MH770742; P. austroamericana Zahlbr./fibrilloides (Gyeln.) Vitik. 4, Costa Rica, Miadlikowska \& Lutzoni 23.03.03-21 (DUKE 0401857), MH758456, MH770964, -, -, -, MH770743; P. austroamericana Zahlbr./fibrilloides (Gyeln.) Vitik. 4, Costa Rica, Miadlikowska \& Lutzoni 22.03.03-37 (DUKE 0401853), MH758457, MH770965,-,-, -, MH770744; P. austroamericana Zahlbr./ fibrilloides (Gyeln.) Vitik. 4, Mexico, Herrera-Campos 137 (MEXU), MH758461, MH770966, MH770193, MH770452, MH769947, MH770745; P. austroamericana Zahlbr./fibrilloides (Gyeln.) Vitik. 4, Costa Rica, Miadlikowska \& Lutzoni 22.03.03-21 (DUKE 0401854), MH758458, -, -, -, -, -; P. austroamericana Zahlbr./fibrilloides (Gyeln.) Vitik. 5, Brazil, Miadlikowska \& al. s.n. (CGMS 34505), MH758438, MH770967, MH770194, MH770453, MH769948, MH770751; P. austroamericana Zahlbr./fibrilloides (Gyeln.) Vitik. 5, Peru, Miadlikowska s.n. (DUKE), MH758443, -,-,-,-, MH770752; P. austroamericana Zahlbr./fibrilloides (Gyeln.) Vitik. 5, Brazil, Canez 10234 (CGMS 35044), MH758447, MH770968, MH770195, MH770454, MH769949, MH770753; P. austroamericana Zahlbr./fibrilloides (Gyeln.) Vitik. 5, Brazil, Magain s.n. (CGMS 34427), MH758448, MH770969, MH770196, MH770455, MH769950, MH770754; P. austroamericana Zahlbr./fibrilloides (Gyeln.) Vitik. 5, Ecuador, Kalb 18391 (DUKE), MH758459, MH770970, MH770197, -, MH769951, MH770755; P. austroamericana Zahlbr./fibrilloides (Gyeln.) Vitik. 5, Brazil, Miadlikowska s.n. (CGMS 34409), MH758449, MH770756; P. austroamericana Zahlbr./fibrilloides (Gyeln.) Vitik. 5, Bolivia, Kukwa 8504 (ex UGDA-L-17700, DUKE dupl. 0401859), MH758445, MH770971, MH770198, MH770456, MH769952, MH770757; P. austroamericana Zahlbr./fibrilloides (Gyeln.) Vitik. 5, Bolivia, Truong 2826 (DUKE 0401858), MH758446, MH770972, MH770199, MH770457, MH769953, -; P. austroamericana Zahlbr./fibrilloides (Gyeln.) Vitik. 5, Peru, Lutzoni 05.23.2012-13 (DUKE 0357966), MH758464,-,-,-,-,-; P. austroamericana Zahlbr./fibrilloides (Gyeln.) Vitik. 6, Peru, Bennett s.n. (WIS), MH758444, MH770973, MH770200, MH770458, MH769954, MH770758; P. austroamericana Zahlbr. s.l., Colombia, Lücking 33653 (UDBC), MH758450,

-, MH770733; P. austroamericana Zahlbr. s.1., Mexico, Barcenas-Penas 1233 (MEXU), MH758441, -, -, -, -, MH770734; P. austroamericana Zahlbr. s.1., Peru, Miadlikowska s.n. (DUKE 0357967), MH758463,-,-,-,-, MH770735; P. austroamericana Zahlbr. s.1., Brazil, Miadlikowska \& al. s.n. (CGMS 34490), MH758439, -, -,-,-, MH770736; P. austroamericana Zahlbr. s.1., Peru, Rivas Plata \& Ramos s.n. (DUKE 0357971), -,-,-,-,-, MH770737; P. austroamericana Zahlbr. s.1., Colombia, Lücking 33631 (UDBC), MH758452, -, -, -, -, MH770738; P. canina (L.) Willd. 1, Canada: BC, O'Brien 020708-4-5-1 (DUKE), FJ708890, -, MH770201, MH770459, MH769955, KC437709; P. canina (L.) Willd. 1, Canada: BC, O'Brien 030611-0-0-6 (DUKE), FJ708881, FJ709294, MH770202, MH770460, MH769956,-; P. canina (L.) Willd. 1, Iceland, Miadlikowska \& Lutzoni s.n. (DUKE 0357980), KU954063, KM005803, MH770203, MH770461, MH769957, KX923097; P. canina (L.) Willd. 1, Russia: Krasnoyarsk Territory, Miadlikowska \& Lutzoni s.n. (DUKE 0357997), MH758475, MH770974,--,-, MH769958, MH770759; P. canina (L.) Willd. 1, Russia: Krasnoyarsk Territory, Miadlikowska \& Lutzoni s.n. (DUKE 0401822), MH758475,-,-,-,-, MH770760; P. canina (L.) Willd. 1, Papua New Guinea, Sérusiaux s.n. (LG), -, -, -, -, -, MH770761; P. canina (L.) Willd. 1, Russia: Krasnoyarsk Territory, Miadlikowska \& Lutzoni s.n. (DUKE 0401836), MH758478, MH770975, MH770204, MH770462, MH769959, MH770762; P. canina (L.) Willd. 1, China: Yunnan, Miadlikowska s.n. (DUKE 0401862), MH758470, MH770976, MH770205,-, MH769960, MH770763; P. canina (L.) Willd. 1, Austria, Hafellner \& Miadlikowska s.n. (DUKE 0130114), MH758467, MH770977, MH770206, MH770463, MH769961, MH770764; P. canina (L.) Willd. 1, France: Corsica, Vust 6421 (G), MH758471, MH770978, MH770207, MH770464, MH769962, MH770765; P. canina (L.) Willd. 1, Switzerland, Vust 279 (G), MH758479, MH770979, MH770208, MH770465, MH769963, MH770766; P. canina (L.) Willd. 1, France: Corsica, Vust 6412 (G), MH758473, MH770980, MH770209, MH770466, MH769964, MH770767; P. canina (L.) Willd. 1, Papua New Guinea, Aptroot 32283 (H), -, , MH770768; P. canina (L.) Willd. 1, Papua New Guinea, Sérusiaux s.n. (LG), MH758472, MH770981, MH770210,-,-,--; P. canina (L.) Willd. 1, The Netherlands, Aptroot 53752 (ABL), MH758474, MH770982, MH770211, MH770467, MH769965, MH770769; P. canina (L.) Willd. 1, Canada: BC, Goward 5305 (UBC), MH758469, MH770983, MH770212, MH770468, MH769966, MH770770; P. canina (L.) Willd. 2, Canada: BC, O'Brien 020708-31-5-2 (DUKE), FJ708874, FJ709304, MH770213,-, MH769967,-; P. canina (L.) Willd. 2, Canada: BC, O'Brien 020708-70-5-2 (DUKE), FJ708876, FJ709303,-,-,-,-; P. canina (L.) Willd. 2, Canada: BC, O'Brien 020708-70-1-3 (DUKE), FJ708875, FJ709304, MH770216, MH770469, MH769968, -; P. canina (L.) Willd. 2, Iceland, Miadlikowska \& Lutzoni 08.08.10-3 (DUKE 0401829), KU954062, KM005821, MH770217, MH770470, MH769969, KX923096; P. canina (L.) Willd. 2, U.S.A.: NC, Miadlikowska \& Lutzoni s.n. (DUKE 0357998), MH758480,-, MH770218,-,-, MH770771; P. canina (L.) Willd. 2, U.S.A.: NC, Miadlikowska \& Lutzoni s.n. (DUKE 0401827), -, -, MH770219, -, -, MH770772; P. canina (L.) Willd. 2, U.S.A.: NC, Miadlikowska \& Lutzoni s.n. (DUKE 0358000), MH758481,-, MH770220,-,-, MH770773; P. canina (L.) Willd. 2, U.S.A.: NC, Lutzoni \& Miadlikowska s.n. (DUKE 0401828), MH758475, -, MH770221, -, -, KX923113; P. canina (L.) Willd. 2, U.S.A.: MO, Buck 48584 (NY 00729928), MH758482, MH770222,-,-, MH770774; P. canina (L.) Willd. 2, U.S.A.: NC, Miadlikowska \& Lutzoni s.n. (DUKE 0357999), MH758483, MH770984, MH770223, MH770471, MH769970, MH770775; P. canina (L.) Willd. 2, U.S.A.: NC, Hollinger 2731 (UBC), MH758484, MH770985, MH770224, MH770472, MH769971, MH770776; P. canina (L.) Willd. 2, U.S.A.: OK, Buck 46463 (DUKE 0138952), MH758485, MH770986, MH770216, MH770473, MH769972, MH770777; P. canina (L.) Willd. 2, U.S.A.: NC, Goffinet 4755 (DUKE), -, MH770987, MH770217, MH770474, -, MH770778; P. canina (L.) Willd. 2, Canada: AB, Miadlikowska \& Lutzoni s.n. (DUKE 0401817), MH758468, MH770988, MH770218,-, MH769973, MH770779; P. canina (L.) Willd. 2, U.S.A.: UT, Truong 3996 (DUKE 0401865), MH758486, MH770989, MH770219, MH770475, MH769974, MH770780; P. canina (L.) Willd. 2, U.S.A.: 
CO, Leavitt SDL-CO-13 (BRY-C), MH758487, MH770990, MH770220,-, MH769975, MH770781; P. canina (L.) Willd. 2, U.S.A.: MI, Miadlikowska \& Lutzoni s.n. (DUKE 0401826), MH758488, MH770991, MH770221, MH770476, MH769976, MH770782; P. canina (L.) Willd. 2, U.S.A.: TN, Chen \& Gajdeczka s.n. (DUKE 0401818), MH758489, MH770992, MH770222, MH770477, MH769977, MH770783; P. castanea Goward \& al., Russia: Krasnoyarsk Territory, Miadlikowska \& Lutzoni s.n. (DUKE 0357981), MH758239, -, MH770029, MH770279, -, MH770534; P. cinnamomea Goward, Canada: BC, O'Brien 030611-0-0-4 (DUKE), FJ708912, FJ709306, MH770129, MH770394, MH769886, -; P. cinnamomea Goward, Canada: BC, O'Brien 040605-11-2 (DUKE), FJ708913, FJ709307, MH770130, MH770395, MH769887, -; P. cinnamomea Goward, Canada: BC, O'Brien 040605-12-3 (DUKE), FJ708911, FJ709305, -,-,-,-; P. cinnamomea Goward, Canada: BC, Goward s.n. (UBC), MH758379, KX880187, MH770131, MH770396, MH769888, MH770687; P. continentalis Vitik., China: Ningxia, Niu 12-0087 (Ningxia Univ.), MH758236, MH770820, MH770026, MH770276, MH769773, MH770531; P. continentalis Vitik., Russia: Krasnoyarsk Territory, Miadlikowska \& Lutzoni s.n. (DUKE 0357965), MH758237, KM005807, MH770027, MH770277, MH769774, MH770532; P. continentalis Vitik., Russia: Krasnoyarsk Territory, Miadlikowska \& Lutzoni s.n. (DUKE 0357969), MH758238, MH770821, MH770028, MH770278, MH769775, MH770533; P. degenii Gyeln. 1, Norway, Magain s.n. (LG), MH758402, KM005828, MH770136, MH770400, MH769890, MH770692; P. degenii Gyeln. 1, Norway, Magain s.n. (LG), MH758403, MH770913, MH770137, MH770401, MH769891, MH770693; P. degenii Gyeln. 1, Norway, Magain s.n. (LG), MH758404, MH770914, MH770138, MH770402, MH769892, MH770694; P. degenii Gyeln. 1, Austria, Hafellner \& Miadlikowska s.n. (DUKE 0032160), MH758399, MH770915, MH770139, MH770403, MH769893, MH770695; P. degenii Gyeln. 1, France, Magain s.n. (DUKE 0401808), MH758400, MH770916, MH770140, MH770404, MH769894, -; P. degenii Gyeln. 1, France, Magain s.n. (DUKE 0401807), MH758401, MH770917, MH770141, MH770405, MH769895, MH770696; P. degenii Gyeln. 1, Ukraine, Dymytrova \& Naumovich 183 (KW 69499), MH758405, MH770918, MH770142, MH770406, MH769896, -; P. degenii Gyeln. 1, Ukraine, Dymytrova \& Savchyn 22 (KW), MH758406, MH770919, MH770143, MH770407, MH769897, MH770697; P. degenii Gyeln. 2a, Canada: BC, O'Brien 040605-10-3 (DUKE), FJ709030, FJ709315, MH770144, MH770408, MH769898, -; P. degenii Gyeln. 2a, Canada: QC, Darnajoux s.n. (DUKE 0401806), MH758410, MH770920, MH770145, -, MH769899, MH770698; P. degenii Gyeln. 2a, Russia: Khabarovsk Territory, Miadlikowska \& Lutzoni s.n. (DUKE 0401824), MH758413, MH770921, MH770146, MH770409, MH769900, MH770699; P. degenii Gyeln. 2a, Canada: BC, Goward 02-380 (ACC L41345), MH758407, MH770922, MH770147, -, MH769901, MH770700; P. degenii Gyeln. 2a, Canada: QC, Roy 11-5914C (QFA 0595636), MH758411, -, MH770148, -, MH769902, MH770701; P. degenii Gyeln. 2a, Canada: QC, Miadlikowska \& Lutzoni 07.04.03-1A (DUKE 0401805), MH758412, MH770923, MH770149,--, MH769903, MH770702; P. degenii Gyeln. 2a, Japan: Hokkaido, Thor 13948 (UPS 392189), MH758409, MH770924, MH770150, MH770410, MH769904, MH770703; P. degenii Gyeln. 2b, Japan: Honshu, Thor 11963 (UPS 395916), MH758408, -, MH770151, MH770411, MH769905, MH770704; P. degenii Gyeln. 3a, Russia: Sakhalin, Tchabanenko s.n. (SAKH 3083), MH758419, MH770925, MH770152, MH770412, MH769906, MH770705; P. degenii Gyeln. 3a, Russia: Sakhalin, Tchabanenko s.n. (SAKH 3081), MH758420, MH770926, MH770153, MH770413, MH769907, MH770706; P. degenii Gyeln. 3b, China: Jilin, Sohrabi 16474 (H), MH758414, MH770927, MH770154, MH770414, MH769908, MH770707; P. degenii Gyeln. 3b, China: Jilin, Sohrabi 16417 (H), MH758415, MH770928, MH770155, MH770415, MH769909, MH770708; P. degenii Gyeln. 3b, Russia: Kurile Islands, Abrahamczyk 15 (H), MH758416, MH770929, MH770156, MH770416, MH769910, MH770709; P. degenii Gyeln. 3c, Japan: Honshu, Sérusiaux s.n. (LG), MH758417, MH770930, MH770157, MH770417, MH769911, MH770710; P. degenii Gyeln. 3c, Japan: Honshu, Ohmura \& al. s.n. (DUKE 0188055), MH758418, MH770931, MH770158, MH770418, MH769912, MH770711; P. didactyla (With.) J.R.Laundon 1, Belgium, Magain s.n. (DUKE 0357985), MH758240, -, MH770030, MH770280, MH769777, MH770535; P. didactyla (With.) J.R.Laundon 1, Norway, Magain s.n. (LG), MH758244, -, MH770031, MH770281, MH769778, -; P. didactyla (With.) J.R.Laundon 1, New Zealand, Campbell Island, Harris 5326 (NY), MH758241, -, -, -, -, MH770536; P. didactyla (With.) J.R.Laundon 1, U.S.A.: UT; Truong 3991 (DUKE 0401851), MH758246, -, MH770032, MH770282, MH769779, MH770537; P. didactyla (With.) J.R.Laundon 2, China: Sichuan, Wang 10-31861 (KUN), MH758243, -, MH770033, MH770283, -, MH770538; P. didactyla (With.) J.R.Laundon 2, Russia: Khabarovsk, Miadlikowska \& Lutzoni. s.n. (DUKE 0357977), -,-,-,-,-, MH770539; P. didactyla (With.) J.R.Laundon 3, U.S.A.: PA, Lendemer 13269 (DUKE 0154812), MH758245, -, -, -, MH769776, MH770540; P. didactyla (With.) J.R.Laundon 3, Canada: BC, Goward s.n. (DUKE 0017197), MH758242, -, MH770034, -, -, MH770541; P. erioderma Vain. 1, Papua New Guinea, Sérusiaux s.n. (LG), MH758380, MH770911, MH770132, MH770397, MH769889, MH770688; P. erioderma Vain. 2, Papua New Guinea, Sérusiaux 14107 (LG), MH758381, -, MH770133, MH770398, -, MH770689; P. evansiana Gyeln., U.S.A.: NC, Miadlikowska \& al. s.n. (DUKE 0401810), MH758490,--,-,-, MH770784; P. evansiana Gyeln., U.S.A.: PA, Lendemer 17422 (NY 01105603), MH758491, KM005808, -, MH770478, MH769978, MH770785; P. evansiana Gyeln., U.S.A.: PA, Lendemer 17753 (NY 01103610), MH758492, KM005809,-,-,-,-;P. evansiana Gyeln., U.S.A.: NC, Miadlikowska \& Lutzoni s.n. (DUKE 0357991), MH758493, MH770993, MH770225, MH770479, MH769979, MH770786; P. evansiana Gyeln., U.S.A.: MI, Miadlikowska \& al s.n. (DUKE 0401813), MH758494, MH770994, MH770226, MH770480, MH769980, MH770787; P. extenuata (Nyl. ex Vain.) Lojka 1, Russia: Kamchatka, Himelbrandt s.n. (H), MH758251, -

MH770542; P. extenuata (Nyl. ex Vain.) Lojka 1, Canada: BC, Goward 10-74 (UBC), MH758250,-,-,-,-, MH770543; P. extenuata (Nyl. ex Vain.) Lojka 1, Chile: Region XI, Wheeler \& Nelson 6297 (CONC), MH758247, -, MH770035, MH770284, MH769780, MH770544; P. extenuata (Nyl. ex Vain.) Lojka 1, Russia: Krasnoyarsk Territory, Miadlikowska \& Lutzoni s.n. (DUKE 0357970), MH758252, -, MH770036, MH770285, MH769781, MH770545; P. extenuata (Nyl. ex Vain.) Lojka 1, U.S.A.: MI, Miadlikowska \& Lutzoni s.n. (DUKE 0357972), MH758253, -, MH770037, MH770286, MH769782, MH770546; P. extenuata (Nyl. ex Vain.) Lojka 1, U.S.A.: NY, Harris 53633 (DUKE 0138925), MH758254, -, MH770038, MH770287, MH769783, MH770547; P. extenuata (Nyl. ex Vain.) Lojka 2, Colombia, Lücking 33627 (UDBC), MH758248, -, MH770039, MH770288, MH769784, MH770548; P. extenuata (Nyl. ex Vain.) Lojka 2, Ecuador: Galapagos, Spielmann 10611 (CDS-51978), MH758249, -, MH770040, MH770289, MH769785, MH770549; P. fimbriata Vitik. \& al., Papua New Guinea, Sérusiaux \& al. 2009, FJ527272, -, -, -, -, -; P. fimbriataVitik. \& al., Papua New Guinea, Sérusiaux \& al. 2009, FJ527273,-,-,-,-, -; P. fimbriata Vitik. \& al., Papua New Guinea, Sérusiaux \& al. 2009, FJ527274 , -, -, -, -, -; P. friesiorum Gyeln., Brazil, Marcelli 25096 (H), MH758323,-,-,-,-, MH770621; P. friesiorum Gyeln., Brazil, Miadlikowska \& al. s.n. (CGMS 34533), MH758324, -, MH770622; P. friesiorum Gyeln., Brazil, Miadlikowska \& al. s.n. (CGMS 34582), MH758325, -, -, -, -, MH770623; P. friesiorum Gyeln., Brazil, Miadlikowska \& al. s.n. (CGMS 34531), MH758326,-,-,-, MH770624; P. friesiorum Gyeln., Brazil, Miadlikowska \& al. s.n. (CGMS 34575), MH758327,-,-,-,-, MH770625; P. friesiorum Gyeln., Brazil, Miadlikowska \& al. s.n. (CGMS 34539), MH758328, MH770870, MH770094, MH770351, MH769848, MH770626; P. friesiorum Gyeln., Peru, Miadlikowska s.n. (DUKE 0401814), MH758337, MH770872, MH770096, MH770353, MH769850, MH770628; P. friesiorum Gyeln., Brazil, Miadlikowska \& al. s.n. (CGMS 35043), MH758330,-,-,-, -, MH770629; P. friesiorum Gyeln., Brazil, Lutzoni \& al. s.n. (CGMS 34570), MH758331, MH770873,-,-,-, MH770630; P. friesiorum Gyeln., Brazil, Miadlikowska \& al. s.n. (CGMS 34587), MH758332, MH770874, MH770097, MH770354, MH769851, MH770631; P. friesiorum Gyeln., Brazil, Miadlikowska \& al. s.n. (CGMS 35050), MH758333, -,

MH770632; P. friesiorum Gyeln., Brazil, Miadlikowska \& al. s.n. (CGMS 35054), MH758334, -, -, -, -, MH770633; P. friesiorum Gyeln., Brazil, Spielmann \& al. 9935 (CGMS 35048), MH758335, MH770875, MH770098, MH770355, MH769852, MH770634; P. friesiorum Gyeln., Bolivia, Kukwa 8465 (ex UGDA-L-17699 DUKE dupl.), MH758322, MH770876, MH770099, MH770356, MH769853, MH770635; P. frigida R. Sant., Chile: Region XI, Rubio 4064 (H), MH758221, -, -, -, -, MH770517; P. frigida R.Sant., Chile: Region XII, Stenroos 2192 (H), MH758222, MH770815, -, MH770262, MH769762, MH770518; P. frigida R. Sant., Argentina, Stenroos 2158 (H), MH758220, MH770816, MH770016, MH770263, MH769763, MH770519; P. frigida R.Sant., Chile: Region XII Goffinet 6643-1 (CONN),-, -, -,-,-, MH770520; P. frigida R.Sant., Chile: Region XII, Shaw 18024 (DUKE), MH758223,-, MH770017, MH770264, MH769764, MH770521; P. “fuscopraetextata”, Canada: BC, O'Brien 020708-62-5-3 (DUKE), FJ708893, FJ709317, MH770175, MH770436, MH769930, -; P. “fuscopraetextata”, Canada: BC, O’Brien 020708-31-5-3 (DUKE), FJ708892, FJ709316, MH770176, MH770437, MH769931, -; P. “fuscopraetextata”, Canada: BC, Goward 06-1538B (UBC), MH758507, MH770947, MH770177, -, MH769932, MH770723; 
P. “fuscopraetextata”, Argentina, Stenroos 2235 (H), MH758500, MH770948, MH770178, MH770438, MH769933, MH770724; P. “fuscopraetextata”, Chile: Region XI, Rubio 4067 (H), MH758503, MH770949, MH770179, MH770439, MH769934, MH770725; P. “fuscopraetextata”, Argentina, Tibell 17537 (UPS 40375), MH758501,

MH770726; $\boldsymbol{P}$. “fuscopraetextata”, Chile: Region XII, Tibell 17788 (UPS 45291), MH758504, MH770727; P. “fuscopraetextata”, Argentina, Kalb s.n. (DUKE 0401830), MH758502, MH770950, MH770180, -, MH769935, MH770728; P. "fuscopraetextata”, Chile: Region XII, Goffinet 10490 (CONN), MH758505, MH770951, MH770181, MH770440, MH769936, MH770729; P. “fuscopraetextata”, Chile: Region XII, Wheeler \& Nelson 6528 (CONC), MH758506, MH770952, MH770182, MH770441, MH769937, MH770730; P. “fuscopraetextata”, U.S.A.: OR, McCune 30990 (OSC), MH758508,-, MH770183, MH770442, MH769938, MH770731; P. “fuscopraetextata”, U.S.A.: UT, Truong 4016 (DUKE 0401863), MH758509, MH770953, MH770184, MH770443, MH769939, MH770732; P. granulosa Sérus. \& al., Papua New Guinea, Sérusiaux 15150 (LG), MH758338, MH770877, MH770100, MH770357, MH769854, MH770637; $\boldsymbol{P}$. hymenina (Ach.) Delise, Canada: NL, Lendemer 10397 (H), -, KX880099, MF947046, MF946937, MF946831 , -; P. isidiophora L.F.Han \& S.Y.Guo, China: Hebei, Han \& al. 2015, KJ095108, -,

-; P. isidiophora L.F.Han \& S.Y.Guo, China: Hebei, Han \& al. 2015, KJ095106, -, -, -, -, -; P. isidiophora L.F.Han \& S.Y.Guo, China: Hebei, Han \& al. 2015, KJ095107,-,-,-,-,--; P. islandica T.Goward \& S.S.Manoharan-Basil, Iceland, Andresson 332 (AMNH), KJ413245, KJ413189, MH770227, MH770481, MH769981, -; P. islandica T.Goward \& S.S.Manoharan-Basil, Iceland, Manoharan-Basil 355 (AMNH), KJ413244, KJ413192, MH770228, MH770482, MH769982, -; P. kristinssonii Vitik., Canada: BC, O'Brien 020708-62-1-5 (DUKE), FJ708952, FJ709345, MH770018, MH770265, -, -; P. kristinssonii Vitik., Canada: BC, O'Brien 020708-70-5-9 (DUKE), FJ708944, FJ709341, MH770019, MH770266, MH769765, -; P. kristinssonii Vitik., Canada: BC, Goward 11-16 (UBC), MH758224, -, MH770020, MH770267, MH769766, MH770522; P. kristinssonii Vitik., Canada: QC, Gagnon s.n. (QFA-0594989), MH758225, KM005796, MH770021, MH770268, MH769767, MH770523; P. laciniata (G.Merr.) Gyeln. 1, Costa Rica, Miadlikowska \& Lutzoni 23-0303-9 (DUKE 0401843), MH758343, KM005815, MH770101, MH770358, MH769855, MH770638; P. laciniata (G.Merr.) Gyeln. 1, Costa Rica, Miadlikowska \& Lutzoni 23-03-03-23 (DUKE 0401841), MH758344, -, -, -, -, MH770639; P. laciniata (G.Merr.) Gyeln. 1, Bolivia, Kukwa 9194 (ex UGDA-L-17705, DUKE dupl. 0401840), MH758339,-,-,-,-, MH770640; P. laciniata (G.Merr.) Gyeln. 1, Ecuador, Yanez-Anabaca 2556 (CDF), MH758347, MH770878, MH770102, MH770359, MH769856, MH770641; P. laciniata (G.Merr.) Gyeln. 1, Colombia, Lücking 33693 (UDBC), MH758341, MH770879, MH770103, MH770360, MH769857, MH770642; P. laciniata (G.Merr.) Gyeln. 1, Colombia, Coca and Patino s.n. (FAUC), MH758342, -,-,-,-, MH770643; P. laciniata (G.Merr.) Gyeln. 1, Ecuador, Truong 3956 (DUKE 0401842), MH758350, MH770880, MH770104, MH770361, MH769858, MH770644; P. laciniata (G.Merr.) Gyeln. 1, Ecuador, Truong 3958 (DUKE 0401838), MH758351,-,-,-,-, MH770645; P. laciniata (G.Merr.) Gyeln. 2, Bolivia, Kukwa 9562 (ex UGDA-L-17724, DUKE dupl. 0401839), MH758340, MH770881, MH770105, MH770362, MH769859, MH770646; P. lepidophora (Vain.) Bitter 1, Canada: BC, Goward s.n. (UBC), MH758354, KM005810, -, MH770363, MH769860, MH770647; P. lepidophora (Vain.) Bitter 1, Iceland, Kristinsson 49244 (AMNH LA-29491), MH758353, MH770882, MH770106, MH770364, MH769861, MH770648; P. lepidophora (Vain.) Bitter 1, U.S.A.: NY, Lendemer 12047 (NY 0154474), MH758355, MH770883, MH770107, MH770365, MH769862, MH770649; P. lepidophora (Vain.) Bitter 2, U.S.A.: AK, Miadlikowska \& Lutzoni s.n. (DUKE 0357968), MH758352, MH770884, MH770108, MH770366, MH769863, MH770650; P. lepidophora (Vain.) Bitter 2, China: Ningxia, Niu 12-0085 (Ningxia Univ.), MH758356,-,-,-,-, MH770651; P. malacea (Ach.) Funck, U.S.A.: AK, Berg 3072 (UBC),-, MH771011, MH770255, MH770506,-,-; P. membranacea (Ach.) Nyl. 1, Canada: BC, O'Brien 040605-10-1-1 (DUKE), FJ709034, FJ709434, MH770159, MH770419, MH769913, -; P. membranacea (Ach.) Nyl. 1, Canada: BC, O'Brien 040605-1-2 (DUKE), KC437646, FJ709435, -, -, -, -; P. membranacea (Ach.) Nyl. 1, Canada: BC, O'Brien 020708-0-9-1 (DUKE), FJ709031, FJ709431, MH770160, MH770420, MH769914, -; P. membranacea (Ach.) Nyl. 1, Iceland, Miadlikowska \& Lutzoni s.n. (DUKE 0357981), MH758426, KM005814, MH770161, MH770421, MH769915, KX923102; P. membranacea (Ach.) Nyl. 1, Spain, Vare L1807 (H), MH758431, MH770932, MH770162, MH770422, MH769916, MH770712; P. membranacea (Ach.) Nyl. 1, Norway, Magain s.n. (LG), MH758428, MH770933, -, MH770423, MH769917, MH770713; P. membranacea (Ach.) Nyl. 1, Canada: BC, Truong s.n. (DUKE 0401833), MH758421, MH770934, MH770163, MH770424, MH769918, MH770714; P. membranacea (Ach.) Nyl. 1, Portugal, Vust 3084 (G), MH758429, MH770935, MH770164, MH770425, MH769919, MH770715; P. membranacea (Ach.) Nyl. 1, France: Corsica, Vust 6423 (G), MH758422, MH770936, MH770165, MH770426, MH769920, MH770716; P. membranacea (Ach.) Nyl. 1, France: Corsica, Vust 6405 (G), MH758423, MH770937, MH770166, MH770427, MH769921, -; P. membranacea (Ach.) Nyl. 1, France, Magain s.n. (DUKE 0401819), MH758424, MH770938, MH770167, MH770428, MH769922, P. membranacea (Ach.) Nyl. 1, Iceland, Heidmarsson 2746 (AMNH LA-31754), MH758427, MH770939, MH770168, MH770429, MH769923, MH770717; P. membranacea (Ach.) Nyl. 1, Greenland, Vust 6432 (G), MH758425,-,-,-,-,-; P. membranacea (Ach.) Nyl.2, Russia: Khabarovsk Territory, Miadlikowska \& al. s.n. (DUKE 0401812), MH758430, MH770940, MH770169, MH770430, MH769924, -; P. montis-wilhelmii Sérus. \& al. 1, Papua New Guinea, Sérusiaux s.n. (LG), MH758382, MH770912, MH770134, MH770399, -, MH770690; P. montis-wilhelmii Sérus. \& al. 2, Papua New Guinea, Sérusiaux 13984 (LG), MH758383, -, MH770135, -, -, MH770691; P. “neocanina” 1, Canada: BC, O’Brien 020708-0-5-1 (DUKE), FJ708922, FJ709443,

-; P. “neocanina” 1, Canada: BC, O'Brien 020708-66-5-2 (DUKE), FJ708916, FJ709444,-,-,-,-; P. “neocanina” 1, Canada:BC, O'Brien 020708-66-9-1 (DUKE), FJ708917, FJ709438, -, MH770382, -, -; P. “neocanina” 1, Canada: BC, O’Brien 040605-2-2 (DUKE), KC437635, MH770899, MH770120, MH770383, MH769875, KC437877; P. “neocanina” 1, U.S.A.: NM, Hollinger 2460 (UBC), MH758395, MH770900, -, -, -, KX923107; P. “neocanina” 1, Canada: BC, Goward 11-37 (UBC), MH758388, -, -, -, -, MH770672; P. “neocanina” 1, Canada: MB, Ahti 63078 (H), -, -, -, -, -, MH770673; P. “neocanina” 1, U.S.A.: NM, Hollinger 2402 (UBC), MH758396,-,-,-, MH770674; P. “neocanina” 1, U.S.A.: AK, Miadlikowska \& Lutzoni s.n. (DUKE 0401834), MH758384, MH770901, MH770121, MH770384, MH769876, MH770675; P. “neocanina” 1, U.S.A.: AK, Miadlikowska \& Lutzoni s.n. (DUKE 0401816), -, MH770902, MH770122, MH770385, MH769877, MH770676; P. “neocanina” 1, Canada: BC, Goward 5306 (UBC), MH758385, MH770903, MH770123, MH770386, MH769878, MH770677; P. “neocanina” 2, U.S.A.: NM, Hollinger 2401 (UBC), MH758394, MH770904, MH770124, MH770387, MH769879, KX923106; P. “neocanina” 2, U.S.A.: CO, King L286 (NY), MH758397, MH770905, -, MH770388, MH769880, MH770678; P. “neocanina” 2, U.S.A.: UT, Truong 3995 (DUKE 0401867), MH758398, MH770906, MH770125, MH770389, MH769881, MH770679; P. “neocanina” 3, Russia: Krasnoyarsk Territory, Miadlikowska \& al. s.n. (DUKE 0401821), MH758390, MH770907, -, MH770390, MH769882, MH770680; P. “neocanina” 3, Russia: Krasnoyarsk Territory, Miadlikowska s.n. (DUKE 0401802), MH758391, -, -,-,-, MH770681; P. “neocanina” 3, Russia: Krasnoyarsk Territory, Miadlikowska s.n. (DUKE 0401801), MH758392,-,-,-,-, MH770682; P. “neocanina” 3, Russia: Krasnoyarsk Territory, Miadlikowska s.n. (DUKE 0401803), MH758393, -, -, -, -, MH770683; P. “neocanina” 3, China: Yunnan, Goffinet 9979 (CONN), MH758386, MH770908, MH770126, MH770391, MH769883, MH770684; P. “neocanina” 4, Iceland, Miadlikowska \& Lutzoni 08.08.10-5 (DUKE 0401832), MH758387, MH770909, MH770127, MH770392, MH769884, MH770685; P. “neocanina” 4, Norway, Goward 02-1480 (UBC), MH758389, MH770910, MH770128, MH770393, MH769885, MH770686; $\boldsymbol{P}$. “neorufescens” 1, Mexico, Barcenas-Peña 1229 (MEXU), MH758362, MH770862, MH770088, MH770343, MH769840, MH770614; P. “neorufescens” 1, Costa Rica, Miadlikowska \& al. s.n. (DUKE 0401820), MH758360, MH770863, MH770089, MH770344, MH769841, MH770613; P. “neorufescens" 2, Bolivia, Kukwa 8958 (ex UGDA-L-17704, DUKE dupl. 0401871), MH758357, MH770864, MH770090, MH770345, MH769842, MH770614; P. “neorufescens” 2, Peru, Bennett s.n. (WIS), MH758363, MH770865, MH770091, MH770346, MH769843, MH770615; $P$. “neorufescens” 3, Germany, Sipman 53601 (B 600127393), MH758361, MH770866, MH770092, MH770347, MH769844, MH770616; P. “neorufescens” 4, Canada: AB, Miadlikowska \& Lutzoni s.n. (DUKE 0401823), MH758359, MH770867, MH770093, MH770348, MH769845, MH770617; P. “neorufescens” 5, Canada: YT, Lendemer 28945 (NY 0159332), MH758358, MH770868,-, MH770349, MH769846, MH770618; P. “neorufescens” 6, U.S.A.: UT, Truong 4023 (DUKE 0401868), MH758364, MH770869, -, MH770350, MH769847, MH770619; P. “neorufescens” 6, U.S.A.: OR, Stone 8083.1 (DUKE 0158517), MH758365, -, -, -, MH770620; P. papuana Sérus. \& al., Papua New Guinea, Sérusiaux 13656 (LG), -, -, -, -, -, MH770652; P. papuana Sérus. \& al., Papua New Guinea, Sérusiaux 13655 (LG), MH758366, MH770885, -, MH770367, -, MH770653; P. patagonica Räsänen, Chile: Region XI, Rubio 
Appendix 1. Continued.

4077 (H), MH758227, -, MH770022, MH770269, MH769768, KX923108; P. patagonica Räsänen, Chile: Region XII, Stenroos 2427 (H), MH758228, -, MH770023, MH770270, MH769769, MH770524; P. patagonica Räsänen, Chile: Region XII, Tibell 18056 (UPS 74661), -, -, -, -, -, MH770525; P.patagonica Räsänen, Argentina, Tibell 17450 (UPS 40293), MH758226, -, -, MH770271, -, MH770526; P. polydactylon (Neck.) Hoffm., Norway; Magain s.n. (LG), -, KM005765, KX365489, KX373621, KX373632, -; P. ponojensis Gyeln./monticola Vitik. 1a, U.S.A.: PA, Lendemer 13556 (H), MH758276, MH770833, MH770059, MH770309, MH769803, KX923111; P. ponojensis Gyeln./monticola Vitik. 1a, Canada: BC, Goward 7-187 (UBC), MH758277, , MH770060, -, MH769804, MH770571; P. ponojensis Gyeln./monticola Vitik. 1a, U.S.A.: ME, Harris 55417 (NY 01103744), MH758278, -, MH769806, MH770573; P. ponojensis Gyeln./monticola Vitik. 1a, Canada: MB, Ahti 62717 (H), MH758279, MH770834,-, MH770310, MH769807, MH770574; P. ponojensis Gyeln./monticola Vitik. 1a, U.S.A.: MO, Harris 48184 (NY 01180306), MH758280, MH770835, MH770062, MH770311, MH769808, MH770575; P. ponojensis Gyeln./monticola Vitik. 1a, U.S.A.: OR, McCune 29956 (OSC), MH758281, MH770836, MH770063, MH770312, MH769809, MH770576; P. ponojensis Gyeln./monticola Vitik. 1a, Canada: AB, Miadlikowska \& Lutzoni s.n. (DUKE 0401809), MH758282, MH770837, MH770064, MH770313, MH769810, MH770577; P. ponojensis Gyeln./monticola Vitik. 1a, Canada: BC, Goward 07-234a (UBC), MH758283, MH770061, -, MH769805, MH770572; P. ponojensis Gyeln./monticola Vitik. 1b, U.S.A.: UT, Truong 4045 (DUKE 0401866), MH758284, MH770838, MH770065, MH770314, MH769811, MH770578; P. ponojensis Gyeln./monticola Vitik. 2, Germany, Türk 34539 (H), MH758285, MH770839, MH770315, MH769812, MH770579; P. ponojensis Gyeln./monticola Vitik. 2, France, Magain s.n. (LG), MH758286, MH770840, MH770066, MH770316, MH769813, -; P. ponojensis Gyeln./monticola Vitik. 2, Switzerland, Vust 1687 (G), MH758287, MH770841, MH770067, MH770317, MH769814, MH770580; P. ponojensis Gyeln./monticola Vitik. 3, Canada: BC, O'Brien 020708-62-1-3 (DUKE), FJ709039, FJ709448, -, -,-,-; P. ponojensis Gyeln./ monticola Vitik. 4, U.S.A.: KS, Buck 46381 (NY 881403), MH758288, MH770842, -, MH770318, MH769815, MH770581; P. ponojensis Gyeln./monticola Vitik. 4, U.S.A.: MO, Harris 45692 (NY), MH758289, MH770843, MH770068, MH770319, MH769816, MH770582; P. ponojensis Gyeln./ monticola Vitik. 4, U.S.A.: AR, Buck 46600 (NY 0050439), MH758290, MH770844, MH770069, MH770320, MH769817, MH770583; P. ponojensis Gyeln./monticola Vitik. 4, U.S.A.: AR, Majestyk 8060 (DUKE 0401845), MH758291, MH770845, MH770070, MH770321, MH769818, MH770584; P. ponojensis Gyeln./monticola Vitik. 5a, India: Uttarakhand, Divakar s.n. (MAF), MH758293, MH770846, MH770071, MH770322, MH769819, MH770585; P. ponojensis Gyeln./monticola Vitik. 5a, China: Yunnan, Rosentreter 15 (DUKE 0401846), MH758292, MH770847, MH770072, MH770323, MH769820, MH770586; P. ponojensis Gyeln./monticola Vitik. 5b, Canada: BC, O'Brien 020708-70-1-4 (DUKE), FJ709040, FJ709449, -, MH770324, MH769821, -; P. ponojensis Gyeln./monticola Vitik. 6, China: Ningxia, Niu 12-0015 (Ningxia Univ.), -, -, -, -, -, MH770587; P. ponojensis Gyeln./ monticola Vitik. 6, China: Ningxia, Niu 12-0016 (Ningxia Univ.),-,-,-,-,-, MH770588; P. ponojensis Gyeln./monticola Vitik. 6, Norway, Magain s.n. (LG), MH758294, -, -, MH770325, MH769822, -; P. ponojensis Gyeln./monticola Vitik. 6, China: Yunnan, Miadlikowska s.n. (DUKE 0401815), MH758295, MH770848,--, MH770326, MH769823, MH770589; P. ponojensis Gyeln./monticola Vitik. 7, Norway, Ahti 65831 (H), MH758296, KM005825, MH770073, MH770327, MH769824, KX923104; P. ponojensis Gyeln./monticola Vitik. 7, U.S.A.: CA, McCune 30357 (OSC), MH758297, MH770849, MH770074, MH770328, MH769825, MH770590; P. ponojensis Gyeln./monticola Vitik. 8, U.S.A.: UT, Buck 55054 (NY01136425), MH758298, MH770850, MH770075, MH770329, MH769826, MH770591; P. ponojensis Gyeln./monticola Vitik. 8, Canada: BC, Goward 5302 (UBC), MH758299, MH770851, MH770076, MH770330, MH769827, MH770592; P. ponojensis Gyeln./monticola Vitik. 8, U.S.A.: UT, Truong 4048 (DUKE 040189), MH758300, MH770077, MH770331, MH769828, MH770593; P. ponojensis Gyeln./monticola Vitik. 8, U.S.A.: UT; Truong 4027 (DUKE 0401847), MH758301,

MH770594; P. ponojensis Gyeln./monticola Vitik. 8, U.S.A.: UT, Truong 4001 (DUKE 0401848), MH758302, MH770852, MH770078, MH770332, MH769829, MH770595; P. ponojensis Gyeln./monticola Vitik. 8, U.S.A.: UT, Truong 4011 (DUKE 0401850), MH758303, -,-,-,-, MH770596; P. ponojensis Gyeln./monticola Vitik. 8, Canada: BC, Goward 5300 (UBC), MH758305, MH770853, MH770079, MH770333, MH769830, MH770597; P. ponojensis Gyeln./monticola Vitik. 8, U.S.A.: OR, Hardman s.n. (DUKE 0158521), MH758304, MH770854, MH770080, MH770334, MH769831, MH770598; P. ponojensis Gyeln./monticola Vitik. 9, China: Ningxia, Niu 12-0005 (Ningxia Univ.), MH758307, MH770855, MH770081, MH770335, MH769832, MH770599; P. ponojensis Gyeln./monticola Vitik. 9, China: Ningxia, Niu 12-0004 (Ningxia Univ.), MH758306, -, -, -, -, MH770600; P. ponojensis Gyeln./monticola Vitik. 9, Austria, Türk 37593 (H), MH758310, KM005824, MH770082, MH770336, MH769833, KX923103; P. ponojensis Gyeln./ monticola Vitik. 9, Russia: Dagestan, Urbanavichus 0902150 (H), MH758308, MH770856, -, MH770337, MH769834, MH770590; P. ponojensis Gyeln./ monticola Vitik. 9, Switzerland, Vust s.n. (G), MH758309, MH770857, MH770083, MH770338, MH769835, MH770591; P. ponojensis Gyeln./monticola Vitik. 10a, U.S.A.: CA, Arnold 73 (YOSE 221393), MH758311, MH770829, -, MH770305, MH769799, MH770567; P. ponojensis Gyeln./monticola Vitik. 10a, U.S.A.: CA, McCune 28024 (OSC), MH758313, MH770830, MH770056, MH770306, MH769800, MH770568; P. ponojensis Gyeln./monticola Vitik. 10a, U.S.A.: CA, McCune 29670 (OSC), MH758314, MH770831, MH770057, MH770307, MH769801, MH770569; P. ponojensis Gyeln./ monticola Vitik. 10b, U.S.A.: UT, Truong \& Magain s.n. (DUKE 0357983), MH758312, MH770832, MH770058, MH770308, MH769802, MH770570; P. praetextata (Flörke ex Sommerf.) Zopf, Canada: BC, O'Brien 030611-0-0-5 (DUKE), FJ708905, FJ709451, MH770229, MH770483, MH769983, P. praetextata (Flörke ex Sommerf.) Zopf, Canada: BC, O’Brien 020708-31-9-2 (DUKE), FJ708904, FJ709450, MH770230, MH770484, MH769984, -; P. praetextata (Flörke ex Sommerf.) Zopf, Canada: BC, O'Brien 030611-0-5-8 (DUKE), FJ708906, FJ709452,-,-,-, -; P. praetextata (Flörke ex Sommerf.) Zopf, Serbia, Uotila 48419 (H), MH758520, -, -, -, MH769985, MH770788; P. praetextata (Flörke ex Sommerf.) Zopf, Norway, Magain s.n. (LG), MH758515, KM005829, MH770231, MH770485, MH769986, MH770789; P. praetextata (Flörke ex Sommerf.) Zopf, Norway, Magain s.n. (LG), MH758516, MH770995, MH770232, MH770486, MH769987, -; P. praetextata (Flörke ex Sommerf.) Zopf, Norway, Magain s.n. (LG), MH758517, MH770790; P. praetextata (Flörke ex Sommerf.) Zopf, China: Yunnan, Miadlikowska s.n. (DUKE 0357962), MH758512, -, -, -, -, MH770791; P. praetextata (Flörke ex Sommerf.) Zopf, China: Yunnan, Miadlikowska s.n. (DUKE 0357961), MH758513, MH770996, MH770233, MH770487, MH769988, MH770792; P. praetextata (Flörke ex Sommerf.) Zopf, Russia: Karachaevo-Cherkesiya Republic, Zhurbenko s.n. (DUKE 0357996), MH758518, MH770997, MH770234, MH770488, MH769989, MH770793; P. praetextata (Flörke ex Sommerf.) Zopf, U.S.A.: NY, Buck 54040 (NY 01077051), MH758521, MH770998, MH770235, MH770489, MH769990, MH770794; P. praetextata (Flörke ex Sommerf.) Zopf, Canada: ON, Harris 56462 (DUKE 0159321), MH758510, MH770999, MH770236,-,-,--; P. praetextata (Flörke ex Sommerf.) Zopf, U.S.A.: ME, Harris 53056 (DUKE 0138948), MH758522, MH771000, MH770237, MH770490, MH769991, MH770795; P. praetextata (Flörke ex Sommerf.) Zopf, India: Himachal Pradesh, Divakar s.n. (MAF), MH758514, MH771001, -, MH770491, MH769992, MH770796; P. praetextata (Flörke ex Sommerf.) Zopf, U.S.A.: MI, Miadlikowska \& Lutzoni s.n. (DUKE 0357993), MH758523, MH771002, MH770238, MH770492, MH769993, MH770797; P. praetextata (Flörke ex Sommerf.) Zopf, Russia: Khabarovsk Territory, Miadlikowska \& Lutzoni s.n. (DUKE 0401831), MH758519, MH771003, MH770239, MH770493, MH769994, MH770798; P. praetextata (Flörke ex Sommerf.) Zopf, Canada: AB, J. Miadlikowska \& Lutzoni s.n. (DUKE 0357995), MH758511, -, -, -, -, MH770799; P. praetextata (Flörke ex Sommerf.) Zopf, U.S.A.: AZ, Miadlikowska \& Lutzoni s.n. (DUKE 0401835), MH758524, MH771004, MH770240, MH770494, MH769995, MH770800; P. retifoveata Vitik., Russia: Sakha Republic, Ahti 61821 (H), MH758213,-, MH770010, MH770257, MH769757, MH770508; P. retifoveata Vitik., Norway, Magain s.n. (LG), MH758214, -, -,-,-, MH770509; P. retifoveata Vitik., U.S.A.: AK, Miadlikowska \& Lutzoni s.n. (DUKE 0357984), MH758215,-, MH770011, MH770258, MH769758, MH770510; P. rufescens (Weiss) Humb. 1, Canada: BC, Goward 10-71 (UBC), MH758369,

, MH770654; P. rufescens (Weiss) Humb. 1, Denmark, Hansen s.n. (H), MH758368, MH770886, -, MH770368, MH769864, MH770655; P. rufescens (Weiss) Humb. 1, Chile: Region XII, Goffinet 7076 (CONN), MH758367, MH770887, MH770109, MH770369, MH769865, MH770656; P. rufescens (Weiss) Humb. 1, U.S.A.: NC, Hollinger 2711 (UBC), MH758370, MH770888, MH770110, MH770370, MH769866, MH770657; P. rufescens (Weiss) Humb. 1, U.S.A.: UT, Truong 4044 (DUKE 0401869), -, MH770889, MH770111, MH770371, MH769867, MH770658; P. rufescens (Weiss) Humb. 2, Costa Rica, Miadlikowska \& Lutzoni 23.03.03-3 (DUKE 0401870), MH758371, MH770890,-, MH770372, MH769868, MH770659; P. rufescentiformis 
Appendix 1. Continued.

(Gyeln.) C.W.Dodge, Kenya, Moberg 3983 (UPS L-536565), MH758372,-, MH770112, MH770373,-, MH770660; P. rufescentiformis (Gyeln.) C.W.Dodge, Kenya, Moberg 4324 (UPS L-536552), MH758373, MH770891, MH770113, MH770374, -, MH770661; P. scabrosa Th. Fr., Canada: QC, Lutzoni \& al. s.n. (DUKE 0401873), -, KM005791, -, MF947024, MF946916, -; P. soredians Vitik., Ecuador, Kalb 39784 (DUKE), MH758346, -, -, -, -, MH770662; P. soredians Vitik., Costa Rica, Miadlikowska \& Lutzoni 22.03.03-2 (DUKE 0401844), MH758345, -, -, -, -, MH770663; P. soredians Vitik., Ecuador, Kalb 39787 (DUKE), MH758348, MH770892, MH770114, MH770375, -, MH770664; P. soredians Vitik., Ecuador, Kalb 39785 (DUKE), MH758349, MH770893, MH770115, MH770376, MH769869, MH770665; P. sorediifera (Nyl.) Vitik., Australia, NSW, Streimann 50996 (H), MH758255, -, MH770041, MH770290, MH769786, MH770550; P. sorediifera (Nyl.) Vitik., Australia: ACT, Streimann \& Curnow 34999 (ex CBG- 9507177 dupl. H), MH758256, -, MH770042, MH770291, -, MH770551; $\boldsymbol{P}$. sp. , China: Ningxia, Niu 12-0064 (Ningxia Univ.), -, -, -, -, -, MH770666; P. sp. 13, China: Yunnan, Goffinet 9974 (CONN), MH758216, -, MH770012,-, MH769759, MH770511; P. sp. 14, Chile: Region XII, Buck 47968 (NY), MH758217, MH770817, -, MH770272, -, MH770527; P. sp. 14, Chile: Region XII, Shaw 17848 (DUKE 0401861), MH758218, MH770818, MH770024, MH770273, MH769770, MH770528; $\boldsymbol{P}$. sp. 14, Chile: Region X, Wheeler \& Nelson 5191 (CONC), MH758219, MH770819, -, MH770274, MH769771, MH770529; P. sp. 15, Ecuador, Frisch 96/Eq101 (H), MH758375, MH770894, MH770116, MH770377, MH769870, MH770667; P. sp. 15, Colombia, Lücking 34027 (UDBC), MH758374, MH770895, MH770117, MH770378, MH769871, MH770668; P. sp. 16, U.S.A.: OR, McCune 31966 (OSC), MH758235, -, MH770025, MH770275, MH769772, MH770530; $\boldsymbol{P}$. sp. 17, Peru, Miadlikowska s.n. (DUKE), MH758316, -, -, -, -, MH770603; $\boldsymbol{P}$. sp. 17, Peru, Lutzoni 05.22.2012-1 (DUKE 0357994), MH758317, -, -, -, -, MH770604; $\boldsymbol{P}$. sp. 17, Peru, Miadlikowska s.n. (DUKE),,,,,,----- MH770605; P. sp. 17, Peru, Miadlikowska \& Lutzoni s.n. (DUKE 0357963), MH758318, -, -, -, -, MH770606; P. sp. 17, Peru, Miadlikowska \& Lutzoni s.n. (DUKE 0357964), MH758319, -, -, -, -, MH770607; P. sp. 17, Peru, Lutzoni 05.22.2012-8 (DUKE 0401804), MH758320, MH770858, MH770084, MH770339, MH769836, MH770610; $\boldsymbol{P}$. sp. 17, Peru, Miadlikowska s.n. (DUKE 0357990), MH758321, MH770859, MH770085, MH770340, MH769837, MH770611; P. sp. 17, Peru, Lutzoni s.n. (DUKE 0401811), -, MH770860, MH770086, MH770341, MH769838, MH770612; P. sp. 17, Ecuador, Truong 3976 (DUKE 0401864), MH758315, MH770861, MH770087, MH770342, MH769839, MH770613; $\boldsymbol{P}$. sp. 18, Russia: Krasnoyarsk Territory, Zhurbenko s.n. (DUKE 0357978), MH758527, MH771005, MH770241, -, MH769996, MH770801; P. sp. 18, India: Uttarakhand, Divakar s.n. (MAF), MH758526, MH771006, MH770242, MH770495, MH769997, MH770802; $\boldsymbol{P}$. sp. 19, U.S.A.: OR, McCune 31048 (OSC), MH758528, MH771007, MH770243, MH770496, MH769998, MH770803; $\boldsymbol{P}$. sp. 19, U.S.A.: OR, McCune 26686 (OSC), MH758529, MH771008, MH770244, MH770497, MH769999, MH770804; P. sp. 19, U.S.A.: OR, McCune 30122 (OSC), MH758530, MH771009, MH770245, MH770498, MH770000, MH770805; $\boldsymbol{P}$. sp. 20, Canada: BC, O'Brien 030611-10-0-4 (DUKE), FJ708909, FJ709455, MH770246, MH770499, MH770001, KC437728; P. sp. 20, Canada: BC, O'Brien 020708-62-1-1 (DUKE), FJ708907, FJ709453, MH770247, MH770500, MH770002, -; $\boldsymbol{P}$. sp. 20, Canada: BC, O'Brien 020708-66-1-4 (DUKE), FJ708908, FJ709454, MH770248, MH770501, MH770003, -; $\boldsymbol{P}$. sp. 20, Canada: BC, O'Brien 030611-10-5-3 (DUKE), FJ708910, FJ709456, MH770249,-, MH770004, -; P. sp. 21, U.S.A.: AZ, Miadlikowska \& Lutzoni s.n. (DUKE 0401825), MH758525, MH771010, MH770250, MH770502, MH770005, MH770806; $\boldsymbol{P}$. sp. 22, Colombia, Lücking MPNNC174 (UDBC), MH758496, -, -, -, -, MH770808; $\boldsymbol{P}$. sp. 22, Colombia, Lücking MPNNC122 (UDBC), MH758495, -, MH770251, MH770503, MH770006, MH770807; P. sp. 22, Peru, Bennett s.n. (WIS), MH758498,-, MH770252,--, MH770007, MH770809; P. sp. 22, Peru, Miadlikowska s.n. (DUKE 0357976), MH758499, -, MH770253, MH770504, -, MH770810; $\boldsymbol{P}$. sp. 22, Colombia, Lücking MPNNC92m (UDBC), MH758497, -, MH770254, MH770505, MH770008, MH770811; P. spuriella Vain., Peru, Maldonado 14 (NY), MH758329, MH770871, MH770095, MH770352, MH769849, MH770627; P. spuriella Vain., Peru, Lutzoni s.n. (DUKE), MH758336, -, -, -, -, MH770636; P. tereziana Gyeln., Australia: VIC, Streimann 50914 (H), MH758432, MH770941, MH770170, MH770431, MH769925, MH770718; P. tereziana Gyeln., Australia: ACT, Kalb 30730 (DUKE), MH758433, MH770942, MH770171, MH770432, MH769926, MH770719; P. tereziana Gyeln., New Zealand, Tibell 9563 (UPS L-536309), MH758437, MH770943, -, -, -, -; P. tereziana Gyeln., Australia: NSW, Streimann 63484 (CANB 604582.1), MH758434, MH770944, MH770172, MH770433, MH769927, MH770720; P. tereziana Gyeln., Australia: NSW, Streimann 60382 (CBG 9906411), MH758435, MH770945, MH770173, MH770434, MH769928, MH770721; P. tereziana Gyeln., Australia: VIC, Elix 39629 (CANB 00792024), MH758436, MH770946, MH770174, MH770435, MH769929, MH770722; P. ulcerata Müll. Arg.., Philippines, Kalb \& Schrogl s.n. (DUKE), MH758266, -, -,-, -, -; P. ulcerata Müll. Arg. 1, Costa Rica, Miadlikowska \& Lutzoni 23.03.03-24 (DUKE 0357988), MH758262,-,-,-,-, MH770553; P. ulcerata Müll. Arg. 1, Costa Rica, Miadlikowska \& Lutzoni 23.03.03-26 (DUKE 0357989), MH758263, -,-,-,-, KX923115; P. ulcerata Müll. Arg. 1, Costa Rica, Miadlikowska \& Lutzoni 23.03.03-31 (DUKE 0357987), MH758264,-, MH770043, MH770292, MH769787, MH770554; P. ulcerata Müll. Arg. 1, Chile: Region X, Wheeler \& Nelson 5444 (CONC), MH758259, -, MH770044, MH770293, MH769788, MH770555; P. ulcerata Müll. Arg. 1, Peru, Lutzoni s.n. (DUKE 0357986), MH758265, -, MH770045, MH770294, MH769789, MH770556; P. ulcerata Müll. Arg. 1, Colombia, Lücking DNA1190 (UDBC), MH758260, -, MH770046, MH770295, MH769790, MH770557; P. ulcerata Müll. Arg. 1, Costa Rica, Miadlikowska \& Lutzoni 23-03-03-16 (DUKE 0357992), MH758261,-,-,-,-, MH770552; P. ulcerata Müll. Arg. 2 , Brazil: Rio, Marcelli \& al. 25096 (H), MH758258, -, MH770047, MH770296, MH769791, MH770558; P. ulcerata Müll. Arg. 2, Australia: NSW, Elix 35980 (ex CBG 9616513 dupl. H), MH758257, -, MH770048, MH770297, MH769792, MH770559; P. vainioi Gyeln., Colombia, Aguirre \& Sipman 5570 (B), MH758267, -, -, -, -, MH770560; P. vainioi Gyeln., Colombia, Miadlikowska s.n. (ANDES), MH758268, -, MH770049, MH770298, MH769793, MH770561; P. vainioi Gyeln., Ecuador, Truong 3983 (DUKE 0401860), MH758269, -, MH770050, MH770299, MH769794, MH770562; P. wulingensis L.F.Han \& S.Y.Guo, Canada: QC, Gagnon s.n. (QFA 0595019), MH758377, MH770896,-, MH770379, MH769872, MH770669; P. wulingensis L.F.Han \& S.Y.Guo, Russia: Krasnoyarsk Territory, Miadlikowska s.n. (DUKE 0357978), MH758378, MH770897, MH770118, MH770380, MH769873, MH770670; P. wulingensis L.F.Han \& S.Y.Guo, Canada: AB, Miadlikowska \& Lutzoni s.n. (DUKE 0357979), MH758376, MH770898, MH770119, MH770381, MH769874, MH770671 